Florida International University FIU Digital Commons

5-18-2010

\title{
Investigation of Mantle Dynamics from Platinum Group Elements and Rhenium-Osmium Isotope Systematics of Mantle Xenoliths from Oahu
}

Indra S. Sen

Florida International University, isen001@fiu.edu

DOI: $10.25148 /$ etd.FI10080402

Follow this and additional works at: https://digitalcommons.fiu.edu/etd

\section{Recommended Citation}

Sen, Indra S., "Investigation of Mantle Dynamics from Platinum Group Elements and Rhenium-Osmium Isotope Systematics of Mantle Xenoliths from Oahu" (2010). FIU Electronic Theses and Dissertations. 232.

https://digitalcommons.fiu.edu/etd/232 


\section{FLORIDA INTERNATIONAL UNIVERSITY \\ Miami, Florida}

\section{INVESTIGATION OF MANTLE DYNAMICS FROM PLATINUM GROUP \\ ELEMENTS AND RHENIUM-OSMIUM ISOTOPE SYSTEMATICS OF MANTLE XENOLITHS FROM OAHU, HAWAII}

A dissertation submitted in partial fulfillment of the

requirements for the degree of

DOCTOR OF PHILOSOPHY

in

GEOSCIENCES

by

Indra Sekhar Sen

2010 
To: Dean Kenneth Furton

College of Arts and Sciences

This dissertation, written by Indra Sekhar Sen, and entitled Investigation of Mantle Dynamics from Platinum Group Elements and Rhenium-Osmium Isotope Systematics of Mantle Xenoliths from Oahu, Hawaii, having been approved in respect to style and intellectual content, is referred to you for judgment.

We have read this dissertation and recommend that it be approved.

Florentin Maurrasse

Michael Bizimis

Rosemary Hickey-Vargas

Surendra Saxena

Gautam Sen, Major Professor

Date of Defense: May 28, 2010

The dissertation of Indra Sekhar Sen is approved.

Dean Kenneth Furton

College of Arts and Sciences

Interim Dean Kevin O'Shea

University Graduate School

Florida International University, 2010 


\section{ACKNOWLEDGMENTS}

I wish to thank the members of my committee Professors Florentin Maurrasse, Rosemary Hickey-Vargas and Surendra Saxena for their support and intellectual guidance. I specially thank my advisor, Professor Gautam Sen, for his continuous encouragement and careful guidance. His invaluable advice for setting me on a successful career pathway is greatly acknowledged. I would also like to express a deep debt of gratitude to Dr. Michael Bizimis, for giving me scientific guidance, teaching me meticulous clean lab procedures, helping me with the instrumentation and for being an excellent mentor. I am thankful for the Doctoral Evidence Acquisition Fellowship award at Florida International University, research grants NSF-OCE: 0622827 and 0852488 to Dr. M. Bizimis, my own Sigma Xi research grant: (G2009100334), and a research grant from the Graduate Student Association (FIU) for assisting this work at various stages.

I thank various members of the FIU Earth Science community for helping me out in various aspects of my work. Sincere thanks go to Bonnie Boddicker and Cary Machado for their help with various administrative aspects. I would like to thank Mrs. Debbie Arnold for her consideration and helpful attitude during my teaching assistantship tenure at FIU. I also thank Mrs. Diane Pirie for being a great lab manager. Last, but not

the least, Tom Beasley and Barbara Maloney are greatly acknowledged for their help and guidance with the electron probe and SEM at FCAEM-FIU.

Finally, I would like to thank my parents and friends for their unconditional love and support. 


\begin{abstract}
OF THE DISSERTATION
INVESTIGATION OF MANTLE DYNAMICS FROM PLATINUM GROUP

ELEMENTS AND RHENIUM-OSMIUM ISOTOPE SYSTEMATICS OF MANTLE

XENOLITHS FROM OAHU, HAWAII
\end{abstract}

by

Indra Sekhar Sen

Florida International University, 2010

Miami, Florida

Professor Gautam Sen, Major Professor

Intraplate volcanism that has created the Hawaiian-Emperor seamount chain is generally thought to be formed by a deep-seated mantle plume. While the idea of a Hawaiian plume has not met with substantial opposition, whether or not the Hawaiian plume shows any geochemical signal of receiving materials from the Earth's Outer Core and how the plume may or may not be reacting with the overriding lithosphere remain debatable issues. In an effort to understand how the Hawaiian plume works I report on the first in-situ sulfides and bulk rock Platinum Group Element (PGE) concentrations, together with Os isotope ratios on well-characterized garnet pyroxenite xenoliths from the island of Oahu in Hawaii.

The sulfides are Fe-Ni Monosulfide Solid Solution and show fractionated PGE patterns. Based on the major elements, Platinum Group Elements and experimental data I interpret the Hawaiian sulfides as an immiscible melt that separated from a melt similar to the Honolulu Volcanics (HV) alkali lavas at a pressure-temperature condition of 1530 $\pm 100^{\circ} \mathrm{C}$ and $3.1 \pm 0.6 \mathrm{GPa}$, i.e. near the base or slightly below the Pacific lithosphere. 
The ${ }^{187} \mathrm{Os} /{ }^{188} \mathrm{Os}$ ratios of the bulk rock vary from subchondritic to suprachondritic (0.123-0.164); and the ${ }^{187} \mathrm{Os} /{ }^{188} \mathrm{Os}$ ratio strongly correlates with major element, High Field Strength Element (HFSE), Rare Earth Element (REE) and PGE abundances. These correlations strongly suggest that PGE concentrations and Os isotope ratios reflect primary mantle processes. I interpret these correlations as the result of melt-mantle reaction at the base of the lithosphere: I suggest that the parental melt that crystallized the pyroxenites selectively picked up radiogenic Os from the grain boundary sulfides, while percolating through the Pacific lithosphere. Thus the sampled pyroxenites essentially represent crystallized melts from different stages of this melt-mantle reaction process at the base of the lithosphere.

I further show that the relatively low Pt/Re ratios of the Hawaiian sulfides and the bulk rock pyroxenites suggest that, upon ageing, such pyroxenites plus their sulfides cannot generate the coupled ${ }^{186} \mathrm{Os}-{ }^{187}$ Os isotope enrichments observed in Hawaiian lavas. Therefore, recycling of mantle sulfides of pyroxenitic parentage is unlikely to explain the enriched Pt-Re-Os isotope systematics of plume-derived lavas. 


\section{TABLE OF CONTENTS}

CHAPTER

PAGE

1.

2.

3.

3.1 .

3.2 .

3.3 .

4.

4.1.

4.2 .

4.3.

4.3.1. Sulfide Petrography .....

4.3.2. Major Element Chemistry of the Sulfides: A Discussion....

4.3.3. Pressure and Temperature Conditions of Liquid Immiscibility

4.3.4. PGE Systematics in Pyroxenitic Sulfides .....

4.3.5. Sulfide PGE Concentrations and Silicate Differentiation

4.3.6. Implication for the ${ }^{186} \mathrm{Os}^{187}$ Os Systematics of the

Hawaiian Lavas and the Lower Mantle - Outer

Core Chemical Exchange.

5.
4.4

Summary.....

ORIGIN OF GARNET PYROXNITES IN THE

HAWAIIAN MANTLE: INSIGHTS FROM PLATINUM

GROUP ELEMENTS AND RHENIUM

OSMIUM ISOTOPES

5.1 .

5.2 .

5.3 .

Introduction

Garnet Pyroxenite Xenoliths

Results.

Bulk Rock Trace Element Systematics.

5.3.2. HSE Systematics

5.3 .3

Sulfide Controls the PGE Budget of the Pyroxenites

62

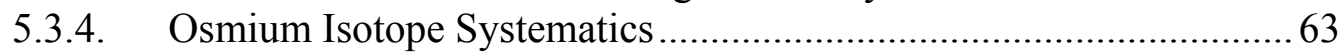

5.4 .

Discussion. 64

5.4.1. Origin of SLC Garnet Pyroxenites: MOR or Plume Related. 65 


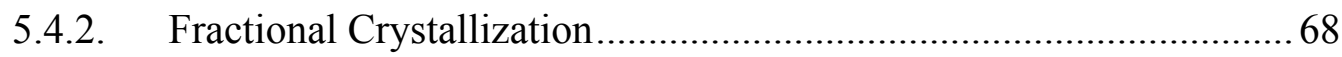

5.4.3. Plume-Lithosphere Interaction...........................................................69

5.5 Recycled Pyroxenites: Implication for the ${ }^{186} \mathrm{Os}^{-187} \mathrm{Os}$ of

Hawaiian Lavas............................................................................... 74

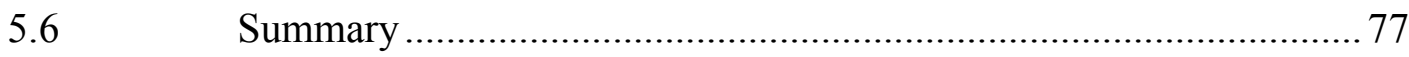

6. PLUME DYNAMICS: SUMMARY AND CONCLUSIONS ...........95

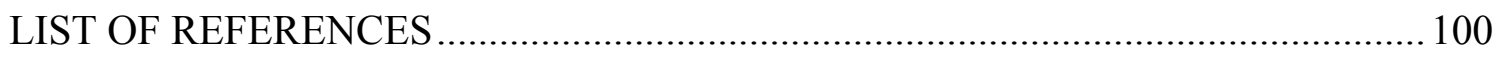

APPENDIX

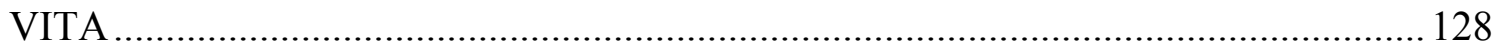




\section{LIST OF TABLES}

TABLE

PAGE

Table 3.1 A Laser Ablation - ICPMS Standards ................................................... 17

Table 3.1 B Measured Concentrations of the USGS Sulfide

Standard MASS-1 .......................................................................... 17

Table 4.1 Modal Composition and Lithology of Studied

Xenoliths and Chemical Index of the Major Mineral Phases...................39

Table 4.2 Major Element Composition of Sulfides (wt. \%) ................................ 40

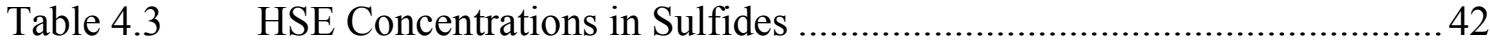

Table 5.1 Bulk Rock Trace Element Concentrations (ppm) and

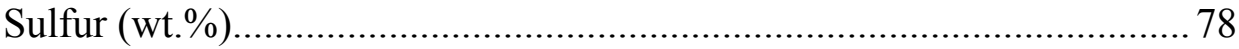

Table 5.2 Bulk Rock HSE Concentrations (ppb) and Os Isotope Ratios................80

Table 5.3 A Sulfide Mode Calculation .................................................................. 81

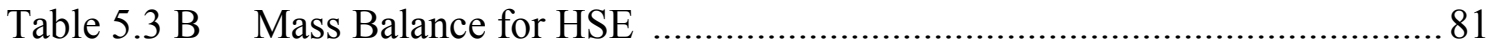




\section{LIST OF FIGURES}

FIGURE

PAGE

Figure 2.1 Schematic Illustration (not to scale) Showing Different Stages

of Hawaiian Magmatism

Figure 2.2 Location of the Hawaiian-Emperor Chain in the Middle of the

Migrating Pacific Plate

Figure 2.3 Highly Siderophile Element (HSE) Consists of Platinum

Group Element ( $\mathrm{Ru}, \mathrm{Rh}, \mathrm{Pd}$, Os, Ir and $\mathrm{Pt})$ and $\mathrm{Re}$ 9

Figure 4.1 SEM Images of Sulfide Grains....

Figure 4.2 Pyroxenitic Sulfide Compositions Plotted in the Fe-Ni-S

System (Kullerud et al., 1969).

Figure 4.3 Mg\# of Clinopyroxene vs. Average Ni Concentrations (wt.\%)

in Coexisting Sulfides $(\mathrm{Mg} \#=$ Molar $\mathrm{Mg} / \mathrm{Mg}+\mathrm{Fe}$ Total $)$

Figure 4.4 Inferred Pressure-Temperature Conditions of Silicate

-sulfide Liquid Immiscibility beneath Hawaii

Figure 4.5 Primitive Mantle-Normalized PGE Abundances of Sulfides ..... 50

Figure 4.6 Primitive Mantle-Normalized (McDonough and Sun, 1995) HSE

Pattern of Included Sulfides

Figure 4.7 Mg\# (Molar $\left.\mathrm{Mg} / \mathrm{Mg}+\mathrm{Fe}_{\text {Total }}\right)$ of Clinopyroxene vs. Total PGE

Concentrations $(\mathrm{Os}+\mathrm{Ir}+\mathrm{Pt}+\mathrm{Pd})$ in Sulfides 52

Figure 4.8 a) Variation of Re/Os Ratios in Silicate Melt Calculated in Equilibrium with Sulfides, Compared with Rejuvenated Stage HV Lavas (Lassiter et al., 2000), Pristine Mid-Ocean-Ridge Glasses from Pacific Ocean (Schiano et al., 1997), and Picritic Lavas from Koolau (Bennett et al., 2000; Ireland et al., 2009)

Figure 4.8 b) $\mathrm{Os}_{\mathrm{N}}$ vs. $\operatorname{Ir}_{\mathrm{N}}$ Concentrations in the Pyroxenites Sulfides Modeled as a Function of Sequential Sulfide Fractionation (N=Primitive Mantle Values from McDonough and Sun 1995).

Figure 4.9 ${ }^{186} \mathrm{Os}^{187}$ Os Isotope Systematics of 1-2-3 Ga Evolved Sulfides from the Hawaiian Pyroxenites Compared with Reported High ${ }^{186} \mathrm{Os}^{-187}$ Os Plume Derived Lavas (Picritic Lavas and Komatiites) (Brandon et al., 1998-99). 
Figure 4.10 Variation of Pt/Re ratios in the Hawaiian Pyroxenitic Sulfides (This Study) Compared to Sulfides from Pyroxenites and Eclogites, Bulk Rock Pyroxenites (Luguet et al., 2008a) and Peridotites (Wang et al., 2009) 56

Figure 5.1 Primitive Mantle Normalized Trace Element Concentrations in The Bulk Rock Compared with Concentrations in Clinopyroxene and Garnet (Bizimis et al., 2005).

Figure 5.2 $\mathrm{Mg} \#(\mathrm{Mg} / \mathrm{Mg}+\mathrm{Fe})$ and $\mathrm{Al}_{2} \mathrm{O}_{3}$ Content in Clinopyroxenes vs. Sr, Sm and $\mathrm{Cr}$ content of the Bulk Rock

Figure 5.3 Chondrite Normalized PGE Pattern of Garnet Pyroxenites \pm Olivine and Websterites

Figure 5.4 Plots of PGE Abundances vs. Os concentration in Bulk Rocks 85

Figure 5.5 Plots of PGE abundances in Bulk Rock vs. $\mathrm{Al}_{2} \mathrm{O}_{3}$ and $\mathrm{Mg} \#$ (Molar $\mathrm{Mg} / \mathrm{Mg}+\mathrm{Fe}_{\text {Total }}$ ) of Clinopyroxenes

Figure 5.6 (a-d) Plots of CI Normalized Pd/Ir Ratio of the Bulk Rock Vs.

Major and Trace Element Content of Clinopyroxenes and Bulk Rocks.

Figure 5.7 (a-c) Mass Balance Estimate of the Contribution of Sulfide

to the HSE Budget of Garnet Pyroxenites for sample Number SL-744, 552

and 559

Figure 5.8 Plot of ${ }^{187} \mathrm{Os} /{ }^{188} \mathrm{Os}$ vs. ${ }^{187} \mathrm{Re} /{ }^{188} \mathrm{Os}$; No Isochronous Relationship

Exists in the Pyroxenitic Xenoliths from Hawaii

Figure 5.9 Plots of ${ }^{187} \mathrm{Os} /{ }^{188} \mathrm{Os}$ vs. Major and Trace Element Content of Clinopyroxenes and Bulk Rocks.

Figure 5.10 Effect of Sulfide Fractionation on the Pd / Ir Ratio of the Silicate Melt

Figure 5.11 (a) Plot of 1/Os and Pd/Ir Ratios vs. ${ }^{187} \mathrm{Os} /{ }^{188} \mathrm{Os}$ Ratios in the Bulk Rock Pyroxenite

Figure 5.11 (b) Variation of Pd/Ir Ratios in the Pyroxenites as a Result of Sequential Sulfide Fractionation from the Mixed Melt Composition 92

Figure 5.12 ${ }^{186} \mathrm{Os}-{ }^{187}$ Os Isotope Systematics of 1-2-3 Ga Evolved Pyroxenites Compared with Reported High ${ }^{186} \mathrm{Os}-{ }^{187}$ Os Plume Derived Lavas (Picritic Lavas and Komatiites) (Brandon et al., 1999;

Brandon et al., 1998). 
Figure 6.1 Final Model - Hawaiian Plume Originates at the Core-Mantle Boundary Layer and While Passing Through the Lithosphere, It Selectively

Picks Up Radiogenic Grain Boundary Osmium from the Lithosphere 


\section{CHAPTER 1}

\section{PREFACE}

This dissertation consists of 6 chapters. Chapter 2 provides a general geological background of Hawaiian volcanism and its associated mantle xenoliths. It presents some of the outstanding problems in Hawaiian volcanism and mantle dynamics and how the present study attempts to resolve some of these issues. Chapter 3 details the analytical protocols, the various instruments that were used and analytical uncertainty. The samples used for the dissertation belong to the Dean Presnall Collection housed at Earth and Environment Department at Florida International University, and quantitative analysis was performed using the facilities at Florida Center of Analytical Electron Microscopy (Florida International University), National High Magnetic Field Laboratory (Florida State University) and Mass Spectroscopy facility at University of South Carolina. Chapter 4 has been published in Chemical Geology (I. S. Sen et al. Chemical Geology 273 (2010) pp.180-192) and chapter 5 is currently under review at Earth and Planetary Science Letters. The last chapter (chapter 6) gives the reader a synopsis about xenolithic sulfides and Os isotopes in the upper mantle, and summarizes the significant observations and conclusions of the dissertation. The dissertation work has resulted in 1 peer-reviewed publication, 1 article for consideration, 4 presentations in international conferences and also a research report submitted to National High Magnetic Field Laboratory. 


\section{CHAPTER 2}

\section{INTRODUCTION}

Global volcanism is mostly limited to mid-ocean ridges, where plates are being created, and at convergent plate boundaries, where oceanic plates subduct back into the mantle. There is a third category of volcanism that occurs within individual plates and is sometime referred to as "intraplate volcanism". Intraplate volcanism is generally thought to be caused by an anomalous hot spot or plume, rooted deep into the mantle. Such a plume rises and melts to generate the magmas that erupt through large volcanoes, such as Mauna Loa and Kilauea (Hawaii). Understanding the chemical and physical processes associated with plume volcanism is fundamental to our knowledge of planetary evolutionary processes, such as mass and heat transfer from the mantle to the surface and elemental recycling.

The Hawaiian volcanic chain occurs in the middle of the Pacific plate and has produced some of the largest volcanoes on earth, is considered a classic example of deep seated plume volcanism (Wilson, 1963; Morgan, 1971; Li et al., 2000; Wolfe et al., 2009). While the idea of a Hawaiian plume has not met with substantial opposition, specific details about the chemical and thermal nature of the plume, whether or how much materials the plume may be receiving from the Outer Core, the presence of recycled (previously subducted) lithosphere in the plume, and how the plume may or may not be reacting with the overriding lithosphere remain debatable issues. During my Ph.D. tenure I have addressed the two most significant issues connected with the Hawaiian plume: (1) Is there any chemical exchange between the Earth's Core and the Hawaiian plume Mantle? Hawaiian shield stage lavas were found to be anomalously enriched in 
${ }^{187} \mathrm{Os} /{ }^{188} \mathrm{Os}$ and ${ }^{186} \mathrm{Os} /{ }^{188} \mathrm{Os}\left({ }^{187} \mathrm{Re}\right.$ decays to ${ }^{187} \mathrm{Os}$ while ${ }^{190} \mathrm{Pt}$ decays to ${ }^{186} \mathrm{Os} ;{ }^{188} \mathrm{Os}$ is unradiogenic) ratios relative to what would be expected from any source in the mantle or crust (Brandon et al., 1998; Brandon et al., 1999). As the outer core is thought to be enriched ${ }^{187} \mathrm{Os} /{ }^{188} \mathrm{Os}$ and ${ }^{186} \mathrm{Os} /{ }^{188} \mathrm{Os}$ ratios, it was suggested that the coupled enrichment of ${ }^{186} \mathrm{Os}-{ }^{187} \mathrm{Os}$ isotopes is a result of Core-Mantle exchange, and that is an important evidence in favor of the origin of the Hawaiian plume from the Core Mantle Boundary (CMB) layer (Helmberger et al., 1998; Russell et al., 1998; Bijwaard and Spakman, 1999; Humayun et al., 2004; Montelli et al., 2004). However, a more recent study of pyroxenites including their sulfides disputes the role of the Outer Core and instead suggests that mantle sulfides have the potential to produce the coupled enrichment of ${ }^{186}$ Os - ${ }^{187}$ Os in oceanic basalts (Luguet et al., 2008). The implications of this debate on Earth's evolution and dynamics are significant. If the Core signal can be unambiguously identified in plume-derived lava then that will favor the whole mantle convection model (Hofmann, 1997). It will also favor relatively rapid mass and heat transfer from the deep mantle to the Earth's surface. On the other hand, if the Os isotopic enrichment can be explained without the enrichment by the Core, then 2 layered or other complex, perhaps less efficient models of mass and heat transfer would be favored (Hofmann, 1997 and references therein).

(2) Does the Hawaiian plume interact with the overriding Pacific lithosphere? In geophysical models of plume-Hawaiian lithosphere interaction, plume-related residues or magmatic cumulates replace the lower lithosphere (Bock, 1991a; Priestley and Tilmann, 1999; Laske et al., 2000; Li et al., 2000; Collins et al., 2002; Li et al., 2004; Constable and Heinson, 2005; Wolfe et al., 2009). If these geophysical models are valid, it is 
reasonable to think that the base of the lithosphere is chemically altered (metasomatized) because of the reaction process between plume-derived magmas and the lithosphere. It is important to understand melt-rock reaction at the base of the lithosphere because recycling of such metasomatized portion of deep lithosphere can introduce geochemical heterogeneity in the mantle and can play important role in magma generation (Niu and O'Hara, 2003; Workman et al., 2004).

In order to answer these first-order questions geochemists have mostly relied on isotope and trace element information on Hawaiian lavas that erupted at different stages of Hawaiian volcanism. A typical Hawaiian volcano evolves through several stages of magmatism. The main magmatism occurs during the shield stage $(95 \%$ of volcanism, picritic-tholeiitic type), followed by a postshield stage (alkalic type) activity. The volcano eventually stops erupting and following a $\leq 1.2$ million year hiatus, post-erosional or rejuvenated stage volcanism (strongly alkaline mafic lavas) occurs (Figure 2.1). The rejuvenated stage lavas brought up mantle xenoliths ( Jackson and Wright, 1970; Clague and Frey, 1982; Sen, 1987; Sen, 1988), which are broken rock fragments from the mantle. Most mantle xenoliths have been reported from the Honolulu Volcanics series in Oahu. In this study, I rely on mantle-derived garnet pyroxenite xenoliths from the rejuvenated stage Honolulu Volcanics (HV) from Salt Lake Crater (SLC) at Oahu (Figure 2.2). The garnet pyroxenite xenoliths represent high-pressure cumulates ( $>2 \mathrm{GPa})$ at the lithosphere-asthenosphere interface (Bizimis et al., 2005). As these rare xenoliths are direct physical samples of the Earth's Upper Mantle, they have a clear advantage over erupted lavas. Their chemical compositions give us a unique snapshot in obtaining the composition of Hawaiian mantle plume and understand the deep mantle processes. In the 
quest to understand Hawaiian plume vis-à-vis deep mantle processes I characterized the garnet pyroxenites and their sulfides in terms of their major element, trace element, highly siderophile element (HSE) and Os isotope composition (Figure 2.3). I used electron microprobe (EPMA) and various mass spectrometers e.g. in-situ Laser Ablation ICP-MS, High Resolution Single Collector ICP-MS and Multi Collector ICP-MS (Inductively Coupled Plasma Mass Spectrometry). Based on low Pt/Re ratios of the garnet pyroxenites and their sulfides, I propose that, upon "aging", mantle derived pyroxenites and sulfides from Hawaii cannot generate the coupled ${ }^{186} \mathrm{Os}^{-187}$ Os isotope enrichments observed in Hawaiian lavas. The obtained data strongly suggest that, recycling of mantle pyroxenites including their sulfides, cannot explain the enriched PtRe-Os isotope systematics of the plume-derived lavas. Instead, I concur that Os enrichment is related to substantial mass exchange between the Earth's Core and plume. The data also show that melts from the Hawaiian plume preferentially reacted with the Pacific lithosphere. The statement is based on the variability of Osmium isotope and its relation with major-trace and highly siderophile element. As the melts from the Hawaiian plume percolate through the Pacific lithosphere they preferentially mobilize the grain boundary sulfides, and as a consequence Os gets decoupled from other elements. I propose that the sampled pyroxenites essentially represent crystallized melts from different stages of this reaction process at the base of the lithosphere (chapters 4 and 5).

The reader may note that chapters 4 and 5 are intentionally "modular" because they are published or being submitted as independent papers to leading Earth Science journals; however together they address two fundamental questions in global geodynamics: 
I) Is there any chemical exchange between the Core and the Hawaiian plume Mantle (Chapter 4)

II) Plume-lithosphere interaction at the base of the Pacific lithosphere (Chapter 5). 


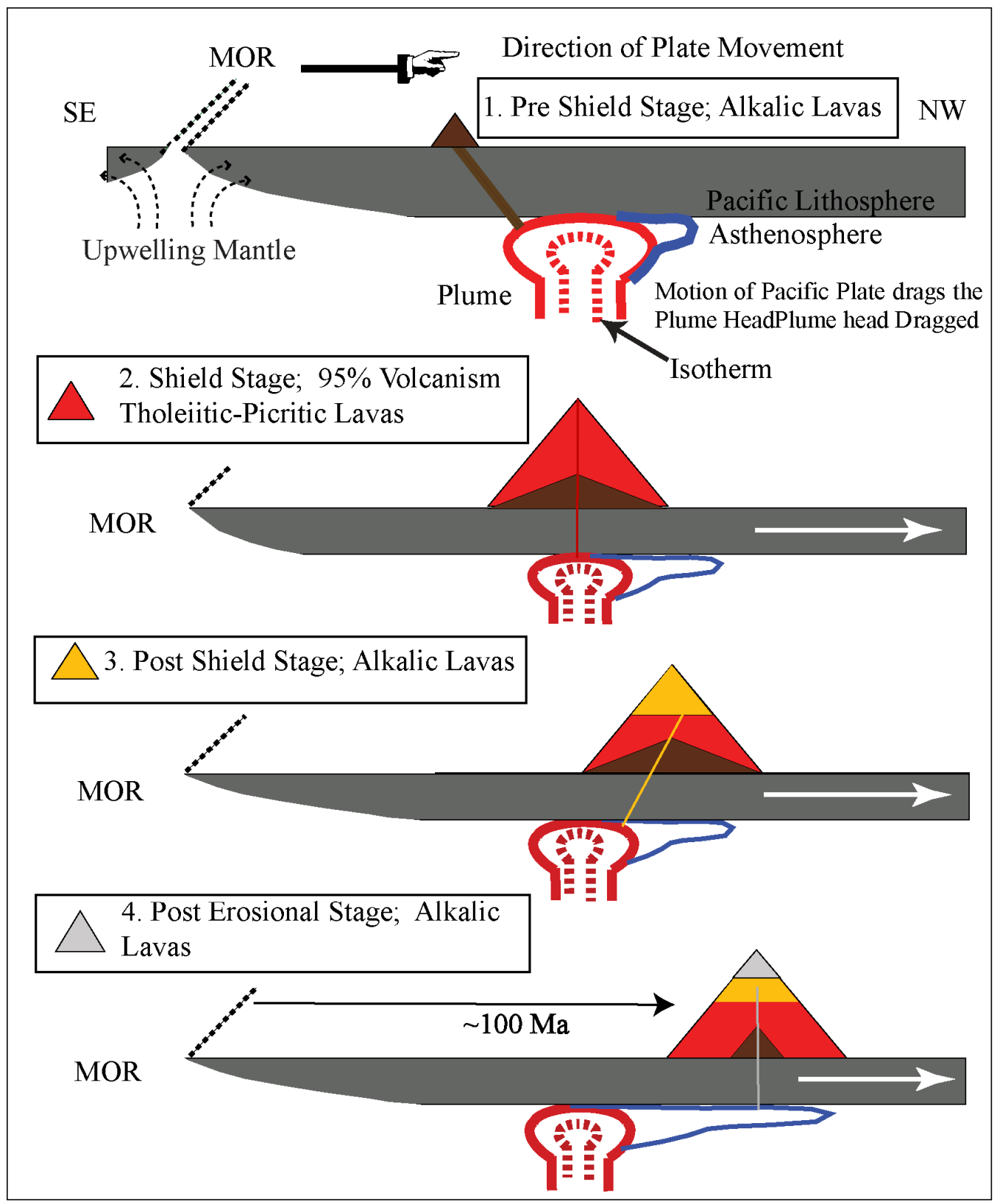

Figure 2.1 Schematic illustration (not to scale) showing different stages of Hawaiian magmatism. A Hawaiian volcano evolves through several stages of magmatism. It starts with a pre-shield stage. The main magmatism occurs during the shield stage, followed by a post-shield stage, followed by post erosional or rejuvenated stage. The Pacific Lithosphere beneath Oahu is 100 Myr old. MOR - Mid Ocean Ridge 


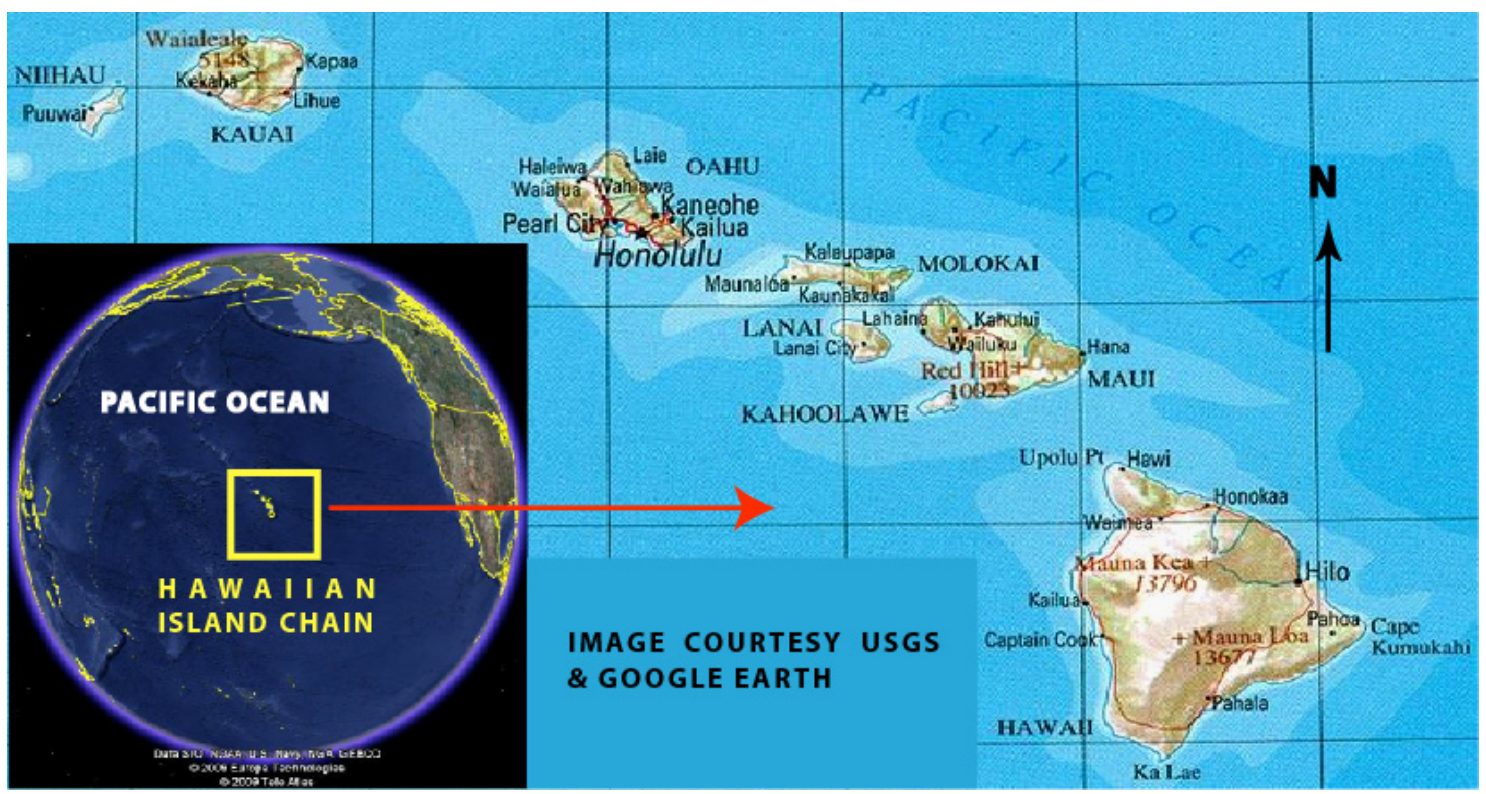

Figure 2.2 Location of the Hawaiian-Emperor Chain in the middle of the migrating Pacific plate. The eight main islands are Hawaii, Maui, Kahoolawe, Lanai, Molakai, Oahu, Kauai and Nihau. My samples are from the Salt Lake Crater vent (very close to the city of Honolulu) in the island of Oahu. 


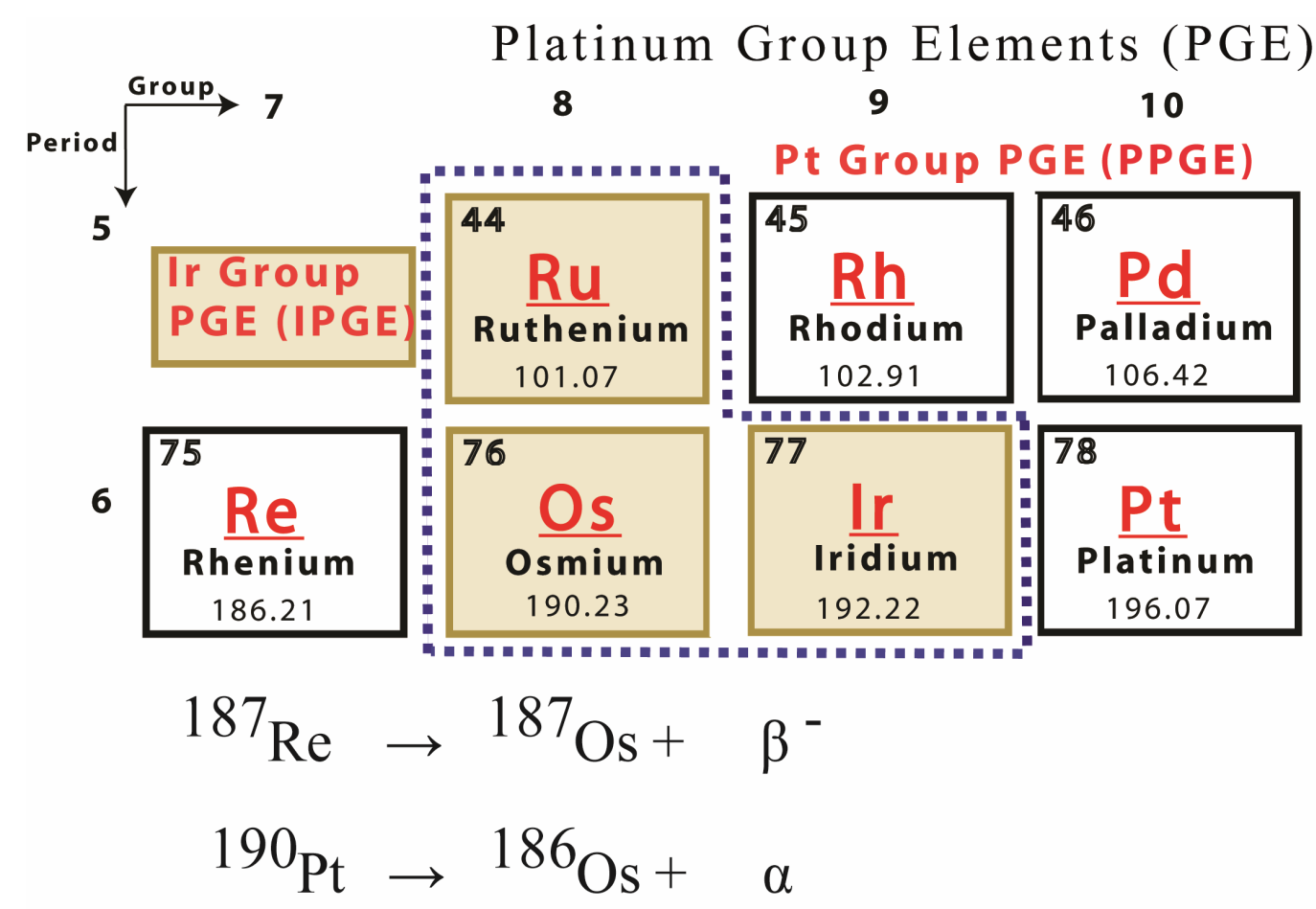

Figure 2.3 Highly Siderophile Element (HSE) consists of Platinum Group Element (Ru, $\mathrm{Rh}, \mathrm{Pd}, \mathrm{Os}, \mathrm{Ir}$ and $\mathrm{Pt}$ ) and Re. The elements inside the blue dotted lines i.e., $\mathrm{Ru}, \mathrm{Os}$ and $\mathrm{Ir}$ are compatible during mantle melting while $\mathrm{Rh}, \mathrm{Pd}, \mathrm{Pt}$ and $\mathrm{Re}$ are incompatible in nature. ${ }^{187} \mathrm{Re}$ decays to ${ }^{187} \mathrm{Os}$ by the emission of negatively charged $\beta$ particle while ${ }^{190} \mathrm{Pt}$ decays to ${ }^{186} \mathrm{Os}$ by the emission of $\alpha$ particle. 


\section{CHAPTER 3}

\section{RESEARCH METHODS}

The xenoliths used for this study are from the Salt Lake Crater (Oahu, Hawaii) and they belong to the Dean Presnall Collection housed at the Department of Earth and Environment, Florida International University. The samples are small $(3-5 \mathrm{~cm}$ in diameter), dark brown in color, and are primarily composed of clinopyroxene with variable percentages of garnet, olivine, orthopyroxene and trace amounts of amphibole, ilmenite, spinel, phlogopite, carbonate and sulfide minerals. Bulk rock aliquots were analyzed for trace element, highly siderophile element and Os isotope ratios using high resolution single collector ICP-MS and Multi Collector ICP-MS (Inductively Coupled Plasma Mass Spectrometry), while the sulfide grains in polished thin $(30 \mu \mathrm{m})$ and thick sections $(2.54 \mathrm{~cm})$ were analyzed for major and highly siderophile elements using electron microprobe (EPMA) and Laser Ablation ICP-MS. Polished thick sections were studied under polarized light microscope and the Scanning Electron Microscope (SEM) and petrographic images were taken with SEM. The analytical protocols and details about the instrumentation are presented in the following sections.

\subsection{Electron Probe (EPMA) and Scanning Electron Microscopy (SEM) Analysis}

The samples were first cut to $2.54 \mathrm{~cm}$ thick slabs for in-situ microprobe (EPMA) and laser ablation analysis (LA-ICPMS, section 3.2). Interior fragments of the xenoliths were then examined under a binocular microscope to ensure that they were free of obvious alteration products and melt infiltration. These samples were then polished using silicon carbide paper and alumina powders down to $0.3 \mu \mathrm{m}$. The polished slabs were first examined under reflected light microscope at magnification of up to $500 \mathrm{X}$ to identify 
samples with large enough sulfides ( $>50$ micron) that would be suitable for LA-ICPMS work. Only samples with large sulfides were subsequently processed further. Prior to laser ablation, secondary and back-scattered electron images of the sulfide grains were taken using JEOL JSM 5900LV Scanning Electron Microscope (SEM) at Florida Center of Analytical Electron Microscopy (FCAEM)-Florida International University (FIU). The Scanning Electron Microscope images of the sulfide grains are shown in figure 4.1.

The major element chemistry of the sulfides were analyzed with an electron microprobe (JEOL Superprobe, JSM 8900R) equipped with five wavelength - dispersive spectrometers at FCAEM-FIU. The analyses were conducted with $20 \mathrm{KV}$ accelerating voltage and $20 \mathrm{nA}$ beam current. Acquisition time was 20 seconds for $\mathrm{Fe}, \mathrm{S}$ and 30 seconds for $\mathrm{Ni}, \mathrm{Zn}$ and $\mathrm{Cu}$. A combination of sulfide and metal standards (source: National Institute of Standards \& Technology) were used.

Whereas most of the sulfides were homogeneous, only sample number SL-590 revealed the presence of micron-scale heterogeneous structures with Ni-poor and Ni-rich domains (Figure 4.1d). Therefore broad beam $(30 \mu \mathrm{m})$ microprobe analyses were performed in order to obtain a homogenized or "bulk" sulfide composition in the latter cases. The fine beam analyses naturally vary more than the broad beam analyses in these sulfides; however, because the heterogeneity is at a finer scale even the finest beam $(1 \mu \mathrm{m})$ could not resolve good quality data of the "unmixed" phases. I note, however, that the averaged concentrations obtained by the broad beam and fine beam methods on the same sulfides agree within analytical error (Fig. A in Appendix). Because the thrust of this paper is on bulk sulfide grain compositions, I present broad beam $(30 \mu \mathrm{m})$ analyses of the bulk major element compositions of the sulfides in all of the samples in Table 4.2 
(chapter 4). The $1 \mu \mathrm{m}$ data are only given in the Appendix (Supplementary Table A1 and A2). For the rest of the dissertation only the broad beam analyses are considered.

\subsection{Laser Ablation ICP-MS Analysis}

The PGE and other trace elements in sulfides were analyzed in situ by Laser Ablation ICP-MS using a $213 \mathrm{~nm}$ Nd: YAG laser (NEW WAVE ${ }^{\mathrm{TM}}$ ) coupled to a FinniganMat ELEMENT-1-HR-ICP-MS at the Geochemistry Division, NHMFL Florida State University. All measurements were performed on polished thick sections (0.5-1 cm in thickness) using a 40-80 $\mu \mathrm{m}$ spot size at $4 \mathrm{~Hz}$ frequency in a He atmosphere. Each spot analysis represents 30 scans across the measured mass spectrum (1.2 sec / mass sweep). Data acquisition was started manually after the ablation signal stabilized (typically $5 \mathrm{sec}$ after the beginning of ablation). Average detection limits (taken as 3 standard deviations of the average blank signal determined before each sample) are reported in Table 3.1A. The signal limitations allowed us to measure only the largest sulfides (generally $>50 \mu \mathrm{m}$ ). The ablation effectively homogenized individual sulfides and any possible micron-size heterogeneity in PGEs cannot be resolved. Since the Fe contents of these sulfides (determined with the $30 \mu \mathrm{m}$ on the electron probe) do not vary significantly (Table 4.2) I normalized all analyzed signal intensities to the Fe 57 intensity with $\mathrm{Fe}=56 \%$ wt.

For external standards I used a combination of the iron meteorites Filomena and Hoba, using the concentrations reported in Campbell et al. (2002) as there are no widely available or cross-calibrated sulfide international standards to be used in LA-ICPMS studies ( Peregoedova et al., 2006; Sylvester, 2008; Jochum and Stoll, 2008;). A comparison between the PGE concentrations in the two meteorites measured by the LA- 
ICP-MS method and the values reported in literature is presented in Table $3.1 \mathrm{~A}$, and shows very good agreement for all elements, especially considering the heterogeneous distribution of PGE within the iron meteorites, and that I ran the analyses in spot mode as opposed to line scan. I also analyzed the USGS sulfide standard MASS-1, also known as PS-1 (Wilson et al., 2002), as an independent check of the procedure and normalization method for quantitative sulfide LA-ICPMS analyses. In addition to the PGE data I also report concentration data for $\mathrm{Co}, \mathrm{Ni}, \mathrm{Cu}, \mathrm{Au}$ in MASS-1, as these were the only other elements accurately known or present in the meteorites I used as standards. For Pt, $\mathrm{Au}$, $\mathrm{Co}$ and $\mathrm{Cu}$ my data are within error identical to reported MASS-1 data. There is no reported Ir concentration data for MASS-1 although it is present (see Wilson et al., 2002). Rhenium and Os have both very low concentrations in MASS-1 and there is no other report on their concentrations.

During the sulfide analyses the $\mathrm{Rh}$ and $\mathrm{Ru}$ signals suffered from large $\mathrm{Ni}$-and $\mathrm{Cu}-$ argide polyatomic interferences. As a result of the low $\mathrm{Rh}$ and $\mathrm{Ru}$ concentrations in these sulfides, the applied $\mathrm{Ni}$-and $\mathrm{Cu}$-argide interference corrections resulted in large raw intensity corrections and subsequently large uncertainties in the calculated concentrations; therefore I do not report $\mathrm{Rh}$ and $\mathrm{Ru}$ values in the sulfides. The excellent agreement between my meteorite and MASS-1 sulfide data with published data (Table 3.1B) is consistent with limited, if any, matrix specific elemental fractionation during laser ablation between metals and sulfides. The HSE contents of the analyzed sulfides are reported in Table 4.3 (Chapter 4). 


\subsection{Element-1-HR-ICP-MS, Neptune MC-ICP-MS and LECO CNS- 2000 Analysis}

For bulk rock trace element, S analysis, HSE and Os isotope analysis, the samples were coarsely crushed to expose the interior fragments of the xenoliths. Interior pieces were hand picked to avoid obvious surface alterations or voids, and powdered either by hand grinding in a pre-cleaned and preconditioned ceramic alumina mortar and pestle, or agate bowl.

Bulk rock trace elements were determined at the Mass Spectrometry facility at University of South Carolina using the THERMO ELEMENT2-High Resolution ICPMS. About $250 \mathrm{mg}$ of sample powder were digested with $4 \mathrm{ml}$ of concentrated $\mathrm{HF}: \mathrm{HNO}_{3}$ (3:1) at $100^{\circ} \mathrm{C}$ for 48 hours. After digestion the samples were dried and the dried cakes were redissolved in concentrated $1 \mathrm{ml} \mathrm{HNO}_{3}$ (2 times). The dried sample cakes were again redissolved with $3-5 \mathrm{ml}$ of $7 \mathrm{~N}^{-1 N O}$ to make a stock solution with $500 \mathrm{ppm}$ of total dissolved solids (TSD). The trace elements were determined at $100 \mathrm{ppm}$ TDS on a single collector THERMO ELEMENT2-HR-ICP-MS. Blanks were measured and corrected for every acquisition sequence and the blank corrected data are reported on Table 5.1 (chapter 5). I used BHVO-2 as a standard (Jochum and Nehring 2006) and here I also report the concentrations of BIR-1 (Jochum et al., 2006) that was run as an unknown.

Bulk rock Sulfur was determined at Activation Laboratories Limited, Canada on a Leco CNS 2000. $\mathrm{S}$ is measured as $\mathrm{SO}_{2}$ produced by the combustion of $0.2 \mathrm{~g}$ rock powder and the data is reported in Table 5.1 (Chapter 5). For the quality control of the data USGS certified standard Green River Shale (SGR-1) was used as the reference material. The 
measured S concentration of SGR-1 (1.5\%) agrees well with the USGS certified value (1.53 wt. \%).

Bulk rock HSE were determined at the National High Magnetic Field LaboratoryFlorida State University with the "carius-tube" digestion technique, following the method of Puchtel et al. 2004a. About 2.5 gm of sample powder were spiked with an isotopically enriched PGE solution (spike \#000601, provided by Prof. Munir Humayun at NHMFL ) The spiked powders were digested with $\sim 10 \mathrm{ml}$ "inverse Aqua Regia (3:1 $-\mathrm{HNO}_{3}$ : $\left.\mathrm{HCl}\right)$ " in pre-cleaned borosilicate glass tubes at $240^{\circ} \mathrm{C}$ for 72 hours. After digestion the tubes were chilled to $0^{\circ} \mathrm{C}$ to prevent possible Os volatilization during opening. Osmium was extracted first from the aqua regia solution, using carbon tetrachloride $\left(\mathrm{CCL}_{4}\right)$ solvent extraction technique, then back-extracted to $\mathrm{HBr}$ and finally purified via micro distillation using chromic acid as an oxidizer and collected in a drop of HBr (Birck et al., 1997). The Ir-Pt-Pd-Ru was extracted from one half fraction of the extracted aqua regia by cation exchange chromatography using $10 \mathrm{~mL}$ of AG50W-X8 exchange resin in $0.15 \mathrm{~N} \mathrm{HCl}$ (Puchtel et al., 2005b). The samples were passed twice through the columns to ensure a clean PGE fraction and minimize potential polyatomic interferences. Rhenium was extracted from the remaining aqua regia solution by anion exchange chromatography in weak $\mathrm{HNO}_{3}$, following the techniques outlined in Lassiter et al. 2003. Extra care was taken to very carefully and slowly dry down the fractions containing Re in order to avoid loss of Re because of volatilization (detailed protocol is given in the appendix section “HSE and Re-Os Extraction Protocol"). The Ir-Pt-Pd-Ru concentrations were determined on a single collector FinniganMat ELEMENT-1-HR-ICP-MS using a low-flow (100ul) PFA nebulizer (ESI) and PFA spray chamber (Savillex). Mass fractionation was 
corrected using the linear law against an in-house $1 \mathrm{ppb}$ mixed PGE standard and Os was determined on a THERMO Neptune MC-ICP-MS respectively. Re analysis was performed using an MCN-6000 desolvating nebulizer coupled with a $50 \mu \mathrm{L}$ PFA nebulizer. The HSE and Os isotope ratios of the bulk rock are reported in Table 5.2 (chapter 5). 
Table 3.1 A Laser Ablation-ICPMS Standards.

\begin{tabular}{|c|c|c|c|}
\hline $\begin{array}{c}\text { Element (Isotope), } \\
\text { detection limit }\end{array}$ & $\begin{array}{l}\text { Meteorite standard } \\
\text { used, concentration }\end{array}$ & $\begin{array}{c}\text { Meteorite standard } \\
\text { measured, concentration }\end{array}$ & $\begin{array}{l}\text { Meteorite standard } \\
\text { reported, concentration }\end{array}$ \\
\hline $\mathrm{Pd}(108), 3.3 \mathrm{ppb}$ & Hoba, $6.65 \pm 0.3 \mathrm{ppm}$ & Filomena, $1.95 \pm 0.12 \mathrm{ppm}$ & Filomena, $1.95 \pm 0.12 \mathrm{ppm}$ \\
\hline $\operatorname{Re}(185), 0.8 \mathrm{ppb}$ & Hoba, $3.15 \pm 0.08$ ppm & Filomena, $0.29 \pm 0.01 \mathrm{ppm}$ & Filomena, $0.24 \pm 0.04 \mathrm{ppm}$ \\
\hline Os (190), $0.5 \mathrm{ppb}$ & Hoba, $42.5 \pm 0.7$ ppm & Filomena, $0.29 \pm 0.01 \mathrm{ppm}$ & Filomena, $1.12 \pm 0.07 \mathrm{ppm}$ \\
\hline $\operatorname{Ir}(195), 0.8 \mathrm{ppb}$ & Hoba, $29.1 \pm 0.4 \mathrm{ppm}$ & Filomena, $3.71 \pm 0.02 \mathrm{ppm}$ & Filomena, $3.37 \pm 0.16 \mathrm{ppm}$ \\
\hline $\operatorname{Pt}(195), 1.9 \mathrm{ppb}$ & Hoba, $28.6 \pm 0.5 \mathrm{ppm}$ & Filomena, $23.72 \pm 0.24 \mathrm{ppm}$ & Filomena, $23.9 \pm 0.3 \mathrm{ppm}$ \\
\hline $\mathrm{Au}(197), 1.2 \mathrm{ppb}$ & Filomena, $0.59 \pm 0.07 \mathrm{ppm}$ & Hoba, $0.07 \pm 0.04 \mathrm{ppm}$ & Hoba, $0.09 \pm .02 \mathrm{ppm}$ \\
\hline
\end{tabular}

Table 3.1 B Measured Concentrations of the USGS Sulfide Standard MASS-1.

\begin{tabular}{cccc}
\hline & $\begin{array}{c}\text { Meteorite standard } \\
\text { used, concentration }\end{array}$ & $\begin{array}{c}\text { Measured concentration } \\
\pm 1 \mathrm{stdev}(\mathrm{n}=4)\end{array}$ & $\begin{array}{c}\text { Reported MASS-1, } \\
\text { concentrations }\end{array}$ \\
\hline $\mathrm{Co}(59)$ & Hoba, 7801 ppm & $67.9 \pm 2.3 \mathrm{ppm}$ & $67 \mathrm{a}$ \\
$\mathrm{Ni}(60)$ & Hoba, $16 \mathrm{wt} \%$ & $91.49 \pm 18.8 \mathrm{ppm}$ & $128 \pm 10 \mathrm{~b}$ \\
$\mathrm{Cu}(63)$ & Filomena, $150 \mathrm{ppm}$ & $12.5 \pm 0.9 \mathrm{wt} \%$ & $13.4 \% \mathrm{a}, 12.72 \% \pm 1.2 \mathrm{~b}$ \\
$\operatorname{Re}(185)$ & Hoba, 3.15 ppm & $0.504 \pm 0.022 \mathrm{ppm}$ & - \\
$\mathrm{Os}(190)$ & Hoba, 42.5 ppm & $0.031 \pm 0.005 \mathrm{ppm}$ & - \\
$\mathrm{Ir}(193)$ & Hoba, 29.1 ppm & $63.51 \pm 4.6 \mathrm{ppm}$ & - \\
$\mathrm{Pt}(195)$ & Hoba, 28.6 ppm & $61.78 \pm 4 \mathrm{ppm}$ & $69 \pm 6 \mathrm{~b}$ \\
$\mathrm{Au}(197)$ & Filomena, 0.59 ppm & $48.44 \pm 2$ & $47 \mathrm{a}, 51 \pm 10 \mathrm{~b}$ \\
\hline Hoba and Filomena values are from Campbell et al 2002 and references therein; a: Wilson et al. 2002; b: Sylvester 2008 \\
\hline \hline
\end{tabular}




\section{CHAPTER 4}

\section{GEOCHEMISTRY OF SULFIDES IN HAWAIIAN GARNET PYROXENITE XENOLITHS: IMPLICATIONS FOR HIGHLY SIDEROPHILE ELEMENTS IN THE OCEANIC MANTLE}

\subsection{Introduction}

Intraplate volcanism that has created the Hawaiian-Emperor seamount chain is generally thought to be formed by a deep-seated mantle plume ( Wilson, 1963; Morgan, 1971; Li et al., 2000; Wolfe et al., 2009). The depth of origin of the Hawaiian plume (and other plumes for that matter) continues to be debated. Some seismic studies suggest a Lower Mantle or Core-Mantle Boundary (CMB) origin ( Helmberger et al., 1998;Russell et al., 1998; Bijwaard and Spakman, 1999; Montelli et al., 2004;), while the view from geochemistry has been equivocal. Humayun et al., (2004), using arguments rooted in lava geochemistry, concluded that the Hawaiian magmas tap a relatively Fe-rich source located at the CMB. A CMB origin is also supported by Brandon et al. (1999) who proposed that the characteristically high ${ }^{186} \mathrm{Os} /{ }^{188} \mathrm{Os}-{ }^{187} \mathrm{Os} /{ }^{188} \mathrm{Os}$ ratios in Hawaiian lavas are inherited from the excess Os contributed by a "leaky" outer core. In contrast, tungsten isotope data on the same set of lavas (Schersten et al., 2004) were found to be inconsistent with core - mantle interaction and instead, Schersten et al. (2004) suggested that the radiogenic Os isotopic signal could be derived from a very old recycled crustal component in the oceanic mantle. In the same vein, Baker and Jensen (2004) suggested that this radiogenic Os signal could also be explained by the presence of recycled oceanic ferromanganese nodules in the mantle source of these lavas as these materials have sufficiently high $\mathrm{Pt} / \mathrm{Re}$ ratios to account for the coupled enriched ${ }^{186} \mathrm{Os}^{-187} \mathrm{Os}$ osmium isotope trend. However, Nielsen et al. (2006) pointed out that the lack of a correlation 
between thallium and osmium isotopes is inconsistent with this hypothesis. A more recent examination of pyroxenite and eclogite hosted sulfides from the Beni Bousera massif and the Mir and Udachnaya kimberlites, respectively (Luguet et al., 2008), found that some mantle sulfides can have sufficiently high $\mathrm{Re} / \mathrm{Os}$ and $\mathrm{Pt} / \mathrm{Os}$ ratios that, upon recycling, could explain the coupled ${ }^{186} \mathrm{Os} /{ }^{188} \mathrm{Os}^{187} \mathrm{Os} /{ }^{188} \mathrm{Os}$ enrichments in Ocean Island Basalts (e.g., Hawaiian lavas) and komatiites, thereby arguing against an outer core contribution.

Hawaiian lavas and xenoliths offer a window into the deeper parts of the mantle. There is a large amount of chemical analyses on the lavas and xenoliths from the Hawaiian Island Chain ( Lassiter and Hauri, 1998; Norman and Garcia, 1999; Lassiter et al., 2000; Huang and Frey, 2003; Humayun et al., 2004; Bizimis et al., 2005; Bryce et al., 2005; Sobolev et al., 2005; Nielsen et al., 2006; Keshav et al., 2007; Jamais et al., 2008; Marske et al., 2008; Ireland et al., 2009) however, very little is known of sulfides associated with the Hawaiian volcanism. Relative to the silicate mineral constituents of the mantle, sulfide minerals are the overwhelming carriers of the highly siderophile elements (HSE), such as Platinum Group Element or PGE (i.e., Os, Ir, Pt, and Pd), Re and $\mathrm{Au}$. The HSE concentrations in sulfides carry valuable information about the Earth's evolution ( Pattou et al., 1996; Roy-Barman et al., 1998a; Alard et al., 2000; Lorand and Alard, 2001; Luguet et al., 2001; Hart and Gaetani, 2006) and may have important implications on the interpretation of the $\mathrm{Pt} / \mathrm{Os}$ and $\mathrm{Re} / \mathrm{Os}$ isotope systematics of the mantle and whether the earth's core is exchanging material with the Earth's mantle ( Walker et al., 1997; Richardson et al., 2001; Alard et al., 2002; Griffin et al., 2002; Brenan et al., 2008; Luguet et al., 2008). To date far more attention has been paid to 
sulfides from peridotites ( Szabo and Bodnar, 1995; Guo et al., 1999; Alard et al., 2000; Luguet et al., 2001;Harvey et al., 2006; Liu et al., 2009; Wang et al., 2009) whereas studies of pyroxenitic sulfide minerals are sparse (De Waal and Calk, 1975; Lorand, 1989; Guo et al., 1999; Luguet et al., 2008). De Waal and Calk (1975) made a pioneering petrographic and major element chemical investigation of sulfides in garnet pyroxenite xenoliths from the Salt Lake Crater vent (SLC, Oahu, Hawaii). Such xenoliths in a major oceanic hot spot are important as they offer a rare opportunity to study the geochemistry of pyroxenitic sulfides that originate directly from the present day oceanic upper mantle and thus can provide important constraints on the distribution and fractionation of HSE in the mantle.

The SLC pyroxenites have been interpreted as high pressure cumulates near the base of the Pacific lithosphere ( Sen, 1988; Bizimis et al., 2005; Keshav et al., 2007). As such they may also represent an analog of the metasomatic processes that take place at the lithosphere/asthenosphere interface as the oceanic lithosphere moves away from a mid oceanic ridge and where low degree asthenospheric melts freeze and become incorporated in the overlying plate (Niu and O'Hara, 2003). Such metasomatized portions of the deep oceanic lithosphere, upon recycling, could become sources of ocean island basalts (Niu and O'Hara, 2003; Workman et al., 2004). Therefore, the pyroxenitic sulfide geochemistry could also have implications on the PGE and HSE fractionation and Pt-ReOs isotope systematics of the sources of OIBs.

Here I report on the first in-situ LA-ICP-MS analyses of sulfides from the SLC garnet pyroxenite xenoliths. The main objectives of this contribution are: (i) to investigate the distribution and fractionation of HSE, PGE and specifically Pt/Os - Re/Os 
ratio in sulfides of pyroxenitic origin, (ii) to evaluate whether recycled sulfides of cumulate nature can account for the high ${ }^{186} \mathrm{Os} /{ }^{188} \mathrm{Os}-{ }^{187} \mathrm{Os} /{ }^{188} \mathrm{Os}$ signatures observed in Hawaiian lavas and komatiites, and validate the uniqueness of core-mantle exchange (Brandon et al., 1999). My results show that recycling of mantle sulfides of pyroxenitic parentage is unlikely to explain the enriched Pt-Re-Os isotope systematics of plumederived lavas.

\subsection{Background Information}

The island of Oahu is built of two tholeiitic shield volcanoes - Koolau to the east and Waianae to the west. Koolau last erupted some 2.5 m.y. ago (Clague, 1987). Following a 1.8-0.9 m.y. hiatus and substantial erosion, strongly alkalic mafic lavas (basanite, nephelinite, alkali basalts) of post-erosional or rejuvenated stage volcanism erupted through some 40 vents that are scattered all across the Koolau shield. These alkalic eruptions are grouped as the Honolulu Volcanics (HV); (Clague and Frey, 1982) and often carry mantle xenoliths, consisting mainly of peridotites and garnet pyroxenites (Jackson and Wright, 1970; Clague and Frey, 1982; Sen, 1987; Sen, 1988). The SLC garnet pyroxenite xenolith suite includes some of the deepest samples found anywhere in the oceans (Keshav and Sen, 2001; Wirth and Rocholl, 2003) and their compositions provide unique snapshots of the deep magma processes and sources of Hawaiian plume volcanism.

There is a significant body of published information on petrography, mineral chemistry, trace element and isotope geochemistry of the SLC pyroxenite xenoliths (Frey, 1980; Sen, 1988; Keshav and Sen, 2001; Bizimis et al., 2005; Sen et al., 2005 Keshav et al., 2007;). The relatively radiogenic ${ }^{187} \mathrm{Os} /{ }^{188} \mathrm{Os}$ compositions of the SLC 
pyroxenites, coupled with their low ${ }^{87} \mathrm{Sr} /{ }^{86} \mathrm{Sr}$ ratios led Lassiter et al. (2000) to propose that they represent 80-100 Myr old cumulates formed at a mid oceanic ridge setting. In contrast Bizimis et al. (2005), showed that both two-mineral pyroxene - garnet Sm/Nd and $\mathrm{Lu} / \mathrm{Hf}$ isochrons and reconstructed bulk - rock Hf-Nd isotope compositions of the SLC pyroxenites (albeit on a different set of samples than the Lassiter et al., 2000 study) are consistent with essentially "zero" age, i.e., the garnet pyroxenites formed beneath Oahu rather than close to a ridge or somewhere between the ridge (where the lithosphere was created $90 \mathrm{Myr}$ ago) and the location of the Hot Spot. Also, their Nd-Sr and Hf isotope compositions overlap with those of the HV lavas; and the calculated trace element composition of the melts in equilibrium with these pyroxenites are akin to HVtype rather than MORB-type melts (Frey, 1980; Sen et al., 1993; Keshav et al., 2004;).

The presence of garnets with majoritic precursors (Keshav and Sen, 2001) and the discovery of nano-diamonds (Wirth and Rocholl, 2003) have led to the suggestion that some of these pyroxenites were brought up from some 180-270 $\mathrm{km}(\mathrm{P}=6-9 \mathrm{GPa})$ by the Hawaiian plume. Therefore, at least some of these rare garnet pyroxenites could conceivably represent recycled, old subducted slab materials, or ultra-deep cumulates that crystallized within the upwelling plume, as opposed to the lithosphere/asthenosphere boundary. With the exception of the few rare and deep, and perhaps recycled fragments, the SLC garnet pyroxenites are considered here to represent high pressure ( $>2 \mathrm{GPa}$ ) accumulates from magmas that were chemically similar to the erupted HV lavas (Bizimis et al., 2005; Keshav et al., 2007). The samples studied here are pyroxenites composed primarily of clinopyroxene with variable modes of garnet and subordinate orthopyroxene and olivine (Table 4.1). Most samples have been previously described in the Bizimis et 
al. (2005) study, with additional silicate mineral data given in the Supplementary material (Table A3). Brief sample information and chemical data on the silicate phases are given in Table 4.1.

\subsection{Results and Discussion}

\subsubsection{Sulfide Petrography}

Sample choice, data acquisition and interpretation are all biased towards xenolith samples with the largest sulfides that are suitable for LA-ICMPS work because the main thrust of this study is the PGE contents of sulfides. Accordingly, the following discussion on the sulfide petrography is by no means exhaustive, but serves to put the sulfides in a petrological context for the interpretation of their HSE concentrations.

I categorized the sulfides into two petrographic varieties in these xenoliths: Type I are globular sulfides that occur as poikilitic inclusions entirely within clinopyroxene crystals; and Type II, irregular sulfides that occur in the interstitial spaces between the silicate minerals (Fig. 4.1). Type I sulfide inclusions are generally $10-100 \mu \mathrm{m}$ in diameter (mostly10-50 $\mu \mathrm{m})$; and the Type II (interstitial) sulfides are generally larger $(50-500 \mu \mathrm{m})$ (Fig. 4.1). The smaller size and lower modal abundance of the included sulfides (also in agreement with the De Waal and Calk (1975) findings) is reflected in the lower number of LA-ICP-MS determinations of included vs. interstitial sulfides in my data (Table 4.3).

The "interstitial" sulfides include both sulfides in triple junctions along grains (Fig. $4.1 \mathrm{~b}, \mathrm{c}$ ) and irregular grains, which may be interstitial or included. The presence of these two petrographically distinct sulfide types is significant because it implies extended sulfide crystallization: the globular sulfide inclusions formed from immiscible sulfide liquids that were trapped by clinopyroxene crystals which crystallized from the 
coexisting silicate melt; while the interstitial types formed after clinopyroxene and garnet crystallization. As noted later, there is no chemical difference between the two sulfide types implying that sulfide chemistry remained essentially invariant while silicate crystallization occurred. Finally, in some samples I also observed ultra fine (less than or equal to1 $\mu \mathrm{m}$ wide) sulfide veins that fill interstices or cracks within individual mineral grains. I could not analyze this and hence I focused only on Types I and II sulfides.

In a pioneering study of sulfides in SLC pyroxenites, De Waal and Calk (1975) reported that the majority of sulfide inclusions occur in clinopyroxene, which is consistent with my observation and with that of Guo et al., (1999). However, they also found some sulfide inclusions in garnet, ilmenite, orthopyroxene and spinel, which I did not find in my study; and the reason for such a discrepancy is not clear. I can only speculate either that (1) I biased my sampling toward xenoliths with large sulfides (>50microns) that could be analyzed by LA-ICP-MS. Perhaps these tend to occur preferentially in clinopyroxene - the first phase which appears on the liquidus during experimental crystallization of garnet pyroxenite melt (Keshav et al., 2007). (2) It is also possible that the reason sulfides are not included in garnet probably has something to do with wetting properties of garnet - perhaps garnet excludes sulfide melt rather than includes and grow around it. As I am unaware of experimental data to this effect, whatever I say would be tantamount to free speculation and so it is best that I stick to the observations that the sulfides are only included in the pyroxenes.

\subsubsection{Major Element Chemistry of the Sulfides: A Discussion}

Detailed petrographic description and analyses of the silicate phases may be found in Bizimis et al., (2005). Here, broad beam $(30 \mu \mathrm{m})$ EPMA analyses of sulfides in 
ten selected Hawaiian pyroxenite xenoliths are given in Table 3.2, which shows that the Hawaiian sulfides are essentially Fe-Ni sulfides with small and variable amounts of $\mathrm{Cu}$. Their compositions are also plotted in Fig. 4.2, which indicates that they are best described as monosulfide solid solution (MSS). Comparison with an early experimental study of the isotherms in the Cu-Fe-Ni-S system at atmospheric pressure (Kullerud et al., 1969) shows that these MSS may be of high-temperature origin.

In an exhaustive study of sulfides in spinel and garnet pyroxenites from an alpinetype massif, Lorand (1989) found that the sulfides started out as high-temperature $\left(1200^{\circ} \mathrm{C}\right) \mathrm{MSS}$ but subsequently broke down to lower temperature $\left(230^{\circ} \mathrm{C}\right)$ sulfides, including Ni-rich pyrrhotite, nickeliferous pentlandite, chalcopyrite and minor pyrite. In an earlier study of Hawaiian xenolithic sulfides, De Waal and Calk (1975) had also identified such phases in Hawaiian xenoliths and therefore, whether or not the presently studied sulfides are also of a low temperature subsolidus origin needs to be evaluated in light of the two studies mentioned above. I took care to examine the sulfides with the highest possible magnification $(220,000 \mathrm{X})$ with SEM and EPMA but did not find these other phases in studied samples. As figure 4.1 shows, all except one of the sulfides are fairly homogeneous. Although it is possible that the one sample that does show inhomogeneous texture (Fig. 4.1d) has experienced subsolidus breakdown (and hence the texture), several experimental studies have shown that such heterogeneous texture can develop during quenching. For example, a very important and relevant recent experimental study by Brenan et al., (2008) at 1 bar using a centrifuge furnace showed that the sulfide melt grew dendritic MSS crystals at $1200^{\circ} \mathrm{C}$ even though the run was quenched rapidly and thus gave the heterogeneous appearance to the sulfide. Also, an 
experimental study by Sugaki \& Kitakaze (1998) produced similar heterogenous textured sulfide melt with quench crystals of pentlandite.

The SLC pyroxenitic sulfides have lower $\mathrm{Ni}$ and $\mathrm{Cu}$ contents than sulfides reported in oceanic and continental peridotites (Alard et al., 2000; Lorand and Alard, 2001; Luguet et al., 2001; Alard et al., 2002; Luguet et al., 2003; Liu et al., 2009). On the ternary Fe-Ni-S system at 1 atm pressure the pyroxenitic sulfides plot near the FeS end of the MSS field and inside the $1100^{\circ} \mathrm{C}$ isotherm, whereas the peridotitic sulfides plot away from the FeS join towards lower equilibration temperatures (Fig. 4.2). I emphasize that none of the pyroxenite sulfides analyzed are of the low-T pentlandite or chalcopyrite variety as often seen in oceanic peridotites (Alard et al., 2000; Lorand and Alard, 2001; Luguet et al., 2001; Alard et al., 2002; Liu et al., 2009). I have further verified this with a scanning electron microscope. The absence of low temperature sulfide phases and the lack of compositional differences between Type I and Type II varieties suggests that both types are primary mantle sulfides related to the crystallization of the pyroxenite, and I consider it unlikely that the interstitial sulfides are the product of late (i.e., unrelated to the crystallization of pyroxenite) melt infiltration or low $-\mathrm{T}$ alteration.

Finally, I note that the Ni contents of the sulfides (both "Type I" and "Type II") show a broad positive correlation with the $\mathrm{Mg} \#$ of the clinopyroxene in the host rock (Fig. 4.3). Such correlation is expected when chemical equilibrium is maintained between sulfide and silicate phases forming from co-existing sulfide-silicate immiscible pairs, and when secondary processes, such as melt infiltration, have negligible effect on the sulfide compositions. This further supports my inference that sulfides and silicates are cogenetic, and most likely originated as immiscible liquids from silicate magmas from 
which clinopyroxene and garnet crystallized. The similarity of included and interstitial sulfides and the lack of evidence for any significant compositional heterogeneity in the cpx or garnet in these pyroxenites (Bizimis et al., 2005; Keshav et al., 2007) suggest that crystallization of the two sulfide types happened near contemporaneously (i.e., within a small P,T interval) with some sulfide being encapsulated by crystallizing cpx and others being trapped between crystals under upper mantle conditions.

\subsubsection{Pressure -Temperature Conditions of Liquid Immiscibility}

Sulfide-silicate liquid immiscibility is a well-established feature in mafic and ultramafic rocks (MacLean, 1969; Mathez, 1976). The globular morphology of the included sulfides (Fig. 4.1a) is consistent with these being early immiscible liquids that were later included by growing clinopyroxene crystals from the more voluminous, silicate conjugate melt. Here I try to evaluate the P-T conditions that controlled the sulfide-silicate liquid immiscibility.

First, for the sulfide-silicate liquid immiscibility to occur, both conjugate melts must be saturated with the other. There have been several experiments conducted on sulfide saturation of silicate melts and silicate-sulfide immiscibility, and it is clear that Ssaturation of silicate melts is controlled by $\mathrm{P}, \mathrm{T}$, and fugacities of Oxygen and Sulfur (Mavrogenes and O'Neill, 1999). Pressure has a particularly strong negative effect on Ssaturation of silicate melt: Mavrogenes and O'Neill (1999) showed in a model calculation that the Sulfur capacity at S-saturation (SCSS) of the erupted lava is $\sim 1075 \mathrm{ppm}$. I note that deep, submarine alkalic glasses found in North Arch volcanic field on the seafloor on Hawaiian flexure contain 1800 ppm S (Davis \& Clague, 2006). The importance of this is that the North Arch and Honolulu Volcanics (which host the xenoliths) are all believed to 
be petrogenetically similar to the parental melts of the pyroxenites (Sen et al., 2005). Thus, on the basis of the comparison between the glass data and the model calculations of Mavrogenes and O'Neill (1999), it seems reasonable to conclude that the erupted glasses were S-saturated (as was concluded by Dixon et al., 1997). Furthermore, it is reasonable to infer that mantle melts that crystallized the pyroxenites and the sulfides at $\sim 3 \mathrm{GPa}$ (Keshav et al., 2007) were also S-saturated since such melts rose rather rapidly (hence carrying xenoliths). Although it is difficult to calculate the SCSS of the pyroxenite-parent melt at $\sim 3 \mathrm{GPa}$, following the model calculations of Mavrogenes and O'Neill (1999) I estimate that it was probably around $400 \mathrm{ppm}$.

The next issue is determining at what $\mathrm{P}, \mathrm{T}$ the sulfide-silicate liquid immiscibility occurred beneath Oahu. The problem is that there has not been an experimental study of sulfide-alkaline silicate immiscibility relevant to the Hawaii-type situation, nor there is any suitable sulfide compositional or exchange thermobarometers embedded in any of the available S-immiscibility type experimental studies that can be used to estimate such P-T conditions. Therefore I must rely on indirect means to evaluate the P-T conditions of the said liquid immiscibility.

One such constraint is provided by the experimental crystallization study of Keshav et al. (2004), which shows that the liquidus temperature of Hawaiian garnet pyroxenites is between $1450^{\circ}-1500^{\circ} \mathrm{C}$ at $2-2.5 \mathrm{GPa}$. Similarly, based on the experimental study by Bockrath et al. (2004), the $(\mathrm{Fe}, \mathrm{Ni}, \mathrm{Cu})_{1-\mathrm{x}} \mathrm{S}$ monosulfide also has a liquidus temperature of $1400^{\circ}-1500^{\circ} \mathrm{C}$ even though the slopes of the silicate and sulfide melt liquidi may be different (Fig. 4.4). The P, T point of intersection of the two liquidi could represent the conditions where the sulfide-silicate liquid immiscibility had occurred. In 
figure 4.4 I show such a possible P-T "point" at $3.1 \pm 0.6 \mathrm{GPa}$ and $1530 \pm 100^{\circ} \mathrm{C}$. Based on earlier estimates from pyroxene thermobarometry conducted on these xenoliths (e.g. Sen et al., 2005), I feel that the lowest $\mathrm{P} / \mathrm{T}$ estimate of $2.5 \mathrm{GPa} / 1480^{\circ} \mathrm{C}$, which still falls within the P,T uncertainty above, is more reasonable. These $\mathrm{P}, \mathrm{T}$ conditions place the sulfide liquid immiscibility to have occurred at the base or below the seismically defined 80-90 km thick oceanic lithosphere beneath Oahu (Bock, 1991b; Priestley and Tilman, 1999).

\section{$\underline{\text { 4.3.4 PGE Systematics in Pyroxenitic Sulfides }}$}

Both included and interstitial sulfides have similar primitive mantle-normalized PGE patterns with low Os and Ir concentrations relative to Pd and Re (Fig. 4.5). Earlier studies have established that the PGE inventory in the upper mantle is controlled by minor non-silicate phases, typically sulfides, oxides or PGE-alloys ( Hart and Ravizza, 1996; Alard et al., 2000; Luguet et al., 2007). Given that the modal abundance, solubility in melts and melting behavior of these non-silicate phases are not well understood, rigorous quantitative modeling of the PGE during melting is generally associated with large uncertainties. However, based on the relative concentrations and PGE patterns between peridotites and lavas in general, it is well established that partial melting in the earth's mantle will fractionate the PGE with Os and Ir being more compatible than Pt and Pd in the mantle peridotite (Pearson et al., 2002). The low Os/Pd ratios and low absolute PGE contents of the pyroxenitic sulfides reported here are qualitatively similar to the patterns observed in lavas (OIB, MORB, Komatiites); (Bennett et al., 2000; PeuckerEhrenbrink et al., 2003; Puchtel et al., 2004b; Puchtel et al., 2005b; Ireland et al., 2009 ) and consistent with an origin of pyroxenites as cumulates from a mantle melt, as 
previously proposed based on the composition of the silicate phases ( Sen, 1988; Keshav et al., 2007;).

I further compare my sulfide data with sulfide inclusions in diamonds, which are generally thought as the best example of primary mantle derived sulfides (Pearson et al., 1998). The major element compositions of sulfide inclusions in African diamonds (Deines and Harris, 1995) are very similar to the SLC pyroxenitic inclusions (Fig. 4.2), and in terms of PGE, the pyroxenitic sulfides are similar to eclogitic ("E" type) sulfide inclusions (Fig. 4.6) in diamond (Pearson et al., 1998). The absolute PGE abundances in pyroxenitic sulfides are lower by a factor of 10 to 1000 when compared to sulfides from "P" type sulfide inclusions in diamond and peridotitic sulfides ( Pearson et al., 1998; Alard et al., 2000; Lorand and Alard, 2001; Luguet et al., 2001; Richardson et al., 2001; Pearson et al., 2002) (Fig 4.5, 4.6).

Some of the pyroxenitic sulfides show occasional Pt depletions with respect to Ir and Pd (e.g. samples 559, 680, 774; Fig. 4.5). Similar Pt depletions have also been observed in $\mathrm{Cu}-\mathrm{Ni}$-rich sulfides from peridotites, and have been broadly attributed to minor Pt-rich alloys exsolved out of sulfides upon cooling (Alard et al., 2000). As shown earlier however, none of the sulfides analyzed here are of the low- $\mathrm{T} \mathrm{Cu}$-Ni-rich variety therefore my data does not directly support a Pt-rich alloy exsolution upon cooling. Peregoedova et al., (2002) have shown that Pt-Ir rich PGE alloys may exsolve from MSS at high $\mathrm{T}\left(1000^{\circ} \mathrm{C}\right)$ upon desulfurization. The extent of Pt depletion in our sulfide data (calculated here as $\mathrm{Pt} / \mathrm{Pt}$, or the deviation of the chondrite-normalized $\mathrm{Pt}$ concentration of the sample from the hypothetical $\mathrm{Pt}$ concentration, $\mathrm{Pt}^{*}$, where $\mathrm{Pt}^{*}$ lies on a straight line between $\mathrm{Ir}$ and $\mathrm{Pd}$ on a chondrite-normalized plot) correlates better with the $\mathrm{Pt}$ 
concentrations of the sulfides $\left(\mathrm{R}^{2}=0.44\right)$ but not $\operatorname{Ir}\left(\mathrm{R}^{2}=0.03\right)$ (not shown). The presence of Pt depletion perhaps suggests that the presence of a Pt-rich alloy alone (as opposed to a Pt-Ir alloy) may control the Pt depletions I observe here. Given that only an extremely small amount of such Pt-rich exsolution will be required to explain the Pt depletions it is quite possible that some Pt alloys escaped detection in our LA-ICPMS study.

\subsubsection{Sulfide PGE Concentrations and Silicate Differentiation}

The total PGE contents (calculated here as the sum of Os+Ir+Pt+Pd concentrations) of the average sulfide in each pyroxenite sample show a positive correlation with the $\mathrm{Mg \#}$ of the host rock cpx (Fig. 4.7), in a similar fashion that the Ni sulfide concentrations correlate with the cpx Mg\# (Fig. 4.3). This is strong additional evidence that these sulfides were in broad equilibrium with the silicates, and therefore of high temperature mantle origin. This also suggests that secondary processes such as metasomatism by melt/gas infiltration by the host lava, decompression during emplacement into the host lava and even possible Sulfur loss by devolatilization (e.g., Lorand et al., 2003) could not have significantly affected the PGE contents of these pyroxenitic sulfides. Such PGE vs. Mg\# trends are common in lavas and komatiites ( Rehkamper et al., 1999; Puchtel and Humayun, 2000; Ireland et al., 2009) and have been explained by a combination of olivine crystallization associated with sulfur saturation and subsequent sulfide precipitation. As the SLC pyroxenites have been interpreted as high pressure cumulates, a similar process may be called upon to explain these correlations, the difference being that the pyroxenites are pyroxene-garnet rich, olivine-poor cumulates as opposed to lavas sampled at the surface which are generally controlled by olivine fractionation / accumulation. 
An examination of experimental studies on peridotite and pyroxenite compositions shows that during high-pressure (2-5 GPa.) isobaric crystallization (Walter, 1998; Keshav et al., 2004) the Mg\# of cpx and garnet decreases with cooling and progressive crystallization. For example, in the SLC pyroxenite composition experiments of Keshav et al., (2004) at $2.5 \mathrm{GPa}$, the $\mathrm{Mg} \#$ in cpx decreases steadily from 0.877 to 0.772 and the cpx abundance increases as the temperature drops from 1478 to $1320{ }^{\circ} \mathrm{C}$. The SLC pyroxenites examined here can be modeled as products of a similar crystallization process where each sample represents a cumulate at different extends of crystallization from a parental melt of similar composition.

I envision the following process of crystallization - induced sulfide immiscibility: The parental pyroxenite melt separates from its source and begins crystallizing at some thermal boundary layer, either at the base of the lithosphere or even within the upwelling plume. Here, the high Mg\# samples represent the earlier higher temperature cumulates. During this early fractionation, the melt becomes saturated with sulfur and separates an immiscible sulfide melt. As I discussed earlier the SCSS of the pyroxenite parental melt at high $\mathrm{P}$ and $\mathrm{T}$ is expected to be low, therefore only limited crystal fractionation will drive the residual liquid to $\mathrm{S}$-saturation and sulfide precipitation. Because of the extremely high sulfide/silicate partition coefficients (Fleet et al., 1999) the sulfide will effectively soak up the PGE out of the melt. Further fractionation along a decreasing temperature path leads to lower $\mathrm{Mg \#}$ in the cumulate cpx and garnet and saturates the melt with sulfur once more, leading to a new immiscible sulfide. The PGE concentrations of this "second generation" sulfide however will be lower than the first one because the residual liquid is now depleted in PGE (and Ni). The process continues with the end 
result that the most evolved cumulates (lowest $\mathrm{Mg} \#$ in cpx) will have sulfides with the lowest Ni and PGE contents. The actual concentrations depend on the amount of sulfur saturation and the amount of precipitated sulfide at each step, but the overall trend will persist.

In order to quantitatively model this process I need an estimate of the parental melt composition. It was discussed in the background section that the parental melts of these pyroxenites may either be a HV-type melt, a MORB-type or a tholeiitic melt related to the Hawaiian shield stage lavas. Here I use the HSE abundances to constrain this parental melt. I calculate Re and Os concentrations in the conjugate silicate melt composition that would have coexisted with the measured sulfides using the sulfide/silicate partition coefficients of 5.0 and 3.7 x1000 for Os and Re respectively (Fleet et al., 1999; Sattari et al., 2002). Figure 4.8a shows that the calculated silicate melt compositions are more akin to the post-erosional HV lavas, and unlike the Hawaiian picrites or MOR type melts and I conclude that melts similar to HV are more likely the parental melt for these sulfides and by inference the pyroxenites.

I now model the immiscibility process using an HV-type parental melt with the highest Os concentrations reported by Lassiter et al. 2000 and a chondritic Os/Ir ratio (a valid assumption as their partition coefficients during mantle melting are very similar). From this melt I sequentially separate $0.05 \%$ of immiscible sulfide using the sulfide / silicate melt partition coefficients from Fleet et al. 1999. This simulates the progressive silicate crystallization and sulfur saturation in our model. While silicate crystallization will also change the PGE contents of the residual liquid because PGE are incompatible in the silicate minerals, this effect is negligible compared to that of the sulfide separation 
and I ignore it in my calculations. My results indicate that only limited $(0.01 \%-0.3 \%$ modal) sulfide precipitation is needed to reproduce the variability in the PGE concentrations of the SLC pyroxenitic sulfides (Fig. 4.8b). With a S concentration of 35 wt $\%$ in the sulfides, my high end estimate of $0.3 \%$ sulfide total fractionation is equivalent to $\sim 1000 \mathrm{ppm}$ sulfur and similar to the concentration of a typical Hawaiian magma (Jamais et al., 2008). Bearing on the validity of these assumptions this suggests near total sulfur precipitation from the parental melt is required to explain the sulfides with the lowest PGE contents.

The above process can explain the fractionation of PGE in the pyroxenitic sulfides in relationship to high-pressure crystallization of a parental magma and the composition of the host pyroxene. However it cannot explain all sulfide patterns I observed in my samples. For example, the two included sulfides in sample 559 with high $\mathrm{Mg} \#$ in cpx (Fig. 4.5) show Os and Ir enrichments and concentrations that overlap peridotite sulfides. This later case could be assigned to melt-rock reaction where the initial high-T melt (and a crystallizing cpx with high $\mathrm{Mg \# )}$ may react with the surrounding peridotite and become enriched in PGE by preferentially dissolving peridotitic sulfides or Os-Ir alloys from the peridotite. Qualitatively, melt-rock reaction between the pyroxenite parental melts and a mantle peridotite should be taking place as a melt (and perhaps more likely the initial high temperature melt) needs to "make space" in the mantle / lithosphere to crystallize the pyroxenites and evidence for that may exist in the PGE contents of pyroxenitic sulfides. Apart for this special case however, I suggest that the broad range of PGE concentrations in the pyroxenite sulfides are consistent with progressive high-pressure 
crystallization of magma similar to the rejuvenated lavas observed on and around the Hawaiian islands.

4.3.6 Implications for the ${ }^{186} \mathrm{Os}^{187}$ Os Systematics of Hawaiian Lavas and the Lower Mantle-Outer Core Chemical Exchange

Whether or not the metallic core of the earth is exchanging material with the silicate mantle is fundamental to our understanding of the composition of the earth's mantle. Brandon et al., (1999) proposed that the coupled enrichments in ${ }^{186} \mathrm{Os} /{ }^{188}$ Os${ }^{187} \mathrm{Os} /{ }^{188}$ Os isotopes observed in some Hawaiian picrites and komatiites result from contributions from the outer core, linking therefore mantle plumes to the core-mantle boundary. This hypothesis is based on metal-liquid partition coefficients for the PGE $\mathrm{Re}$ that result in coupled $\mathrm{Pt} / \mathrm{Os}, \mathrm{Re} / \mathrm{Os}$ enrichments and $\mathrm{Pt} / \mathrm{Re}$ ratios such that, over time, will result in coupled suprachondritic ${ }^{187} \mathrm{Os} /{ }^{188} \mathrm{Os}$ and ${ }^{186} \mathrm{Os} /{ }^{188} \mathrm{Os}$ ratios in the outer core (Brandon and Walker, 2005). Brandon and Walker (2005) also discussed the possibility that mantle pyroxenites may have high enough $\mathrm{Pt} / \mathrm{Re}$ ratios that upon recycling and aging may lead to such coupled ${ }^{186} \mathrm{Os} /{ }^{188} \mathrm{Oss}^{187} \mathrm{Os} /{ }^{188}$ Os enrichments, however the limited data at that time prevented a full analysis of that possibility. Based on a study of pyroxenites from the Beni Bousera ophiolitic massif, Luguet et al., (2008) recently suggested that pyroxenites plus their sulfides can have high enough $\mathrm{Pt} / \mathrm{Os}$ and Re/Os ratios that upon recycling and aging can generate the enriched osmium isotope signatures observed in plume volcanism thereby providing an alternative to the leaky core hypothesis. In contrast, Ireland et al. (2009) suggested that hybridization of a peridotitic mantle source with a pyroxenite melt and its associate sulfides, such as those determined by Luguet et al. (2008) could not have played a major role in the source of Hawaiian picrites, since this 
process will substantially increase the $\mathrm{Pt}$ abundance and the $\mathrm{Pt} / \mathrm{Os}$ ratio of the Hawaiian mantle source which is not supported by the lava data (Ireland et al., 2009).

The SLC pyroxenites analyzed here contain sulfides from the present day oceanic upper mantle and therefore are uniquely suited to test the pyroxenite-recycling hypothesis as a source for the coupled ${ }^{186} \mathrm{Os} /{ }^{188} \mathrm{Os}-{ }^{187} \mathrm{Os} /{ }^{188} \mathrm{Os}$ enrichments in the mantle. I assume that the sulfides are the main repository of Pt-Re-Os in these pyroxenites and that the sulfide $\mathrm{Pt} / \mathrm{Os}$ and $\mathrm{Pt} / \mathrm{Re}$ ratios represent that of the bulk rock. Using the measured $\mathrm{Pt} / \mathrm{Os}$ and Re/Os ratios of these sulfides I can calculate the range of ${ }^{187} \mathrm{Os} /{ }^{188} \mathrm{Os}$ and ${ }^{186} \mathrm{Os} /{ }^{188} \mathrm{Os}$ compositions that these could develop by "ageing" the sulfides over 1, 2 and 3Ga from a chondritic earth and assuming the ratios will not change during the recycling process. Figure 4.9 shows the "aged" compositions of all the sulfides measured here compared with the present day isotope compositions of the mantle and the osmium isotope-enriched Hawaiian lavas and komatiites. These sulfides upon aging can generate relatively radiogenic ${ }^{187} \mathrm{Os} /{ }^{188} \mathrm{Os}$ and ${ }^{186} \mathrm{Os} /{ }^{188} \mathrm{Os}$ ratios, but do not generate the steep array required by the plume samples (Fig. 4.9). Brandon et al. (1999) demonstrated that in order to produce the slope of the Hawaiian picrites in ${ }^{187} \mathrm{Os} /{ }^{188} \mathrm{Os}$ vs. ${ }^{186} \mathrm{Os} /{ }^{188} \mathrm{Os}$ isotope space their source should have a $\mathrm{Pt} / \mathrm{Re}$ ratio of $88-100$. The pyroxenite sulfides analyzed here have a Pt/Re range from 0.03 to 10 (Fig. 4.10) and as such they cannot generate the steep array in ${ }^{187} \mathrm{Os} /{ }^{188} \mathrm{Os}$ vs. ${ }^{186} \mathrm{Os} /{ }^{188} \mathrm{Os}$ isotope space required by the plume data (Fig. 4.9). Even if $\operatorname{Re}$ is compatible in garnet (Righter et al., 1998) and there are appreciable amounts of Re in the silicate portion of these pyroxenites this will only decrease the $\mathrm{Pt} / \mathrm{Re}$ ratio of the bulk rock, further removing it from the required and high $\mathrm{Pt} / \mathrm{Re}$ ratio of $88-100$. 
Figure 4.10 further shows the distribution of $\mathrm{Pt} / \mathrm{Re}$ ratios in pyroxenite sulfides from our study including the pyroxenite and eclogite sulfide data of Luguet et al. 2008, and peridotitic sulfides from Wang et al. 2009. It is evident that the vast majority of pyroxenitic sulfides have much lower $\mathrm{Pt} / \mathrm{Re}$ ratio than the $88-100 \mathrm{Pt} / \mathrm{Re}$ range required to explain the ${ }^{186} \mathrm{Oss}^{187}$ Os isotope enrichments of Hawaiian lavas and komatiites. In fact, only one pyroxenite (Beni Bousera sample GP 87T in Luguet et al., 2008) has a high enough Pt/Re ratio $(\sim 115)$ to generate, over time, the observed ${ }^{186} \mathrm{Os}_{-}{ }^{187}$ Os enrichments in plume lavas.

One possible workaround to the low $\mathrm{Pt} / \mathrm{Re}$ ratios of the pyroxenites would be the fortuitous involvement of Pt-rich alloys in the source of these plume lavas, in addition to a pyroxenitic component. The Pt-rich alloys from the Josephine ophiolite have extremely high $\mathrm{Pt} / \mathrm{Re}$ ratios $(>10,000$, Luguet et al., 2008) and will generate over time very radiogenic ${ }^{186} \mathrm{Os} /{ }^{188} \mathrm{Os}$ ratios. Mixing of high ${ }^{186} \mathrm{Os} /{ }^{188} \mathrm{Os}$ ratios with the pyroxenitegenerated high ${ }^{187} \mathrm{Os} /{ }^{188} \mathrm{Os}$ could theoretically produce the required radiogenic ${ }^{186} \mathrm{Os} /{ }^{188} \mathrm{Oss}^{187} \mathrm{Os} /{ }^{188} \mathrm{Os}$ end member seen in the Hawaiian and komatiite lavas. While such a fortuitous scenario may be theoretically possible, I consider how likely it could be, especially when the distribution of Pt-rich alloys in the mantle is virtually unknown and considering the Ireland et al. (2009) arguments that such a high Pt/Re source is not compatible with the PGE contents of the Hawaiian lavas, at least. Based on the above discussion I suggest that recycled, mantle-derived pyroxenites and perhaps eclogites are not, on average, a likely source of the enriched ${ }^{186} \mathrm{Os}-{ }^{187}$ Os osmium isotope compositions seen in the Hawaiian plume and komatiites. Therefore an outer core contribution to the 
Hawaiian and other komatiite plume volcanism may still be required to explain these features.

\subsection{SUMMARY}

My investigation on the major and HSE contents of sulfides from garnet pyroxenite xenoliths from Salt Lake Crater, Oahu, Hawaii has shown that these sulfides are consistent with a high temperature mantle origin. Petrographic and experimental considerations suggest that these sulfides originate at the base of the Pacific lithosphere, or even deeper, as immiscible sulfide melt from a crystallizing silicate melt that is similar to lavas erupting during the rejuvenated volcanism. The Ni and PGE contents in the sulfides correlate with the $\mathrm{Mg} \#$ of the host clinopyroxene, providing direct evidence for sulfide / silicate equilibration, and some of the strongest evidence that these sulfides are primary mantle sulfides. As such they represent some of the best available material to investigate the behavior of PGE and other HSE elements in the mantle. The variability in the HSE concentrations of the SLC pyroxenitic sulfides can be explained by limited $(0.01 \%-0.3 \%$ modal $)$ sulfide precipitation during high pressure crystallization. The pyroxenitic sulfides have relatively low $\mathrm{Pt} / \mathrm{Re}$ ratios and do not have the potential to produce the coupled radiogenic ${ }^{186} \mathrm{Os} /{ }^{188} \mathrm{Os}-{ }^{187} \mathrm{Os} /{ }^{188} \mathrm{Os}$ ratios as observed in Hawaiian lavas or komatiites upon recycling and aging. My data therefore argue against the presence of recycled pyroxenitic sulfides in the source of high ${ }^{186} \mathrm{Os} /{ }^{188} \mathrm{Os}-{ }^{187} \mathrm{Os} /{ }^{188} \mathrm{Os}$ plumes, leaving an outer core contribution to these plumes as a valid hypothesis. 
Table 4.1

Modal Composition and Lithology of Studied Xenoliths and Chemical Index of the Major Mineral Phases.

\begin{tabular}{|c|c|c|c|c|c|}
\hline Sample Number & Clinopyroxene & Garnet & Orthopyroxene & Olivine & Rock Name \\
\hline 77 SL- 552 & $95 \%(\mathrm{Mg} \# 0.69)$ & $2-5 \%(\mathrm{Mg} \# 0.62)$ & & & Garnet Pyroxenite \\
\hline $77 S L-555$ & $80 \%(\mathrm{Mg} \# 0.77)$ & $20 \%(\mathrm{Mg} \# 0.68)$ & $<1 \%(\mathrm{Mg} \# 0.79)$ & & Garnet Pyroxenite \\
\hline$\underline{77 \text { SL -559 }}$ & $85 \%(\mathrm{Mg} \# 0.77)$ & $15 \%(\mathrm{Mg} \# 0.65)$ & & & $\begin{array}{c}\text { Garnet Pyroxenite } \\
\text { Olivine-bearing }\end{array}$ \\
\hline$\underline{77 \text { SL -590 }}$ & $80 \%(\mathrm{Mg} \# 0.78)$ & $15 \%(\mathrm{Mg} \# 0.67))$ & $1-2 \%(\mathrm{Mg} \# 0.79)$ & $1-5 \%$ & $\begin{array}{c}\text { Garnet Pyroxenite } \\
\text { Olivine-bearing }\end{array}$ \\
\hline $77 S L-594$ & $85 \%(\mathrm{Mg} \# 0.78)$ & $10 \%(\mathrm{Mg} \# 0.69)$ & $<5 \%(\mathrm{Mg} \# 0.79)$ & $<2 \%$ & $\begin{array}{c}\text { Garnet Pyroxenite } \\
\text { Olivine-bearing }\end{array}$ \\
\hline $77 S L-620$ & $75 \%(\mathrm{Mg} \# 0.80)$ & 20\% (Mg \# 0.68) & $5 \%(\mathrm{Mg} \# 0.81)$ & $1-5 \%$ & Garnet Pyroxenite \\
\hline $77 \mathrm{SL}-680$ & $90 \%(\mathrm{Mg} \# 0.72)$ & $10 \%(\mathrm{Mg} \# 0.58)$ & & & Garnet Pyroxenite \\
\hline$\overline{77 \mathrm{SL}-744}$ & $60 \%(\mathrm{Mg} \# 0.68)$ & $40 \%((\mathrm{Mg} \# 0.62)$ & & & Garnet Pyroxenite \\
\hline 77 SL -774 & $95 \%(\mathrm{Mg} \# 0.69)$ & $<5 \%(\mathrm{Mg} \# 0.64)$ & & & Garnet Pyroxenite \\
\hline $77 \mathrm{SL}-776$ & $50 \%(\mathrm{Mg} \# 0.84)$ & & $50 \%(\mathrm{Mg} \# 0.84)$ & & Websterite \\
\hline
\end{tabular}


Table 4.2 Major Element Composition of Sulfides (wt. \%)

\begin{tabular}{|c|c|c|c|c|c|c|c|c|c|c|}
\hline \multirow[t]{2}{*}{ Sample No } & \multicolumn{2}{|c|}{ SL $552_{\text {inclusion }}$} & \multicolumn{2}{|c|}{ SL $559_{\text {inclusion }}$} & \multicolumn{2}{|c|}{ SL $590_{\text {inclusion }}$} & \multicolumn{2}{|c|}{ SL $744_{\text {inclusion }}$} & \multicolumn{2}{|c|}{ SL $774_{\text {inclusion }}$} \\
\hline & $\mathrm{Wt} \%$ & $1 \sigma$ Error & $\mathrm{Wt} \%$ & $1 \sigma$ Error & $\mathrm{Wt} \%$ & $\begin{array}{c}1 \sigma \\
\text { Error }\end{array}$ & $\mathrm{Wt} \%$ & $\begin{array}{c}1 \sigma \\
\text { Error } \\
\end{array}$ & $\mathrm{Wt} \%$ & $1 \sigma$ Error \\
\hline & & $\mathrm{n}=4$ & & $\mathrm{n}=2$ & & $\mathrm{n}=2$ & & $\mathrm{n}=2$ & & $n=2$ \\
\hline $\mathbf{F e}$ & 57.44 & 0.24 & 56.58 & 0.45 & 55.04 & 0.03 & 57.40 & 0.71 & 56.71 & 0.66 \\
\hline $\mathbf{N i}$ & 4.60 & 0.13 & 6.11 & 0.13 & 9.52 & 0.17 & 5.30 & 0.28 & 3.48 & 0.18 \\
\hline Zn & 0.41 & 0.02 & 0.50 & 0.15 & 0.01 & 0.01 & 0.41 & 0.01 & 0.36 & 0.05 \\
\hline $\mathrm{Cu}$ & 1.51 & 0.05 & 1.21 & 0.27 & 0.55 & 0.07 & 1.27 & 0.02 & 1.34 & 0.06 \\
\hline $\mathbf{S}$ & 36.66 & 0.93 & 37.40 & 0.14 & 36.10 & 0.71 & 36.42 & 0.77 & 37.38 & 0.17 \\
\hline Total & 100.62 & 0.65 & 101.79 & 0.61 & 101.22 & 0.44 & 100.79 & 0.33 & 99.26 & 0.21 \\
\hline \multirow[t]{2}{*}{ Sample No } & \multicolumn{2}{|c|}{ SL 552 interstitial } & \multicolumn{2}{|c|}{ SL 559 $9_{\text {interstitial }}$} & \multicolumn{2}{|c|}{ SL $590_{\text {interstitial }}$} & \multicolumn{2}{|c|}{ SL $744_{\text {interstitial }}$} & \multicolumn{2}{|c|}{ SL 774 $4_{\text {interstitial }}$} \\
\hline & $\mathrm{Wt} \%$ & $\begin{array}{c}1 \sigma \text { Error } \\
n=6\end{array}$ & $\mathrm{Wt} \%$ & $\begin{array}{c}1 \sigma \text { Error } \\
n=3\end{array}$ & $\mathrm{Wt} \%$ & $\begin{array}{c}1 \sigma \\
\text { Error } \\
n=4\end{array}$ & $\mathrm{Wt} \%$ & $\begin{array}{c}1 \sigma \\
\text { Error } \\
n=4\end{array}$ & $\mathrm{Wt} \%$ & $\begin{array}{c}1 \sigma \text { Error } \\
n=3\end{array}$ \\
\hline $\mathbf{F e}$ & 55.95 & 0.41 & 56.30 & 0.58 & 55.87 & 0.47 & 56.90 & 0.77 & 56.56 & 0.47 \\
\hline $\mathbf{N i}$ & 4.80 & 0.32 & 5.67 & 0.45 & 8.59 & 0.67 & 4.98 & 0.15 & 3.24 & 0.15 \\
\hline $\mathbf{Z n}$ & 0.42 & 0.02 & 0.47 & 0.12 & 0.01 & 0.01 & 0.37 & 0.01 & 0.34 & 0.08 \\
\hline $\mathbf{C u}$ & 1.54 & 0.14 & 1.62 & 0.24 & 0.50 & 0.06 & 1.47 & 0.33 & 1.28 & 0.08 \\
\hline $\mathbf{S}$ & 37.87 & 1.25 & 37.44 & 0.12 & 35.76 & 0.52 & 37.19 & 0.59 & 37.42 & 0.14 \\
\hline Total & 99.29 & 1.15 & 101.49 & 1.14 & 100.73 & 0.19 & 100.906 & 0.29 & 98.84 & 0.47 \\
\hline
\end{tabular}


Table 4.2 Continued..

\begin{tabular}{|c|c|c|c|c|c|c|c|c|c|c|}
\hline \multirow[t]{3}{*}{ Sample No } & \multicolumn{2}{|c|}{ SL $555_{\text {inclusion }}$} & \multicolumn{2}{|c|}{ SL $594_{\text {inclusion }}$} & \multicolumn{2}{|c|}{ SL $620_{\text {inclusion }}$} & \multicolumn{2}{|c|}{ SL $776_{\text {inclusion }}$} & \multicolumn{2}{|c|}{ SL $680_{\text {inclusion }}$} \\
\hline & & $1 \sigma$ & & $1 \sigma$ & & $1 \sigma$ & & $1 \sigma$ & & $1 \sigma$ \\
\hline & $\mathrm{Wt} \%$ & Error & $\mathrm{Wt} \%$ & Error & $\mathrm{Wt} \%$ & Error & $\mathrm{Wt} \%$ & Error & $\mathrm{Wt} \%$ & Error \\
\hline & & $n=2$ & & $\mathrm{n}=2$ & & $n=2$ & & $\mathrm{n}=2$ & & $\mathrm{n}=2$ \\
\hline $\mathbf{F e}$ & 56.53 & 0.46 & 55.45 & 0.07 & 55.43 & 0.27 & 56.15 & 0.07 & 56.71 & 0.66 \\
\hline $\mathbf{N i}$ & 7.43 & 0.25 & 8.15 & 0.07 & 7.75 & 0.21 & 7.80 & 0.42 & 3.87 & 0.04 \\
\hline Zn & 0.01 & 0.01 & 0.40 & 0.14 & 0.36 & 0.07 & 0.48 & 0.18 & 0.30 & 0.03 \\
\hline $\mathrm{Cu}$ & 0.54 & 0.03 & 0.85 & 0.06 & 1.05 & 0.21 & 0.63 & 0.19 & 1.04 & 0.23 \\
\hline $\mathbf{S}$ & 36.20 & 0.42 & 35.65 & 0.64 & 35.75 & 0.49 & 35.85 & 0.92 & 37.38 & 0.17 \\
\hline Total & 100.70 & 0.24 & 100.50 & 0.70 & 100.34 & 0.30 & 100.90 & 0.55 & 99.30 & 0.71 \\
\hline \multirow[t]{3}{*}{ Sample No } & \multicolumn{2}{|c|}{ SL $555_{\text {interstitial }}$} & \multicolumn{2}{|c|}{ SL 594 interstitial } & \multicolumn{2}{|c|}{ SL $620_{\text {interstitial }}$} & \multicolumn{2}{|c|}{ SL $776_{\text {interstitial }}$} & \multicolumn{2}{|c|}{ SL $680_{\text {interstitial }}$} \\
\hline & & $1 \sigma$ & & $1 \sigma$ & & $1 \sigma$ & & $1 \sigma$ & & $1 \sigma$ \\
\hline & $\mathrm{Wt} \%$ & $\begin{array}{c}\text { Error } \\
n=3\end{array}$ & $\mathrm{Wt} \%$ & $\begin{array}{c}\text { Error } \\
n=2\end{array}$ & $\mathrm{Wt} \%$ & $\begin{array}{c}\text { Error } \\
n=3\end{array}$ & $\mathrm{Wt} \%$ & $\begin{array}{c}\text { Error } \\
n=4\end{array}$ & $\mathrm{Wt} \%$ & $\begin{array}{c}\text { Error } \\
n=3\end{array}$ \\
\hline $\mathbf{F e}$ & 55.22 & 0.16 & 56.17 & 0.09 & 55.17 & 0.07 & 55.26 & 0.23 & 57.45 & 0.31 \\
\hline $\mathbf{N i}$ & 7.87 & 0.35 & 6.53 & 0.24 & 7.85 & 0.49 & 8.15 & 0.35 & 4.01 & 0.62 \\
\hline Zn & 0.06 & 0.08 & 0.38 & 0.03 & 0.17 & 0.10 & 0.15 & 0.07 & 0.01 & 0.01 \\
\hline $\mathbf{C u}$ & 0.49 & 0.22 & 0.68 & 0.06 & 0.61 & 0.07 & 0.51 & 0.13 & 0.70 & 0.12 \\
\hline $\mathbf{S}$ & 35.97 & 0.40 & 36.95 & 0.35 & 36.85 & 0.07 & 37.00 & 0.15 & 37.42 & 0.14 \\
\hline Total & 99.60 & 0.72 & 100.71 & 0.59 & 100.97 & 0.07 & 101.07 & 0.53 & 99.58 & 0.40 \\
\hline
\end{tabular}


Table 4.3 HSE Concentrations in Sulfides

\begin{tabular}{|c|c|c|c|c|c|c|c|c|c|}
\hline & & & Os & Ir & $\mathbf{P t}$ & Pd & $\mathbf{R e}$ & Au & $\mathbf{P b}$ \\
\hline Sample No. & nature & & ppm & ppm & ppm & ppm & ppm & ppm & ppm \\
\hline 744_1 & interstitial & & 0.060 & 0.036 & 0.126 & 0.198 & 0.221 & 0.033 & 0.134 \\
\hline $744 \_2(n=3)$ & interstitial & & 0.044 & 0.023 & 0.099 & 0.190 & 0.257 & 0.009 & 0.158 \\
\hline $744 \_3$ & interstitial & & 0.009 & 0.005 & 0.074 & 0.141 & 0.311 & 0.001 & 0.128 \\
\hline $744 \_4$ & interstitial & & 0.059 & 0.036 & 0.112 & 0.154 & 0.264 & 0.013 & 0.158 \\
\hline $744 \_5$ & interstitial & & 0.045 & 0.025 & 0.067 & 0.127 & 0.286 & 0.023 & 0.275 \\
\hline $744 \_6$ & interstitial & & 0.008 & 0.003 & 0.027 & 0.054 & 0.136 & 0.011 & 0.333 \\
\hline $744+7$ & interstitial & & 0.022 & 0.013 & 0.038 & 0.138 & 0.396 & 0.125 & \\
\hline \multirow[t]{3}{*}{$744 \_8$} & interstitial & & 0.019 & 0.009 & 0.048 & 0.108 & 0.005 & 0.008 & \\
\hline & & Average & 0.033 & 0.019 & 0.074 & 0.139 & 0.234 & 0.028 & 0.198 \\
\hline & & STDEV & 0.021 & 0.013 & 0.036 & 0.046 & 0.119 & 0.040 & 0.085 \\
\hline 744_9 & inclusion & & 0.010 & 0.006 & 0.107 & 0.138 & 0.236 & 0.108 & 0.523 \\
\hline $552 \_1$ & interstitial & & 0.058 & 0.027 & 0.033 & 0.100 & 0.218 & 0.004 & 0.083 \\
\hline $552 \_2$ & interstitial & & 0.027 & 0.013 & 0.057 & 0.130 & 0.232 & 0.006 & 0.128 \\
\hline $552 \_3$ & interstitial & & 0.010 & 0.006 & 0.161 & 0.276 & 0.224 & 0.027 & 0.572 \\
\hline $552 \_4$ & interstitial & & 0.090 & 0.057 & 0.269 & 0.826 & 0.192 & 0.048 & 0.109 \\
\hline $552 \_5$ & interstitial & & 0.095 & 0.045 & 0.137 & 0.273 & 0.214 & 0.006 & 0.132 \\
\hline $552 \_6$ & interstitial & & 0.092 & 0.048 & 0.125 & 0.258 & 0.205 & 0.012 & 0.117 \\
\hline $552 \_7$ & interstitial & & 0.055 & 0.049 & 0.219 & 0.429 & 0.208 & 1.148 & 0.960 \\
\hline $552 \_8$ & interstitial & & 0.122 & 0.062 & 0.264 & 0.286 & 0.358 & 0.411 & 0.215 \\
\hline $552 \_9$ & interstitial & & 0.156 & 0.078 & 0.172 & 0.187 & 0.373 & 0.335 & 0.143 \\
\hline
\end{tabular}


Table 4.3 Continued............

\begin{tabular}{|c|c|c|c|c|c|c|c|c|c|}
\hline & & & Os & Ir & $\mathbf{P t}$ & Pd & $\mathbf{R e}$ & $\mathbf{A u}$ & $\mathbf{P b}$ \\
\hline Sample No. & nature & & ppm & ppm & ppm & ppm & ppm & $\mathrm{ppm}$ & $\mathrm{ppm}$ \\
\hline $552 \_10$ & interstitial & & 0.241 & 0.096 & 0.481 & 0.396 & 0.439 & 0.318 & 0.242 \\
\hline $552 \_11$ & interstitial & & 0.297 & 0.175 & 0.256 & 0.224 & 0.391 & 0.208 & 0.284 \\
\hline \multirow[t]{3}{*}{$552 \_12$} & interstitial & & 0.322 & 0.194 & 0.139 & 0.142 & 0.316 & 0.036 & 0.188 \\
\hline & & Average & 0.130 & 0.071 & 0.193 & 0.294 & 0.281 & 0.213 & 0.264 \\
\hline & & STDEV & 0.104 & 0.059 & 0.119 & 0.195 & 0.088 & 0.331 & 0.255 \\
\hline $552 \quad 13$ & inclusion & & 0.144 & 0.110 & 0.646 & 1.008 & 0.289 & 0.066 & 0.094 \\
\hline \multirow[t]{3}{*}{$552 \_14$} & inclusion & & 0.103 & 0.065 & 0.182 & 0.353 & 0.250 & 0.012 & 0.224 \\
\hline & & Average & 0.123 & 0.087 & 0.414 & 0.680 & 0.270 & 0.039 & 0.159 \\
\hline & & STDEV & 0.029 & 0.032 & 0.328 & 0.463 & 0.027 & 0.038 & 0.092 \\
\hline 5901 & interstitial & & 0.293 & 0.151 & 0.530 & 0.412 & 0.540 & 0.728 & 0.189 \\
\hline $590 \_2$ & interstitial & & 0.345 & 0.197 & 0.298 & 0.229 & 0.616 & 0.378 & 0.205 \\
\hline \multirow[t]{3}{*}{$590 \_3$} & interstitial & & 0.044 & 0.079 & 0.302 & 0.985 & 0.131 & 0.570 & 0.913 \\
\hline & & Average & 0.227 & 0.142 & 0.377 & 0.542 & 0.429 & 0.559 & 0.435 \\
\hline & & STDEV & 0.161 & 0.060 & 0.133 & 0.395 & 0.261 & 0.176 & 0.413 \\
\hline 774_1 & interstitial & & 0.022 & 0.013 & 0.032 & 0.037 & 0.262 & 0.086 & 0.070 \\
\hline $774 \_2$ & interstitial & & 0.014 & 0.016 & 0.066 & 0.062 & 0.208 & 0.032 & 0.244 \\
\hline $774 \_3$ & interstitial & & 0.014 & 0.013 & 0.020 & 0.034 & 0.217 & 0.009 & 0.158 \\
\hline $774 \_4$ & interstitial & & 0.029 & 0.017 & 0.011 & 0.025 & 0.258 & 0.043 & 0.066 \\
\hline
\end{tabular}


Table 4.3 Continued............

\begin{tabular}{|c|c|c|c|c|c|c|c|c|c|}
\hline & & & Os & Ir & $\mathbf{P t}$ & Pd & $\mathbf{R e}$ & Au & $\mathbf{P b}$ \\
\hline Sample No. & nature & & ppm & ppm & ppm & ppm & ppm & ppm & ppm \\
\hline $774 \_5$ & interstitial & & 0.040 & 0.027 & 0.022 & 0.082 & 0.197 & 0.040 & 0.065 \\
\hline $774 \_6$ & interstitial & & 0.046 & 0.023 & 0.013 & 0.054 & 0.203 & 0.004 & 0.034 \\
\hline 774_7 & interstitial & & 0.043 & 0.022 & 0.019 & 0.047 & 0.218 & 0.000 & 0.218 \\
\hline $774 \_8$ & interstitial & & 0.028 & 0.020 & 0.015 & 0.037 & 0.212 & 0.000 & 0.071 \\
\hline 774_9 & interstitial & & 0.024 & 0.016 & 0.008 & 0.035 & 0.219 & 0.000 & 0.034 \\
\hline $774 \_10$ & interstitial & & 0.036 & 0.019 & 0.009 & 0.046 & 0.256 & 0.003 & 0.117 \\
\hline \multirow[t]{3}{*}{ 774_11 } & interstitial & & 0.028 & 0.019 & 0.006 & 0.033 & 0.232 & 0.000 & 0.144 \\
\hline & & Average & 0.030 & 0.019 & 0.020 & 0.045 & 0.226 & 0.020 & 0.111 \\
\hline & & STDEV & 0.011 & 0.004 & 0.017 & 0.016 & 0.023 & 0.028 & 0.072 \\
\hline 680_1 & interstitial & & 0.029 & 0.016 & 0.075 & 0.194 & 0.142 & 0.009 & 0.101 \\
\hline $680 \_2$ & interstitial & & 0.027 & 0.015 & 0.068 & 0.193 & 0.145 & 0.007 & 0.056 \\
\hline $680 \_3$ & interstitial & & 0.059 & 0.036 & 0.412 & 0.625 & 0.197 & 0.036 & 0.096 \\
\hline $680 \_4$ & interstitial & & 0.096 & 0.046 & 0.413 & 0.580 & 0.199 & 0.037 & 0.237 \\
\hline $680 \_5$ & interstitial & & 0.071 & 0.040 & 0.015 & 0.076 & 0.193 & 0.000 & 0.120 \\
\hline 680_6 & interstitial & & 0.068 & 0.039 & 0.012 & 0.076 & 0.185 & 0.000 & 0.961 \\
\hline $680 \_7$ & interstitial & & 0.069 & 0.036 & 0.016 & 0.103 & 0.232 & 0.029 & 0.944 \\
\hline \multirow[t]{3}{*}{$680 \_8$} & interstitial & & 0.014 & 0.009 & 0.037 & 0.127 & 0.256 & 0.005 & 0.206 \\
\hline & & Average & 0.054 & 0.030 & 0.131 & 0.247 & 0.194 & 0.015 & 0.340 \\
\hline & & STDEV & 0.028 & 0.014 & 0.175 & 0.225 & 0.038 & 0.016 & 0.383 \\
\hline
\end{tabular}


Table 4.3 Continued......

\begin{tabular}{cccccccccc} 
& & Os & Ir & Pt & Pd & Re & Au & Pb \\
\hline Sample No. & nature & & ppm & ppm & ppm & ppm & ppm & ppm & ppm \\
\hline 559_1 & interstitial & & 1.224 & 1.380 & 0.051 & 0.108 & 0.421 & 0.017 & 0.106 \\
$559 \_2$ & interstitial & & 0.155 & 0.079 & 0.057 & 0.160 & 0.443 & 0.017 & 0.499 \\
& & & & & & & & & \\
559_3 & interstitial & & 0.167 & 0.089 & 0.183 & 0.349 & 0.401 & 0.147 & 6.833 \\
559_4 & interstitial & & 0.062 & 0.025 & 0.075 & 0.308 & 0.408 & 0.018 & 0.029 \\
$559 \_5$ & interstitial & & 0.062 & 0.035 & 0.020 & 0.086 & 0.417 & 0.004 & 0.084 \\
& & Average & 0.334 & 0.322 & 0.077 & 0.202 & 0.418 & 0.040 & 1.510 \\
& & STDEV & 0.500 & 0.592 & 0.062 & 0.119 & 0.016 & 0.060 & 2.981 \\
& & & & & & & & & \\
$559 \_6$ & inclusion & & 0.059 & 0.052 & 0.212 & 0.316 & 0.292 & 0.085 & 0.066
\end{tabular}



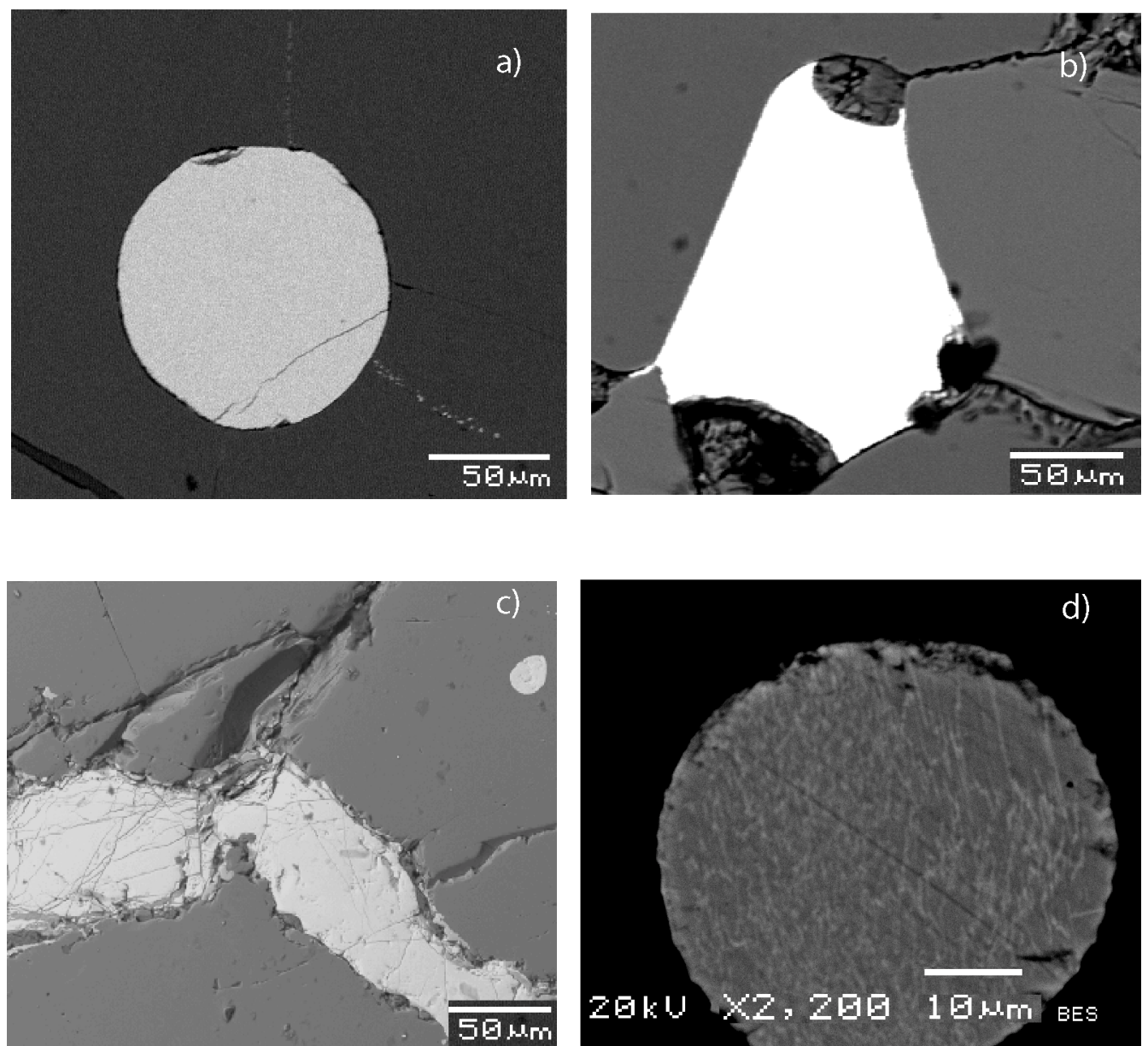

Figure 4.1 SEM images of Sulfide grains. (a) SL-552: Sulfide inclusion within clinopyroxene. (b) SL-590: Interstitial sulfide in triple junctions along cpx grains. (C) SL744: Interstitial and included sulfide. (d) SL-590: Interfingered $\mathrm{Ni}$ rich and $\mathrm{Ni}$ poor portions in sulfide inclusion observed on a single sample SL-590 (white bands are the Ni rich portion). Pictures are taken using the Scanning Electron Microscope at FCAEM, Florida International University. 


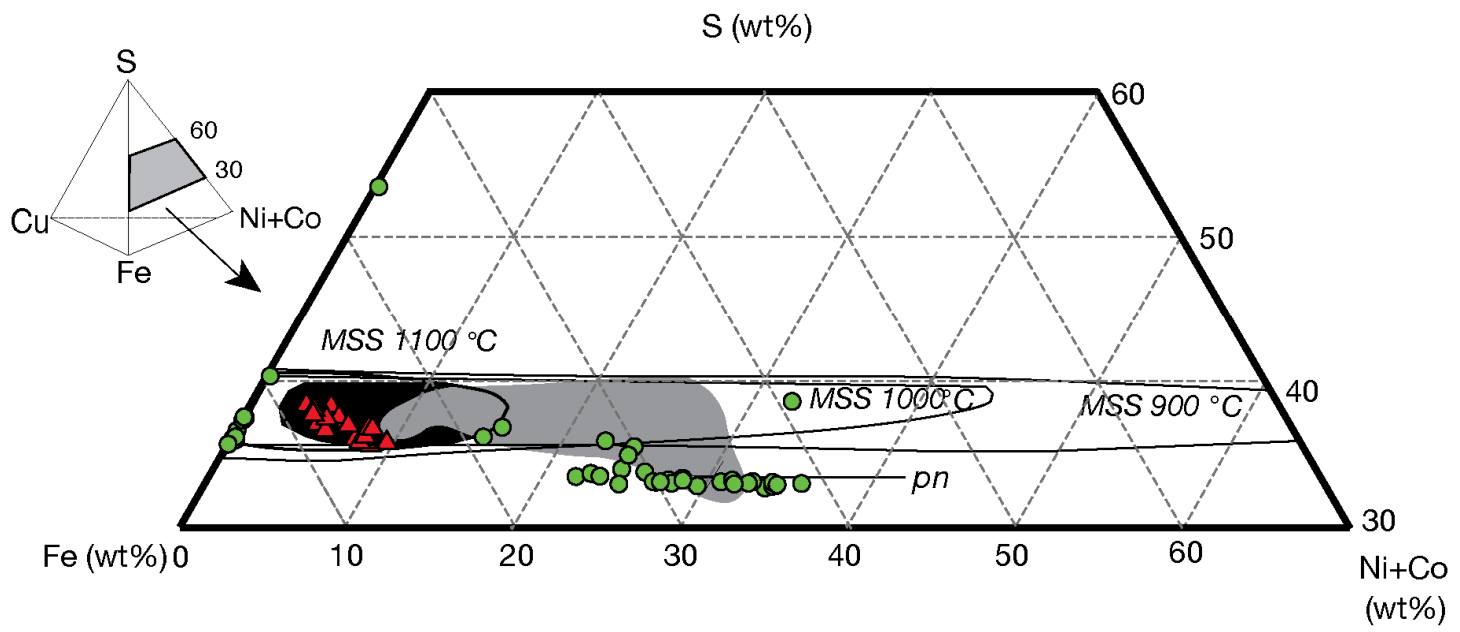

Figure 4.2 Pyroxenitic sulfide compositions plotted in the Fe-Ni-S system (Kullerud et al., 1969). Filled triangle, sulfides in pyroxenite xenoliths (this study); Filled circle, sulfides in abyssal peridotites (Liu et al., 2009); black field, sulfide inclusion in African diamonds (Deines and Harris, 1995); grey field; sulfides in peridotites (Alard et al., 2000). End member phases: MSS - monosulfide solid solution; Pn - pentlandite. 


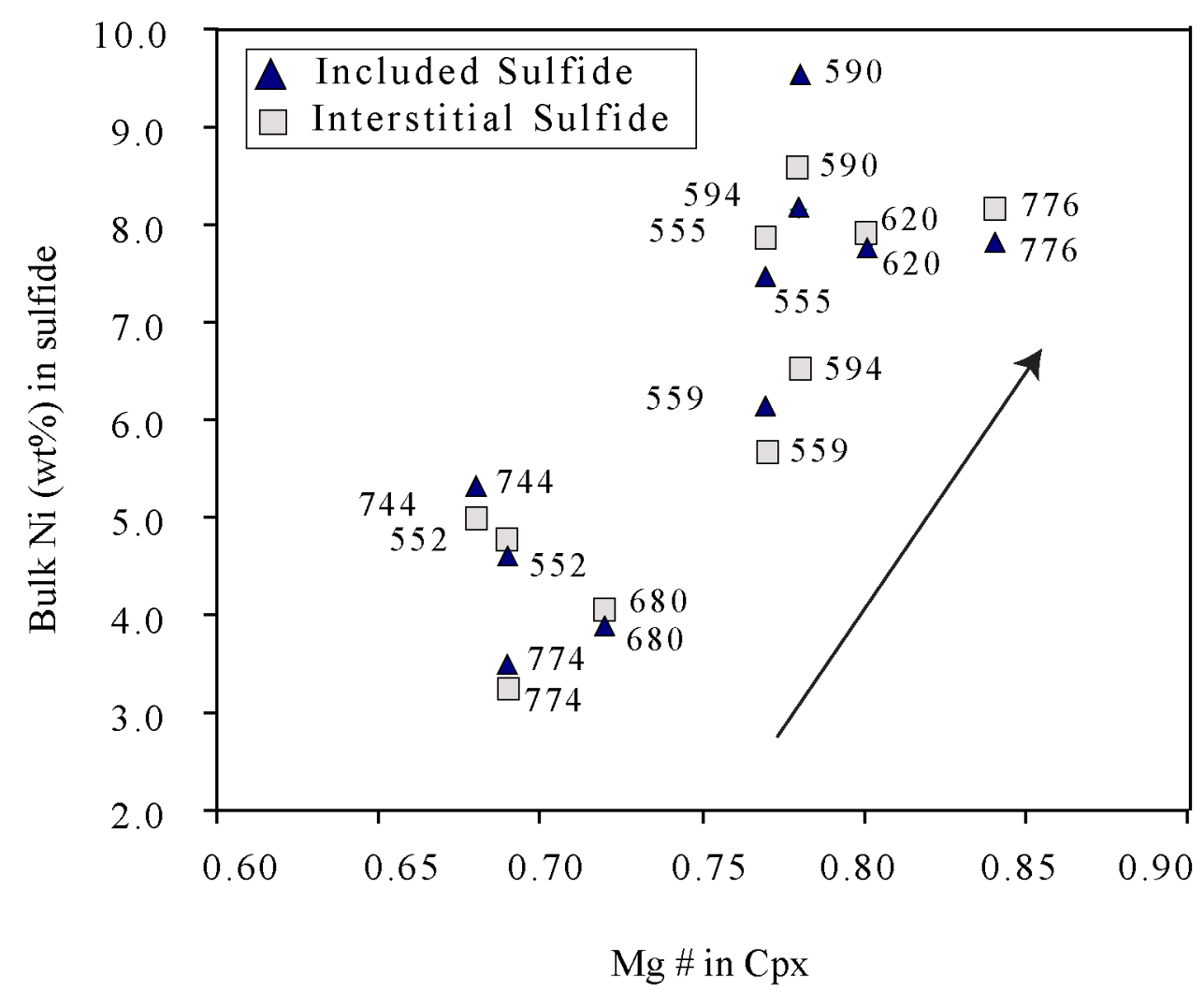

Figure 4.3 Mg\# of clinopyroxene vs. average Ni concentrations (wt. \%) in coexisting sulfides $(\mathrm{Mg} \#=$ Molar $\mathrm{Mg} / \mathrm{Mg}+\mathrm{Fe}$ Total). Sulfide data from this study and most of the major element data for clinopyroxene from Bizimis et al. (2005) (Additional data in appendix supplement Table A3). The sulfides with the highest Ni contents coexist with the most Mg-rich cpx (also garnet; not shown). This suggests chemical equilibrium between cpx and sulfides in these pyroxenites. Also note that the average interstitial and included sulfides for each sample have very similar $\mathrm{Ni}$ contents. 


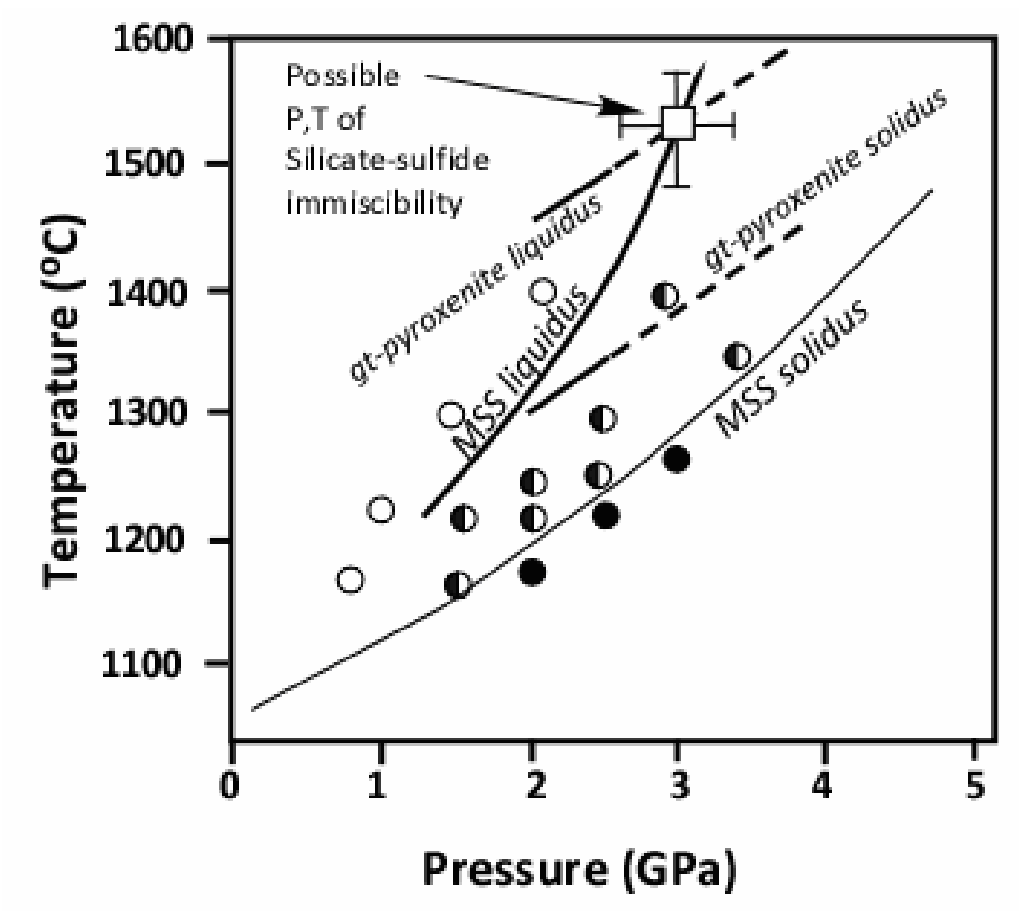

Figure 4.4 Inferred Pressure - Temperature conditions of silicate-sulfide liquid immiscibility beneath Hawaii. MSS solidus and liquidus are drawn from Bockrath et al.'s (2004) run data (filled circle-solid, unfilled circles-melt, half-filled circle solid + melt). The garnet pyroxenite solidus and liquidus are from Keshav et al. (2004). The MSS liquidus is drawn as a curve halfway between adjacent melt vs. solid + melt runs. I infer the intersection of the MSS liquidus and extrapolated garnet pyroxenite liquidus curves as the likely P-T point where the sulfide-silicate liquid immiscibility have occurred. Note that the experimental constraint on the placement of MSS liquidus is not as strong, leading to large error bar in the location of the P-T intersection point. Based on the previous pyroxene thermobarometry of the xenoliths, lava and melt inclusion thermometry, the lower limit of $1480^{\circ} \mathrm{C}$ and $2.5 \mathrm{GPa}$ is perhaps a more plausible condition of sulfide silicate liquid immiscibility. 


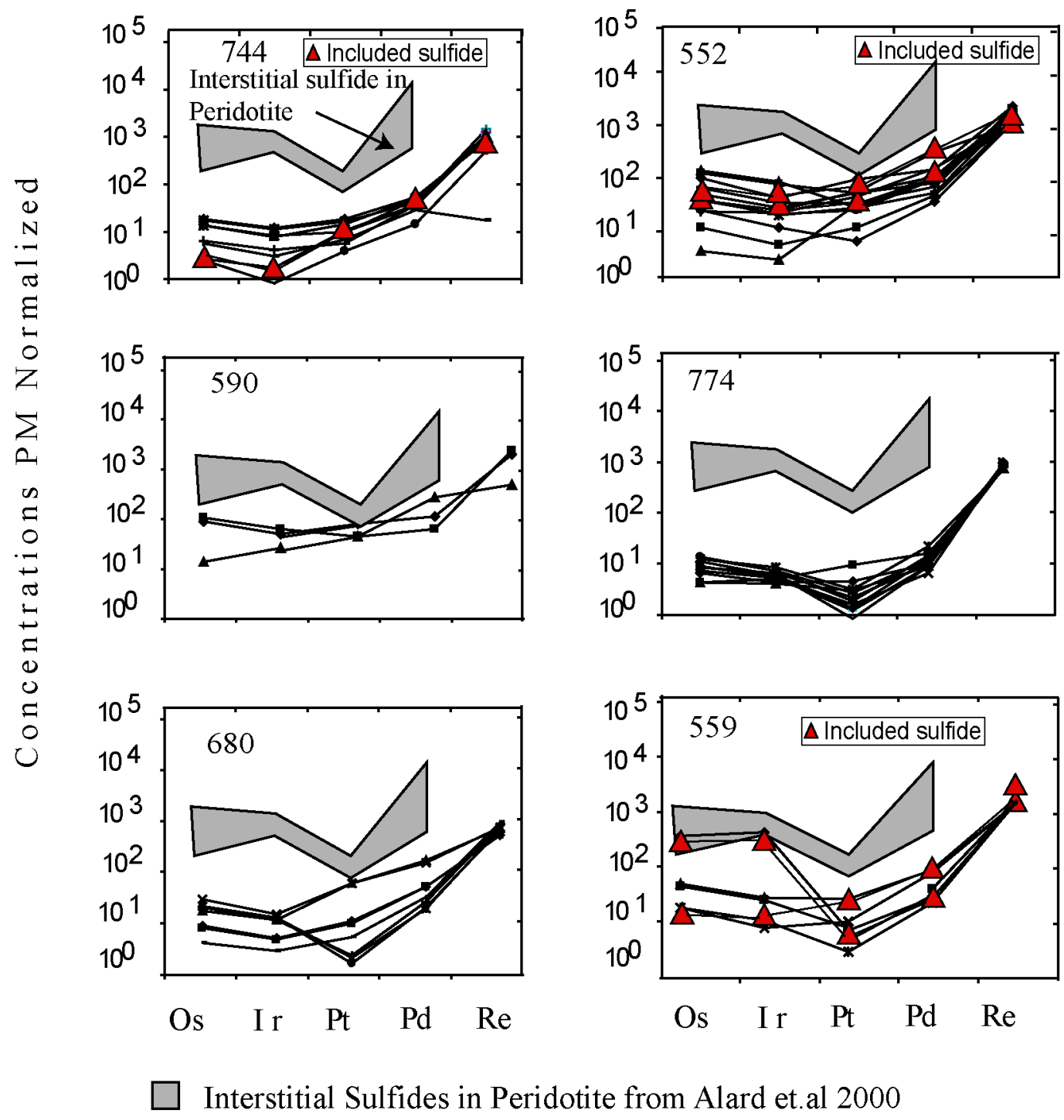

Figure 4.5 Primitive Mantle normalized PGE abundances of sulfides. Large solid triangle, "type I" included sulfides and the rest are "type II" interstitial sulfides. Type II sulfides are compared with interstitial sulfides in mantle peridotite (Alard et al., 2000). Interstitial sulfides in pyroxenite and peridotite have similar PGE pattern but the latter is enriched in PGE by a factor of 10 to 100 and interstitial and included sulfides in pyroxenite are similar, both in pattern and abundance. Primitive Mantle values are from McDonough and Sun (1995). 


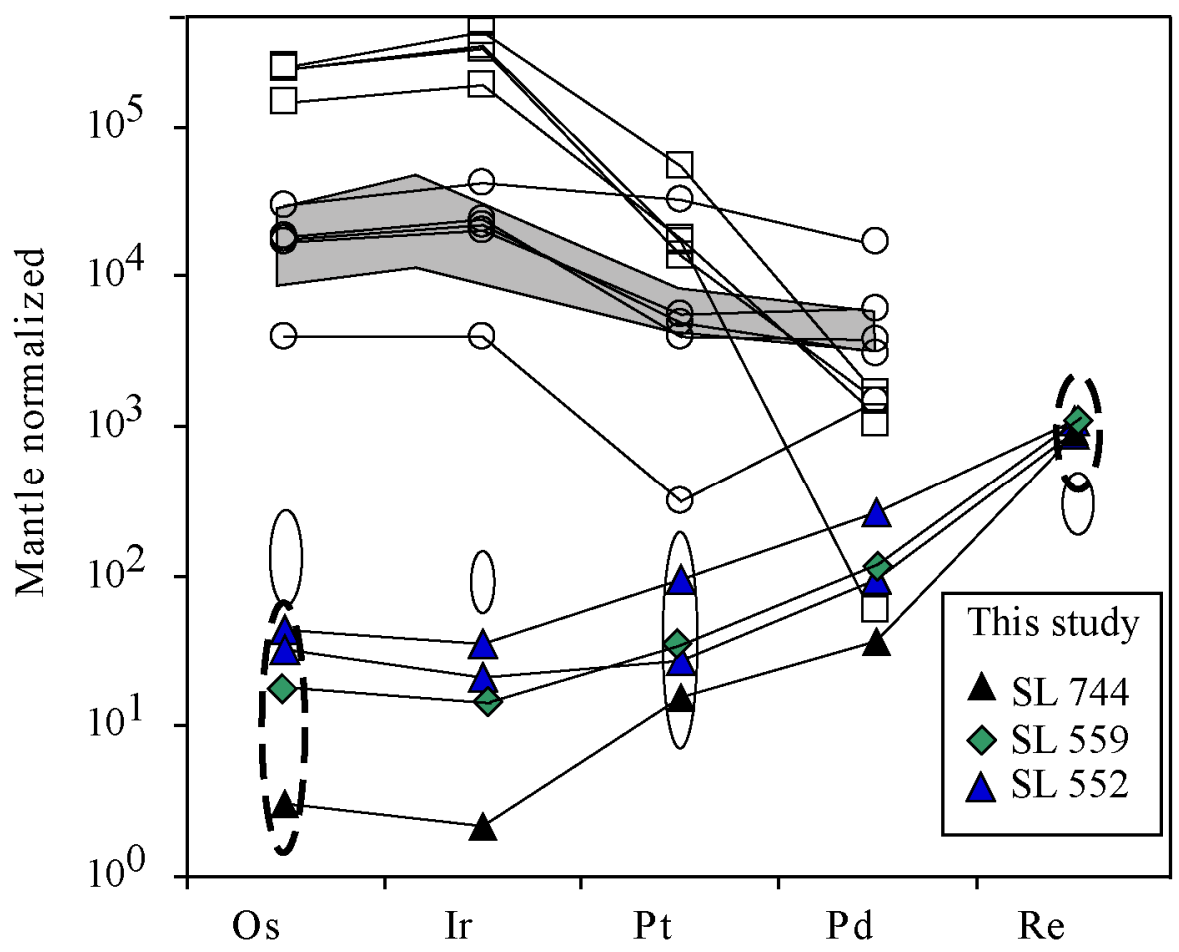

Figure 4.6 Primitive Mantle normalized (McDonough and Sun, 1995) HSE pattern of included sulfides. Open circles, sulfides in peridotites; open square, sulfides in kimberlite; grey area, sulfide inclusion in peridotitic ("P" type) diamonds (Alard et al., 2000); elliptical field with solid boundary, pyroxenitic sulfides (Luguet et al., 2008); elliptical field with dashed boundary, sulfide inclusion in eclogitic ('E” type) diamonds (Pearson et al., 1998). 


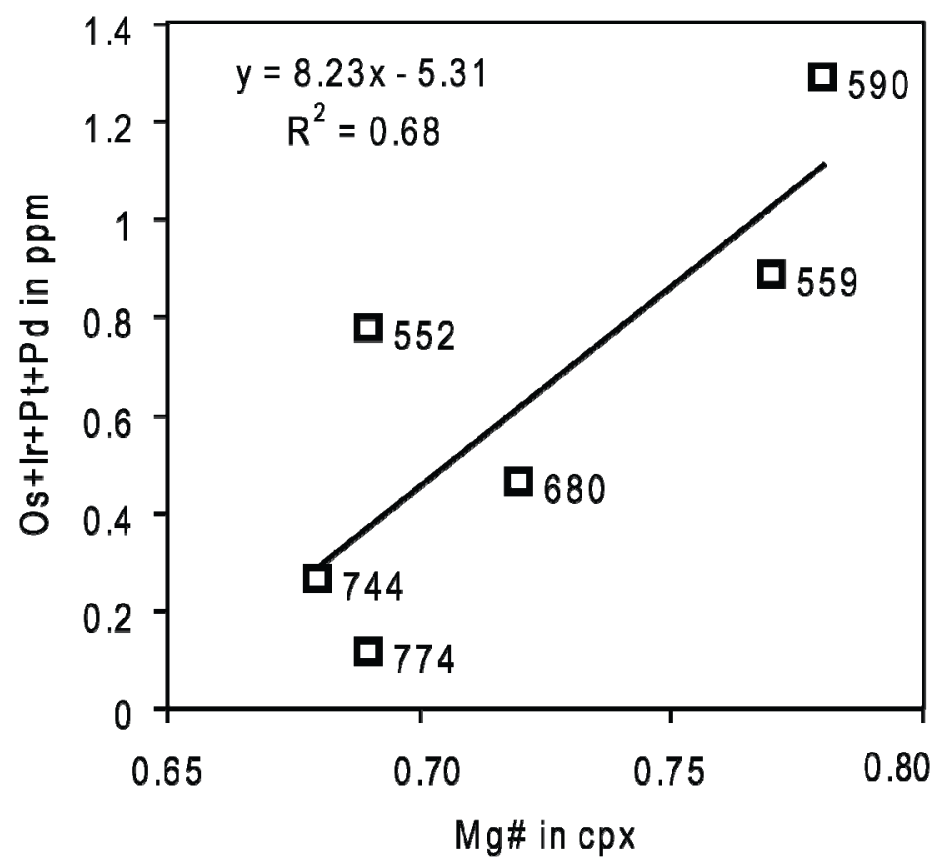

Figure 4.7 Mg\# (Molar $\mathrm{Mg} / \mathrm{Mg}+\mathrm{Fe}$ Total) of clinopyroxene vs. total PGE concentrations $(\mathrm{Os}+\mathrm{Ir}+\mathrm{Pt}+\mathrm{Pd})$ in sulfides. Sulfide data from this study and most of the major element data for clinopyroxene from Bizimis et al. (2005) with additional major element data reported in Appendix Table A3. 

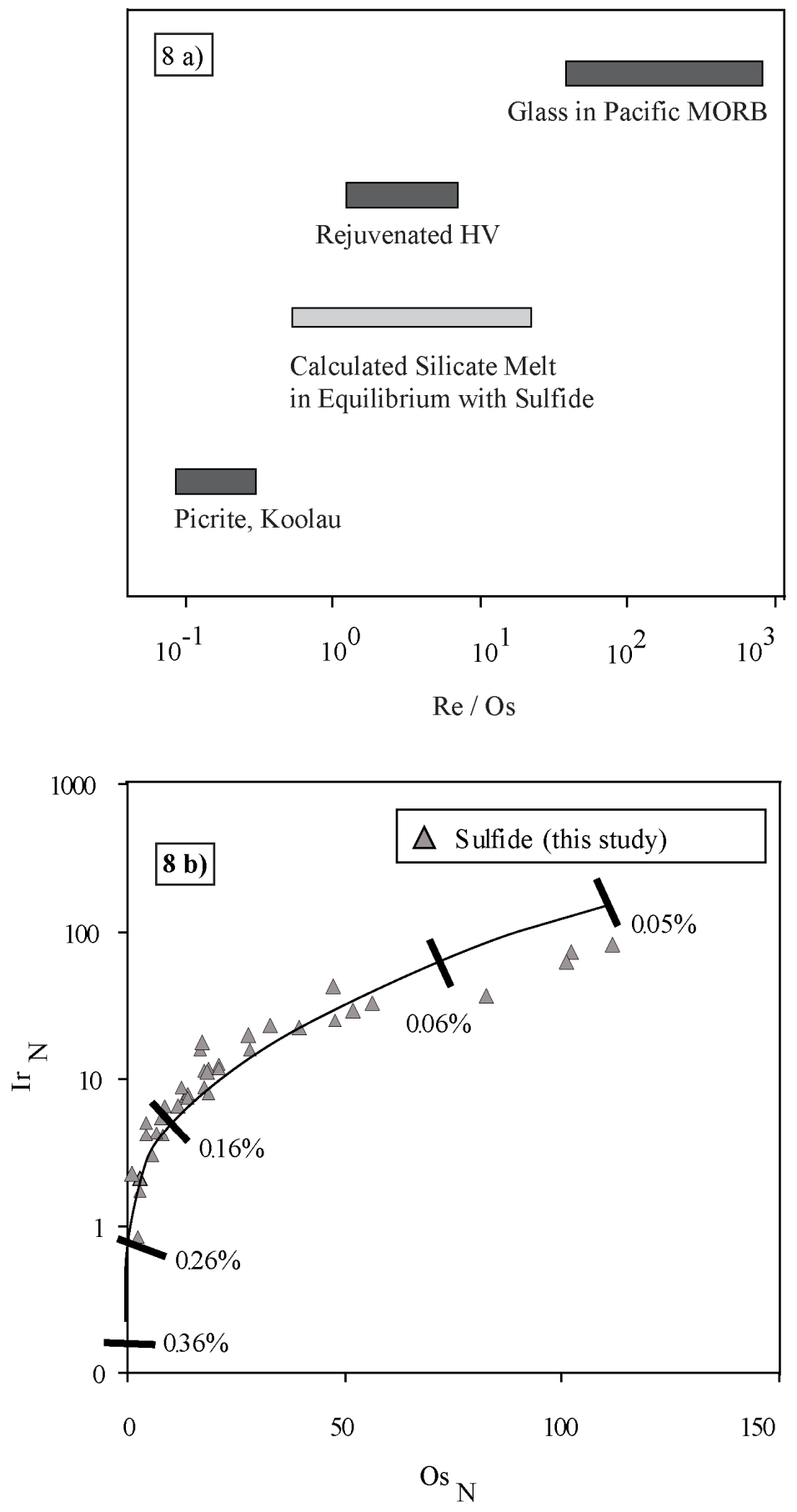

Figure 4.8 a) Variation of $\mathrm{Re} / \mathrm{Os}$ ratios in silicate melt calculated in equilibrium with sulfides, compared with rejuvenated stage HV lavas (Lassiter et al., 2000), pristine MidOcean-Ridge-glasses from Pacific ocean (Schiano et al., 1997), and picritic lavas from Koolau (Bennett et al., 2000; Ireland et al., 2009). A silicate melt in equilibrium with the pyroxenitic sulfides will be more akin to $\mathrm{HV}$ lavas, arguing for a genetic relationship between the two.

Figure 4.8 b) $\operatorname{Os}_{N} v_{s} \operatorname{Ir}_{N}$ concentrations in the pyroxenitic sulfides modeled as a function of sequential sulfide fractionation $(\mathrm{N}=$ Primitive mantle values from McDonough and Sun 
1995). I used $0.3 \mathrm{ppb}$ of Os in the parent silicate melt (highest concentration in HV lava data from Lassiter et al., (2000) and assumed chondritic Os/Ir ratios. From this melt I sequentially $(0.05 \%, 0.06 \%, 0.16 \%, 0.26 \%$. and $0.36 \%)$ fractionated and separated out immiscible sulfides and calculated the sulfide melt composition at each step. The variable and low abundances of PGE concentration in these sulfides can be explained $0.05 \%$ to $0.3 \%$ sulfide separation from a silicate melt. 


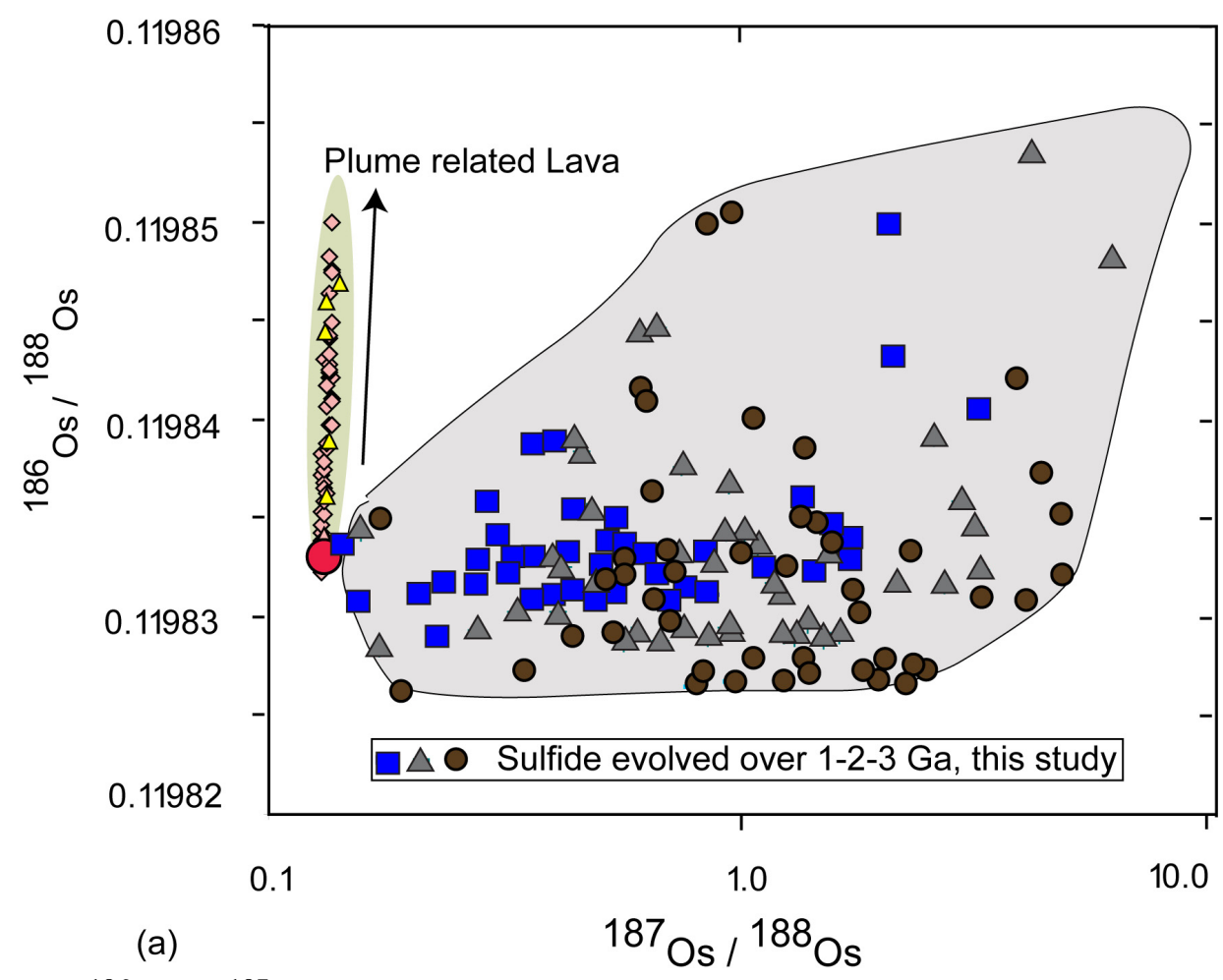

Figure 4.9 ${ }^{186} \mathrm{Os}-{ }^{187} \mathrm{Os}$ isotope systematics of 1-2-3 Ga evolved sulfides from the Hawaiian pyroxenites compared with reported high ${ }^{186} \mathrm{Os}-{ }^{187} \mathrm{Os}$ plume derived lavas (picritic lavas and komatiites) (Brandon et al., 1998-99;). The sulfides are assumed to have chondritic ${ }^{186} \mathrm{Os} /{ }^{188} \mathrm{Os}$ and ${ }^{187} \mathrm{Os} /{ }^{188} \mathrm{Os}$ ratios at $1-2-3 \mathrm{Ga}$ ago, calculated using present day ${ }^{186} \mathrm{Os} /{ }^{188} \mathrm{Os}=0.119834$ and ${ }^{187} \mathrm{Os} /{ }^{188} \mathrm{Os}=0.127$ (red circle), chondritic ${ }^{190} \mathrm{Pt} /{ }^{188} \mathrm{Os}=0.001692$ and ${ }^{187} \mathrm{Re} /{ }^{188} \mathrm{Os}=0.40186, \quad$ and decay constants $\lambda^{190} \mathrm{Pt}=$ $1.417 \times 10^{-12}$ /year and $\lambda^{187} \mathrm{Re}=1.67 \times 10^{-11}$ /year (Brandon and Walker, 2005). The sulfides are then evolved to present day using the measured $\mathrm{Pt} / \mathrm{Os}$ and Re/Os ratios. Our calculations show that these pyroxenitic sulfides will develop coupled radiogenic ${ }^{186} \mathrm{Os}$ ${ }^{187}$ Os compositions but at much shallower slope than observed in Hawaiian lavas and komatiites. 


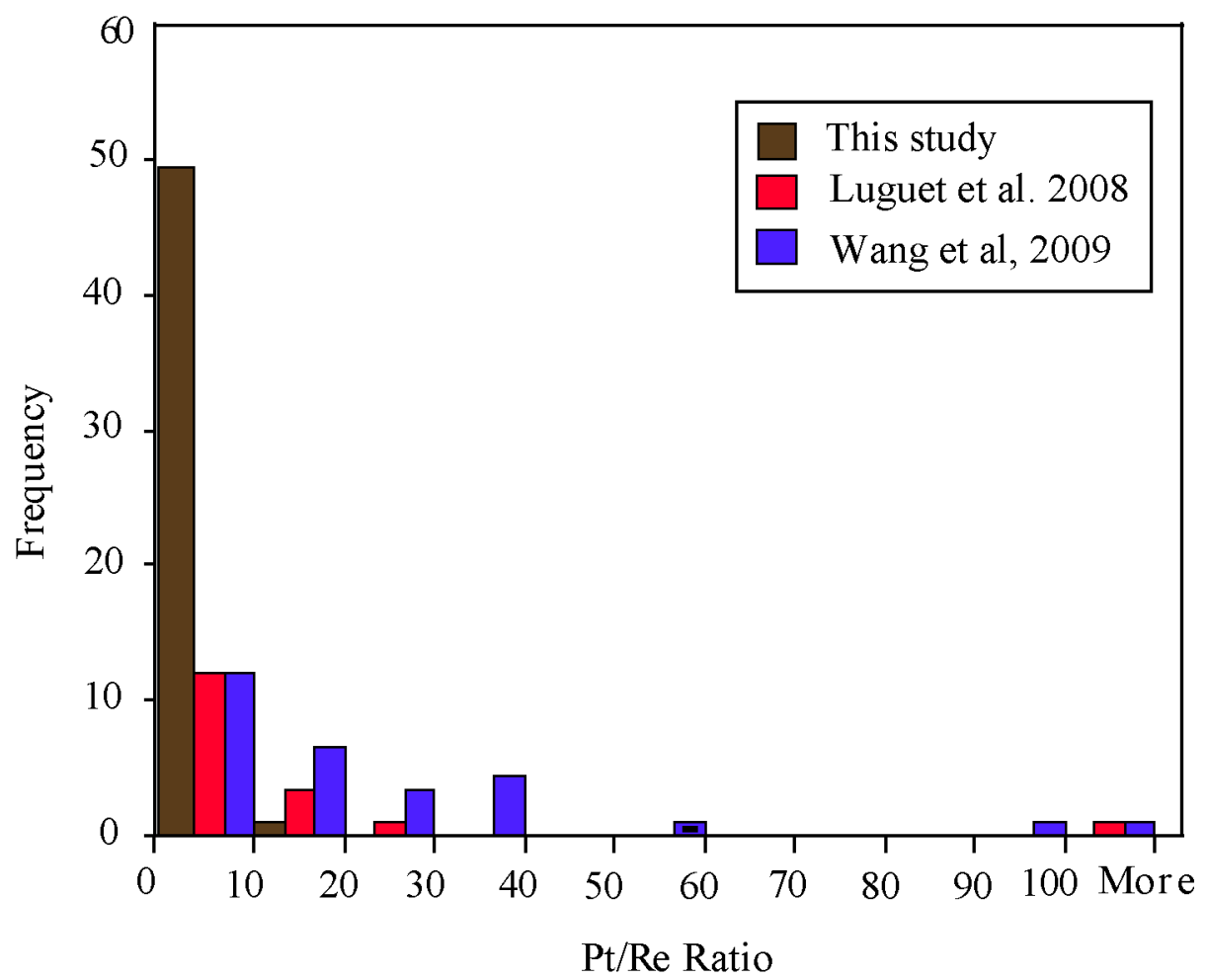

Figure 4.10 Variation of $\mathrm{Pt} / \mathrm{Re}$ ratios in the Hawaiian pyroxenitic sulfides (this study) compared to sulfides from pyroxenites and eclogites, bulk rock pyroxenites (Luguet et al., 2008) and peridotites (Wang et al., 2009). It is evident that the vast majority of pyroxenitic and peridotitic sulfides have much lower Pt/Re ratio than the $88-100 \mathrm{Pt} / \mathrm{Re}$ range required to explain the coupled ${ }^{186} \mathrm{Os}^{187}$ Os isotope enrichments of Hawaiian lavas and komatiites. 


\section{CHAPTER 5}

\section{ORIGIN OF GARNET PYROXENITES IN THE HAWAIIAN MANTLE: INSIGHTS FROM PLATINUM GROUP ELEMENTS AND RHENIUM-OSMIUM ISOTOPES}

\subsection{Introduction}

The Hawaiian-Emperor seamount chain is generally considered to be a classic example of deep seated plume volcanism (Wilson, 1963; Morgan, 1971; Li et al., 2000; Wolfe et al., 2009). Although, the plume theory has gained broad acceptance, our knowledge about the composition of the plume and how it works is still limited. For example, the ${ }^{187} \mathrm{Os} /{ }^{188} \mathrm{Os}$ isotopic compositions of all Hawaiian lavas show that the plume taps a source enriched in radiogenic Os (Hauri and Kurz, 1997; Lassiter and Hauri, 1998; Brandon et al., 1998; Lassiter et al., 2000; Jamais et al., 2008;Ireland et al., 2009). However, the source of this radiogenic Os is not clear and several conflicting hypotheses, such as, input of Outer Core materials versus the presence of recycled oceanic crust in the source region of these lavas have been invoked. The other first order question that has been extensively discussed is how the Hawaiian plume interacts with the Pacific lithosphere (e.g., Class and Goldstein, 1997; Hauri and Kurz, 1997; Priestley and Tilmann, 1999; Ribe and Christensen, 1999; Li et al., 2004; Bizimis et al., 2007). Understanding plume-lithosphere interaction is important because such processes may contribute to the chemical make-up of plume derived lavas, and can metasomatize the deep oceanic lithosphere, which upon recycling, can introduce geochemical heterogeneity in the mantle (Niu and O'Hara, 2003; Workman et al., 2004).

Geochemical data have mostly relied on Re-Os isotopic investigation of mantlederived magmas to understand plume-lithosphere interaction (Ellam et al., 1992; Martin 
et al., 1994; Hauri and Kurz, 1997; Jamais et al., 2008). In this study I take a different approach to understand the composition of the plume and whether the plume is reacting with the overriding lithosphere. My approach involves detailed Re-Os isotope and highly siderophile element investigation of the garnet pyroxenite xenoliths from Oahu that appear to have come from the basal part of the Pacific lithosphere (e.g., Sen et al. 2005). Earlier studies have suggested that the pyroxenites xenoliths are high pressure cumulates $(>16 \mathrm{~Kb})$ from a melt similar to the rejuvenated stage HV lava series and as such, their chemical composition gives us a high resolution image of the mantle plume composition (e.g., Sen 1983, 1988; Bizimis et al., 2005; Keshav et al., 2007). Moreover, as these xenoliths are closer to the lithosphere-asthenosphere interface, it is reasonable to think that they would carry the strongest signal of any plume-lithosphere interaction. This study suggests that the pyroxenites are likely to be product of melt-mantle reaction, where the parental melt that crystallized the pyroxenites selectively picked up radiogenic Os from the grain boundary sulfides while percolating through the Pacific lithosphere.

\subsection{Garnet Pyroxenite Xenoliths}

There is a significant body of published information on petrography, mineral chemistry, trace element and isotope geochemistry of the SLC pyroxenite xenoliths (e.g., White 1966; Green 1966; Jackson and Wright 1970; Frey, 1980; Sen, 1988; Keshav and Sen, 2001; Bizimis et al., 2005; Sen et al., 2005; Keshav et al., 2007). On the basis of the available literature I summarize the possible origin of these rocks: (1) Based on mineral thermobarometry and the Sr-Nd-Hf isotope composition of the xenoliths, G. Sen and his co-workers proposed that the pyroxenites are high pressure $(>20 \mathrm{~Kb})$ cumulates from a melt similar to the HV lava series (e.g., Sen et al. 1983; 2005; Bizimis et al. 2005; 
Keshav et al. 2007). (2) The relatively radiogenic ${ }^{187} \mathrm{Os} /{ }^{188}$ Os compositions of the SLC pyroxenites, coupled with their low ${ }^{87} \mathrm{Sr} /{ }^{86} \mathrm{Sr}$ ratios led Lassiter et al. (2000) to propose that they represent 80-100 Myr old cumulates formed at a mid oceanic ridge setting. (3) The presence of garnets with majoritic precursors (Keshav and Sen, 2001) and the discovery of nano-diamonds (Wirth and Rocholl, 2003) in some rare xenoliths have led to the suggestion that at least a few of these pyroxenites were brought up from some 180$270 \mathrm{~km}(\mathrm{P}=6-9 \mathrm{GPa})$ by the Hawaiian plume (Keshav and Sen 2001). Thus, with the exception of the few rare and deep fragments, there is a general consensus among the previous authors that the bulk of these pyroxenites formed as igneous veins in the deep lithosphere. Bizimis et al. (2005) showed that coexisting garnet-clinopyroxene pairs yielded essentially zero age isochrons and confirmed that these veins formed at or near Hawaii and not at a 90 Ma paleo-ridge.

\subsection{Results}

\subsubsection{Bulk Rock Trace Element Systematics}

Primitive mantle normalized trace element concentrations, as determined in this study, are plotted in Figure 5.1. This figure also shows a comparison with elemental concentrations of clinopyroxene and garnet separates from these rocks (source of data: Bizimis et al. 2005). It is apparent that, with the exception of $\mathrm{Cs}, \mathrm{Rb}$, and $\mathrm{Ba}$, all elemental abundances in the bulk rock can be explained as a mixture of constituent garnet and clinopyroxene. While we cannot be absolutely certain, the higher values for $\mathrm{Cs}, \mathrm{Ba}$, and $\mathrm{Rb}$ may be attributed to the trace amounts of amphibole and phlogopite that occur in these rocks (e.g., Sen 1983, 1987, 1988). 
The incompatible element ( $\mathrm{Cs}, \mathrm{Rb}, \mathrm{Ba}, \mathrm{U}, \mathrm{Th}, \mathrm{Nb}, \mathrm{Sr}$ and $\mathrm{Ta})$ concentrations in the bulk rock do not correlate with $\mathrm{Mg} \#$ or $\mathrm{Al}_{2} \mathrm{O}_{3}$ content of clinopyroxenes. The $\mathrm{REE}$ and compatible element $(\mathrm{Ni}, \mathrm{Cr})$ content of the pyroxenites generally correlate with $\mathrm{Mg \#}$ and $\mathrm{Al}_{2} \mathrm{O}_{3}$ content of the clinopyroxenes: the most $\mathrm{Ni}$ and $\mathrm{Cr}$ enriched samples have the highest $\mathrm{Mg \#}$ and lowest $\mathrm{REE}$ and $\mathrm{Al}_{2} \mathrm{O}_{3}$ concentrations (Fig 5.2).

The analyzed xenoliths display a large range of $\mathrm{S}$ concentrations $(0.01-0.28$ wt.\%; Table 5.1), reflecting the variable modal abundance of sulfides present in these rocks. The sulfide mineralogy and sulfide-silicate relationship has been reported in Sen et al. 2010. The S content of the bulk rock shows correlation with major element, trace element and isotope compositions of the bulk rock and the clinopyroxenes: the most $\mathrm{S}$ enriched samples have the highest $\mathrm{Pd} / \mathrm{Ir}, \mathrm{Al}_{2} \mathrm{O}_{3},{ }^{187} \mathrm{Os} /{ }^{188} \mathrm{Os}$ and lowest $\mathrm{Mg \#}$, Ni and $\mathrm{Cr}$ concentrations. My mass balance calculation taking 37 wt.\% of S in the sulfides shows that the pyroxenites contains $0.02-0.76$ wt. $\%$ modal abundance of sulfides (Sen et al., 2010).

\subsubsection{HSE Systematics}

The HSE concentrations in the studied rocks (garnet pyroxenites \pm olivine and websterites) are significantly depleted compared to primitive upper mantle composition (Becker et al., 2006). The absolute HSE concentrations show more than one order of magnitude variability, with relatively high concentrations of HSE in the websterites when compared to the pyroxenites. The concentration ranges for Hawaiian pyroxenites are similar to the published pyroxenite data from other localities (Kumar et al., 1996; Pearson and Nowell, 2004; Luguet et al., 2008; Acken et al., 2010), however the websterites seems to have a lower abundance of PGEs (Acken et al., 2010). The garnet pyroxenites 
and websterites are enriched in $\mathrm{Pd}, \mathrm{Pt}$ and $\mathrm{Re}$ relative to $\mathrm{Os}$, Ir and $\mathrm{Ru}$ and show strong fractionation pattern $(\mathrm{Pd} / \mathrm{Ir} \sim 3-24, \mathrm{Pd} / \mathrm{Os} \sim 1-12)$ and very high $\mathrm{Re} / \mathrm{Os}$ ratios $(\sim 2-49)$. The enrichment of Pd, Pt, Re over Os and Ir reflects a more melt like HSE pattern as observed in the lavas (Fig 5.3) (Bennett et al., 2000; Peucker-Ehrenbrink et al., 2003; Puchtel et al., 2004a; Puchtel et al., 2005a; Ireland et al., 2009; ).

The PGE concentrations of the pyroxenites show positive correlations with each other (Fig 5.4), for example, good correlation exists between Os, Ir, $\mathrm{Ru}\left(\mathrm{R}^{2}>0.9\right)$ and moderate correlation between Os and $\mathrm{Pd}\left(\mathrm{R}^{2}=0.6\right)$. Platinum shows a strong positive trend with Ir, Os and Ru, however there are two samples (SL-571; 716) which have very high Pt content. Similar platinum enrichments have also been observed in peridotite xenoliths (Ackerman et al., 2009), basalts (Bennett et al., 2000) and pyroxenites ( Maier et al., 2001; Luguet et al., 2008) and in these pyroxenitic sulfides (Sen et al., 2010), although the origin of the Pt enrichment in these samples is not currently understood.

Unlike the other siderophile elements Re is decoupled from the PGEs. Rhenium shows correlation with the modal abundance of garnet (not clinopyroxene), it seems likely that the Re abundance of the bulk rocks is a function of sulfide and garnet mode, unlike the PGEs which reflect only the variable mode of Fe-Ni sulfide phases present in these xenoliths (further discussed in section 5.3.3) (Sen et al., 2010). The absolute abundance of PGEs do not correlate with $\mathrm{Mg} \#$ and $\mathrm{Al}_{2} \mathrm{O}_{3}$ content of the clinopyroxenes (Fig 5.5); however incompatible/compatible PGE ratios such as $\mathrm{Pd} / \mathrm{Os}, \mathrm{Pd} / \mathrm{Ir}, \mathrm{Pd} / \mathrm{Ru}$ shows intra-correlations (not shown, $\mathrm{Pd} / \mathrm{Ir}$ vs. $\mathrm{Pd} / \mathrm{Os} \mathrm{R}^{2} \sim 0.6$; $\mathrm{Pd} / \mathrm{Ir}$ vs. $\mathrm{Pd} / \mathrm{Ru} \mathrm{R}^{2} \sim 0.72$ ) and correlations with major and trace element concentrations of clinopyroxenes and bulk 
rock (Fig 5.6), consistent with the correlations reported in pyroxenites from ultramafic massif (Acken et al., 2010).

\subsubsection{Sulfide Controls the PGE Budget of the Pyroxenites}

The studied rock suite contains $0.02-0.76$ wt.\% modal abundance of sulfides (calculated on the basis of S content). The sulfides are interpreted as immiscible liquid separated from a silicate melt that crystallized the garnet and the clinopyroxenes (Sen et al., 2010). As the sulfide/silicate partitioning coefficients are very high (Crocket et al., 1997), it is reasonable to assume that the sulfide may be the major repository of HSEs in the pyroxenites. However the relation of sulfides to the PGE budget of the bulk rock at upper mantle conditions has never been explicitly performed, as in the case of peridotite which have been identified as a dominant PGE carrier in the Earth's mantle (Alard et al., 2000; Lorand and Alard, 2001).

In an effort to verify to what degree sulfides control the PGE and Re in the bulk rock pyroxenite, I carried out detailed mass balance calculations on 3 pyroxenites (SL552, 744 and 559) for which both sulfide and bulk rock PGE data exists (Sen et al., 2010). In order to have an additional check on the recomputed sulfide weight fraction (calculated from $\mathrm{S}$ measurements), I performed rigorous Ni mass balance calculations between the constituent phases and the bulk rock to have a accurate estimation of the sulfide mode. Using the appropriate modes and concentration of $\mathrm{Ni}$ in the bulk rock and the other silicate phases, I calculate $0.42-0.74$ wt. \%. of sulfide mode (Table 5.3a), which is near identical to the estimation from the $\mathrm{S}$ measurements.

I then use this abundance to calculate bulk rock PGE and Re concentrations using the range of PGE concentration reported in Sen et al. 2010, and assuming no PGE or Re 
in the silicate phases. The calculated bulk rock Os and Ir values are within the measured range (Table 5.3b; Fig 5.7 a-c); however Pd and Pt distribution cannot be mass balanced in one of the samples. However since my in situ PGE data (Sen et al., 2010) were necessarily restricted to large sulfide grains ( $>50 \mu \mathrm{m}$ ), the PGE dataset which I used to calculate the bulk rock compositions may be biased towards composition of large sulfide grains. It is conceivable that there are smaller Pd and Pt enriched sulfides grains in the studied rock that may contribute to the PGE budget of the bulk rock, and where missed during the previous LA-ICPMS investigation. I also note that the $\mathrm{Pd} / \mathrm{Ir}$ and $\mathrm{Re} / \mathrm{Os}$ ratio of the bulk rocks are systematically higher in some of these samples (Fig 5.7d)

The measured bulk rock Re abundance is significantly higher and well outside range of the calculated abundances (Fig.5.7). As Re is thought to be compatible in garnet (Righter et al., 1998), the "excess" Re in the bulk rock may reflect Re residence in garnet. There is a weak but positive correlation of Re concentration with the modal abundance of garnet $\left(\mathrm{R}^{2} \sim 0.5\right.$; not shown) that supports the inferred compatibility of Re in garnet.

I think that my simplistic assumptions may be valid; sulfides are the major repository of PGE in the pyroxenites (and presumably the rest of my samples), and the Re budget of the rocks are primarily controlled by sulfide and garnet phases.

\subsubsection{Osmium Isotope Systematics}

The osmium isotope data of eleven selected garnet pyroxenites (Bizimis et al., 2005) are reported in Table 5.2. The ${ }^{187} \mathrm{Os} /{ }^{188} \mathrm{Os}$ ratios vary from subchondritic to suprachondritic (0.1233-0.1643), similar to the previously published dataset of Lassiter et al. 2000. However, it is important to note that my dataset overlap that of the Lassiter et al. 2000 study and extends to less radiogenic ${ }^{187} \mathrm{Os} /{ }^{188} \mathrm{Os}$ ratios. Sample number SL-571 is 
the most unradiogenic sample $(0.1233)$ of the suite and it falls below the estimates for depleted upper mantle (DMM: ${ }^{187} \mathrm{Os} /{ }^{188} \mathrm{Os}=0.125-0.128$ ( Snow and Reisberg, 1995; Brandon et al., 2000; Walker et al., 2002)), or primitive upper mantle (PUM: ${ }^{187} \mathrm{Os} /{ }^{188}$ Os $=0.129$ (Meisel et al., 2001)) composition of the Earth.

The websterites have relatively unradiogenic Os (0.1233-0.1324) when compared to garnet pyroxenites $(0.1334-0.1643)$ and ${ }^{187} \mathrm{Os} /{ }^{188} \mathrm{Os}$ do not correlate with ${ }^{187} \mathrm{Re} /{ }^{188} \mathrm{Os}$ (Fig 5.8). Further more the bulk rock ${ }^{187} \mathrm{Os} /{ }^{188}$ Os ratios do not correlate with the Hf-NdSr isotope compositions of clinopyroxenes (Bizimis et al., 2005), nor with bulk rock 1/Os ratios. However, Os isotope systematics show correlations with major element and trace element concentrations of clinopyroxenes (Bizimis et al., 2005) and the bulk rock (Fig 5.9); with the most radiogenic samples have the highest REE (e.g., Sm, Nd), HFSE (e.g., $\mathrm{Zr}, \mathrm{Hf}$ ), $\mathrm{S}, \mathrm{Pd} / \mathrm{Ir}, \mathrm{Al}_{2} \mathrm{O}_{3}$ and lowest $\mathrm{Mg \#}$ and $\mathrm{Ni}, \mathrm{Cr}$ contents of clinopyroxenes and bulk rock (Fig 5.9).

\subsection{Discussion}

The key observations of this detailed geochemical study are: (1) pyroxenites show a large variation in ${ }^{187} \mathrm{Os} /{ }^{188}$ Os ratio from subchondritic to suprachondritic ratios $(0.1233$ 0.1643 ) and its correlations with major element, trace element, PGE and S concentration. The correlations strongly suggest that the PGE and the Os isotopes reflect primary mantle processes. (2) ${ }^{187} \mathrm{Os} /{ }^{188}$ Os ratios do not correlate with other lithophile element isotopic systems (Rb-Sr, Sm-Nd and Lu-Hf) and also do not show any correlations with $\mathrm{Re} / \mathrm{Os}$ nor with 1/Os. The lack of correlations between Os and Sr-Nd-Hf isotope systematics indicates that the Os is decoupled from other elements. Therefore, models that aims to 
explain the origin of these garnet pyroxenites must be consistent with all these key observed features.

\subsubsection{Origin of SLC Garnet Pyroxenites: MOR or Plume Related}

Chondrite normalized PGE patterns in figure 5.3 shows that the pyroxenites have lower concentrations of Os and Ir relative to Pt and Pd. An Experimental study in the sulfide-silicate system by Bockrath et al. 2004 has shown that the platinum group element shows significant fractionation during mantle melting at upper mantle condition. In general, during silicate melt segregation Os, Ir and Ru behave as a compatible element and stays in the solid residue, while $\mathrm{Pt}, \mathrm{Pd}$ and $\mathrm{Rh}$ behave as an incompatible element and are enriched in the basaltic melt fraction ( Bockrath et al., 2004; Ballhaus et al., 2006;). The high Pd/Ir, Re/Os ratio (Table 5.2) of the pyroxenites are qualitatively similar to the patterns observed in lavas (OIB, MORB, komatiites (Bennett et al., 2000; PeuckerEhrenbrink et al., 2003; Puchtel et al., 2004b; Puchtel et al., 2005b; Ireland et al., 2009) and consistent with an origin of pyroxenites as cumulates from a mantle melt. But whether this cumulates formed at a mid-ocean ridge setting or near the plume is not clear (Lassiter et al., 2000; Bizimis et al., 2005).

Based on the correlations of Re/Os with the suprachondritic ${ }^{187} \mathrm{Os} /{ }^{188} \mathrm{Os}$ ratios (set of 5 samples) Lassiter et al. 2000 proposed that these cumulate may be tens of millions of years. The radiogenic Os was to the result of the ingrowth of ${ }^{187} \mathrm{Os}$ from ${ }^{187} \mathrm{Re}$, while the pyroxenites remained stored in the lithosphere for $80-100 \mathrm{Myr}$, the approximate age of the ocean floor beneath Oahu. 80-100 Myr is sufficient for the pyroxenites to develop high ${ }^{187} \mathrm{Os} /{ }^{188} \mathrm{Os}$ ratios, but insufficient to evolve significantly different $\mathrm{Sr}-\mathrm{Nd}-\mathrm{Hf}$ composition. So Lassiters's radiogenic ingrowth model can effectively explain the 
correlations of Os isotope with major and trace element and the lack of correlations with other lithophile element isotopes. Lassiter et al. 2000 also proposed that the high $\operatorname{Re}$ content of the pyroxenites (average $0.6 \mathrm{ppb}$ their study, $2.2 \mathrm{ppb}$ this study) are consistent with their formation in a mid ocean ridge setting, because MORBs have a higher Re concentrations than the OIB (mean MORB $\mathrm{Re}=0.926 \mathrm{ppb}$ and mean $\mathrm{OIB}=0.42 \mathrm{ppb}$ (Ireland et al., 2009; Roy-Barman et al., 1998b; Schiano et al., 1997)). However combined Os and HSE data show that the pyroxenites I studied are related to the Hawaiian plume and not the MOR setting. The pyroxenites are plume related because (1) Chondrite normalized PGE patterns in Fig 3 shows that although the MORB and Hawaiian lavas have similar PGE patterns, the MORB has a much lower concentrations of PGEs when compared to the pyroxenites and the Hawaiian lavas. (2) The high Re concentration of the pyroxenites can be explained with the fractionation of garnet and sulfide which are of primary magmatic origin (Bizimis et al., 2005; Sen et al., 2010). Sattari et al. 2002 estimated a $\mathrm{K}_{\mathrm{D}}$ (sulfide /silicate melt) of 3.3-5.2 x 104 and Righter et al. 1998 estimated $\mathrm{K}_{\mathrm{D}}$ (garnet/silicate melt) of 2.7 for Re. Assuming the bulk rock contains $10 \%$ of garnet and $0.02 \%$ of sulfides (sample with the lowest modal abundance of sulfide, from the $\mathrm{S}$ data presented in Table 5.1) I calculated the bulk distribution coefficient $\mathrm{D}_{\mathrm{Re}} \sim$ 7. Since the Re concentration in the pyroxenites ranges from $0.34-4.2 \mathrm{ppb}$ and assuming the $\mathrm{D}_{\mathrm{Re}} \sim 7$, I calculated the melt in equilibrium with these pyroxenites. My calculation shows that the Re concentrations in the parental melt will range from 0.05-0.6 ppb, which is much lower than the mean MORB Re concentration (0.926 ppb). It is important to note that increasing $\mathrm{X}_{\text {sulfide }}$ in the fractionating assemblage will significantly increase the bulk $D$, for example, if $X_{\text {sulfide }}=0.2$ wt. $\%$ the bulk $D_{R e}$ will increase by $\sim 60$. However, even 
with increasing sulfide scenario, the melt that will be in equilibrium with the pyroxenites will have a Re concentrations even lower than the present estimate. Therefore, the high Re content of the pyroxenites can be explained with sulfide and garnet fractionation from a melt similar to the Hawaiian lavas, it does not require a Re concentrated parental melt similar to the MORB type lavas (3) No isochronous relationship exists between ${ }^{187} \mathrm{Os} /{ }^{188} \mathrm{Os}$ and ${ }^{187} \mathrm{Re} /{ }^{188} \mathrm{Os}$. If these are $100 \mathrm{Myr}$ cumulates then a correlation between Os isotopes and Re/Os ratio should be expected. However, I do not see any correlations between Os isotopes and $\mathrm{Re} / \mathrm{Os}$ ratios (4) $\mathrm{Rb} / \mathrm{Sr}, \mathrm{Sm} / \mathrm{Nd}$ and $\mathrm{Lu} / \mathrm{Hf}$ isotope systematics does not support a MOR origin. Bizimis et al. 2005, showed that both two-mineral (pyroxene - garnet) $\mathrm{Sm} / \mathrm{Nd}$ and $\mathrm{Lu} / \mathrm{Hf}$ isochrons and reconstructed bulk - rock Hf-Nd isotope compositions of the SLC pyroxenites (albeit on a different set of samples than the Lassiter et al. 2000 study) are consistent with essentially "zero" age, i.e., the garnet pyroxenites formed beneath Oahu rather than close to a ridge or somewhere between the ridge and the location of the Hot Spot. Also, their Nd-Sr and Hf isotope compositions overlap with those of the HV lavas; and the calculated trace element composition of the melts in equilibrium with these pyroxenites are akin to HV-type rather than MORB-type melts (Frey, 1980; Sen et al., 1993; Keshav et al., 2004).

Based on the all the above arguments it is more likely that the pyroxenites are related to the Hawaiian plume. Although, it is reasonable to expect that the mafic melts may get arrested as "veins" in the lower lithosphere during upwelling of the mantle at the MOR setting, however it appears that none of these pyroxenites are related to the MOR setting. 


\subsection{2 "Fractional Crystallization"}

The distinct trends between the major element, trace element and PGE (Fig 5.2, 5.6) in clinopyroxenes and bulk rock can be explained by fractional crystallization i.e., the concentrations of these elements reflect the composition of the parental melt from which the pyroxenites crystallized. However, it is unlikely that the pyroxenites being crystal fractionate from a single parental composition because of the significant Os isotope $(0.123-0.164)$ variability in the pyroxenites, and secondly our calculation (Fig 5.10, calculation parameters in figure caption) shows that the large variability in the $\mathrm{Pd} / \mathrm{Ir}$ ratio (4-24) for the pyroxenites cannot be simply explained with sulfide fractionation from a single evolving parental melt.

Figure 5.10 also shows that the $\mathrm{Pd} / \mathrm{Ir}$ ratio of the Hawaiian picrite (Ireland et al., 2009) is lower than the post shield lava (Crocket, 2002), from figure 5.10 it seems that the Hawaiian picrites have seen more sulfide fractionation than the post shield lavas. However, if this is true the picrites should be depleted in the PGEs when compared to the Hawaiian post-shield lavas. Crocket, 2002 showed that the PGE concentrations in the alkali basalts from Hawaii are as much as eight times lower than the Hawaiian picrites. So I speculate the low PGE concentration of the post shield lava is a source feature, I further infer that it is likely that the parental melt which crystallized the pyroxenites are coming from a depleted source, which has been stripped of the PGEs in a prior melting event. Although the thought is speculative, it supports the evidence for a depleted component in Hawaiian volcanism (Bizimis et al., 2005). 


\subsection{3 "Plume-Lithosphere Interaction"}

The variation in the Os isotope and its correlation with major and trace element concentration of clinopyroxene and bulk rock (Fig 5.9) can be a result of melt-mantle reaction at the base of the lithosphere. Mantle residue with low Re/Os develops less radiogenic ${ }^{187} \mathrm{Os} /{ }^{188} \mathrm{Os}$, while mantle melt with high $\mathrm{Re} / \mathrm{Os}$ ratio develops more radiogenic ${ }^{187} \mathrm{Os} /{ }^{188} \mathrm{Os}$; so any interaction between these two components can produce variation in the Os isotopes. It is likely that melt from the Hawaiian plume with high FeREE-HFSE contents and radiogenic ${ }^{187} \mathrm{Os} /{ }^{188} \mathrm{Os}$ is reacting with the $100 \mathrm{Ma}$ Pacific lithosphere with unradiogenic ${ }^{187} \mathrm{Os} /{ }^{188} \mathrm{Os}$, and higher abundance of compatible elements like $\mathrm{Os}, \mathrm{Ir}, \mathrm{Ru}, \mathrm{Ni}$ and $\mathrm{Cr}$. With progressive reaction the mixed melt becomes richer in Cr-Ni-Os-Ir, and poorer in REE and HFSE, while ${ }^{187} \mathrm{Os} /{ }^{188} \mathrm{Os}$ ratios become more unradiogenic. In other words, the pyroxenites may represent crystallized melts from different stages of this melt-mantle reaction process at the base of the lithosphere. This process however requires either that the Pacific lithosphere partially melts or it is consumed by the (presumably) hotter plume melt.

Several modeling attempts have been done to understand such interactions processes at the base of Pacific Lithosphere ( Lassiter et al., 2000; Bizimis et al., 2005). Lassiter et al. 2000 calculated the mixing curves between the depleted mantle and plume mantle and their derived melts (Fig 5; in Lassiter et al. 2000). As the melts will have significantly higher $\mathrm{Sr} / \mathrm{Os}$ ratio than the depleted mantle peridotite, it will produce hyperbolic mixing arrays. Such mixing scenario cannot produce the variability in the Os isotopes at a nearly identical $\mathrm{Sr}$ isotope composition. 
The Hf-Nd isotope modeling between plume derived melt and 100 Ma Pacific lithosphere by Bizimis et al. 2005, also supports the lack of plume-lithosphere interaction. Bizimis et al. 2005 showed that in order to explain the Hf variability in these rocks $\left(\varepsilon_{\mathrm{Hf}} 12-18\right)$, inordinate amount of peridotite ( $>90 \mathrm{wt} \%$.) must be added to the plume derived melt (Fig 11; in Bizimis et al. 2005). Such a large amount of peridotite assimilation is not conceivable, as Os in the mantle mineralogy does not allow more than few weight percent addition of lithospheric peridotite before the Os isotope composition becomes completely overprinted by that of peridotites (Hauri and Kurz, 1997). Thus from Os-Sr-Nd-Hf perspective it seems that the pyroxenites do not record any signal of melts from the Pacific lithosphere, as Os is decoupled from $\mathrm{Sr}-\mathrm{Nd}$ and $\mathrm{Hf}$ isotopes.

The variation in Os isotopes and the reason for Os being decoupled from the other elements may be explained by preferential mobilization of sulfides during melt rock reaction. As the melting temperature of sulfides is much lower than that of the silicate (Ballhaus et al., 2006) phases, plume derived melt may pick up grain boundary sulfides (interstitial) while percolating through the Pacific lithosphere. Griffin et al. 2004 reported the presence of radiogenic Os in the interstitial sulfides $\left({ }^{187} \mathrm{Os} /{ }^{188} \mathrm{Os}\right.$ up to 1.6 ; ), and it is known that sulfide metasomatism can significantly shift the bulk rock ${ }^{187} \mathrm{Os} /{ }^{188} \mathrm{Os}$ ratios of bulk rock (Rudnick and Walker, 2009). However as the reported radiogenic grain boundary sulfides by Griffin et al. 2004 are from cratonic samples, one may reasonably argue against the presence of such radiogenic sulfide component in the Pacific lithosphere. But a more recent study by Alard et al. 2005 on the abyssal peridotites and ophiolites reports the variation in ${ }^{187} \mathrm{Os} /{ }^{188} \mathrm{Os}$ ratios between interstitial and included sulfides. Alard et al. 2005 showed that within a single sample within oceanic mantle, the 
interstitial sulfides can have much more radiogenic Os than the included sulfides. The interstitial sulfides can have ${ }^{187} \mathrm{Os} /{ }^{188} \mathrm{Os}$ ratio as high as 0.167 (average ${ }^{187} \mathrm{Os} /{ }^{188} \mathrm{Os}$ ratio for interstitial sulfides in abyssal peridotites and ophiolites are $0.142 \pm 0.012$ and $0.134 \pm$ 0.005 respectively, while the included sulfides have less radiogenic values of $0.120 \pm$ 0.003 and $0.119 \pm 0.004$ respectively). Also based on the $\mathrm{Pd} / \mathrm{Ir}$ and ${ }^{187} \mathrm{Os} /{ }^{188} \mathrm{Os}$ correlations, Alard et al. 2005 showed that these radiogenic interstitial sulfides are not inherited or affected by sea water alteration and represent a primary mantle signature.

At the present moment only bulk rock Os isotope data on the peridotite xenoliths are available (Bizimis et al., 2007). The peridotite xenoliths represent a 80-100 Myr depleted Pacific lithosphere (Bizimis et al., 2004). As the Os isotopic signature in the bulk rock can be fully accounted by the mixing of two magmatic sulfide populations (included and interstitial) (Alard et al., 2005), the radiogenic ${ }^{187} \mathrm{Os} /{ }^{188} \mathrm{Os}$ ratios $(0.1297)$ measured in these xenoliths (Bizimis et al., 2007) may indicate the presence of a sulfide component in the Pacific lithosphere with more radiogenic Os. As there are no reported Os isotope data on the sulfide populations within Hawaiian lithosphere, based on the Alard et al. 2005 and Griffin et al. 2004 study I think, it is reasonable to expect that the grain boundary sulfides may carry radiogenic Os within the Pacific lithosphere.

I envision the following process of plume-lithosphere interaction: the parental pyroxenite melt separate from its source either at the base of the lithosphere or even within the upwelling plume. As the parental melt percolates through the lithosphere it is preferentially mobilizing the radiogenic grain boundary Os and the mixed melt undergoes progressive fractionation of silicate and sulfide phases. Here, the high $\mathrm{Mg \# ,} \mathrm{Ni}$ and $\mathrm{Cr}$ rich sample with less radiogenic ${ }^{187} \mathrm{Os} /{ }^{188} \mathrm{Os}$ ratio represent cumulates which has seen the 
least amount of radiogenic grain boundary Os while the sample with low $\mathrm{Mg} \#, \mathrm{Ni}$ and $\mathrm{Cr}$ depleted samples has entrained more radiogenic interstitial sulfides. This process of assimilation and fractional crystallization can effectively explain the correlations of Os isotopes with other lithophile elements, PGE ratios and it can also explain why Os is decoupled from other elements.

In order to quantify this process I try to model a mixing scenario, where the plume derived melt is preferentially picking up grain boundary sulfides from the Pacific lithosphere. Fig 5.11a shows the mixing line between depleted mantle derived melt and grain boundary sulfide (modeling parameters are given in the figure caption) and shows that limited $(<0.05$ wt.\%.) addition of radiogenic sulfide to the depleted mantle derived melt can effectively explain the range of Os isotope variability in these studied pyroxenites.

As the bulk rock pyroxenites (this study and Lassiter et al. 2000 study) shows a considerable scatter along the mixing line, one may argue that direct mixing of melts, in principle, should create a rigid linear mixing trends in the ${ }^{187} \mathrm{Os} /{ }^{188} \mathrm{Os}$ vs. $1 / \mathrm{Os}$ space. However, as Os is highly compatible during sulfide fractionation (sulfide/silicate partition coefficient of the order of $\sim 10^{3}$ (Fleet et al., 1999)) I think that the original mixing trends, once created, are difficult to preserve because of the sulfide fractionation. Therefore, I argue that the scatter along the mixing line can be explained with progressive sulfide fractionation and removal of Os during sulfide fractionation.

I now model how much sulfide fractionation is required to explain this scatter in the ${ }^{187} \mathrm{Os} /{ }^{188} \mathrm{Os}$ vs. $1 / \mathrm{Os}$ space. I used $\mathrm{Pd} / \mathrm{Ir}$ ratio to quantify the process of sulfide fractionation; as relative to Ir, Pd is more compatible to sulfide melt. From the parental 
melt composition (model parameters are discussed in figure caption) I sequentially separate $0.1 \mathrm{wt} . \%$. of sulfide using the sulfide/silicate partitioning coefficient from Fleet et al. 1999. Fig 5.11b shows that limited sulfide fractionation ( $\sim 0.4$ wt.\%) from mixed parental melt (depleted mantle derived melt + radiogenic interstitial sulfides in the Pacific lithosphere) can explain the observed the range of $\mathrm{Pd} / \mathrm{Ir}$ ratios in the pyroxenites and as Ir and Os has similar sulfide/silicate partitioning coefficient, similar fractionation can explain the scatter in the $1 / \mathrm{Os}$ and ${ }^{187} \mathrm{Os} /{ }^{188}$ Os space.

I further calculated whether $0.4 \% \mathrm{~S}$ fractionation seems a reasonable estimation for what I should expect for an S saturated -sulfide fractionating magma. The North Arch and the Honolulu Volcanics are believed to be petrogenetically similar to the parental melt of the pyroxenites (Sen et al., 2005). Davis and Clague (2006) reported that deep, submarine alkalic glasses found in North Arch volcanic field on the seafloor on Hawaiian flexure contain $1800 \mathrm{ppm} \mathrm{S}$. Assuming $1800 \mathrm{ppm}$ of $\mathrm{S}$ in the parental melt of the pyroxenites, $1 \%$ crystallization of the melt (a valid assumption as the HV lavas are very primitive so it has suffered very little silicate fractionation) would produce $18 \mathrm{ppm}$ of $\mathrm{S}$ over-saturation. As sulfides in these pyroxenites have ( $\sim 38 \%)$ of $S$ (Sen et al., 2010$)$, removal of this $18 \mathrm{ppm}$ of excess sulfur would produce $38 \mathrm{ppm}$ of sulfides or $\sim 0.4 \%$ of sulfides.

The above process can explain the variation in the Os isotopes and why it is decoupled from other lithophile elements. The data show that melts from the Hawaiian plume preferentially reacted with the Pacific lithosphere. I envision as melts from the Hawaiian plume percolate through the Pacific lithosphere they preferentially mobilize the grain boundary sulfides, and as a consequence Os gets decoupled from other elements. I 
propose that the sampled pyroxenites essentially represent crystallized melts from different stages of this reaction process at the base of the lithosphere.

\subsection{Recycled Pyroxenites: Implication for the ${ }^{186}$ Os $-{ }^{187}$ Os of Hawaiian Lavas}

Geochemistry and seismic studies suggest that the Hawaiian plume originate at the core-mantle boundary (CMB) (Helmberger et al., 1998; Humayun et al., 2004; Montelli et al., 2004), but whether or not the Hawaiian plume is entraining materials from the outer core is a subject of debate. This latest idea of core-mantle exchange came from an observation that, some Hawaiian picrites are unusually enriched in radiogenic ${ }^{186}$ Os and ${ }^{187}$ Os isotopes.

The outer core is considered as a major repository of radiogenic Os; as with the crystallization of the inner core, the outer core has likely developed a higher $\mathrm{Pt} / \operatorname{Re}(\sim 62)$ ratio relative to Chondrite and the Earth's mantle (Brandon et al., 1999). This conclusion is based on the assumption that Re-Os-Pt strongly partitions between solid metal and liquid metal in the Earth's core (Lauer et al., 1998; Walker 2000) in a similar manner to their partitioning behavior in asteroidal cores, where $\mathrm{D}_{\mathrm{Os}}>\mathrm{D}_{\mathrm{Re}}>\mathrm{D}_{\mathrm{Pt}}(\mathrm{D}=$ solid metal/liquid metal bulk distribution coefficient (Cook et al., 2004). Based on the empirical and experimental results Brandon and colleagues (Brandon et al., 1998, 2003) first proposed that the coupled enrichments in ${ }^{186} \mathrm{Os} /{ }^{188} \mathrm{Os}-{ }^{187} \mathrm{Os} /{ }^{188} \mathrm{Os}$ isotopes observed in some Hawaiian picrites and komatiites are the result of contributions of the outer core, where it is proposed that the plume originating at $\mathrm{CMB}$ is entraining outer core material. However, study of pyroxenites and metasomatized sulfides from the famed Beni Bousera massif in Morocco disputes the role of outer core and instead suggests that the coupled enrichment of ${ }^{186} \mathrm{Os}-{ }^{187}$ Os in oceanic basalts can be explained by bulk rock pyroxenites 
plus their sulfides (Luguet et al., 2008). Luguet et al. 2008 suggests that the pyroxenites plus their sulfides can have high enough $\mathrm{Pt} / \mathrm{Os}$ and $\mathrm{Re} / \mathrm{Os}$ ratios that upon recycling and aging can generate the enriched osmium isotope signatures observed in plume derived lavas, thereby removes the requirement for core-mantle exchange in explaining radiogenic Os in plume derived lavas. In contrast, a recent study of pyroxenites layers in the Totalp ultramafic massif (Swiss Alps) shows that the pyroxenites do not possess the requisite Pt-Re-Os composition to explain the coupled enrichment of ${ }^{187} \mathrm{Os} /{ }^{188} \mathrm{Os}$ and ${ }^{186} \mathrm{Os} /{ }^{188} \mathrm{Os}$ ratios recorded in plume derived lavas. The new HSE data on the SLC pyroxenites from the present day oceanic upper mantle gives us a unique opportunity to test the pyroxenite recycling hypothesis as a source for the coupled ${ }^{186} \mathrm{Os} /{ }^{188} \mathrm{Os}$ ${ }^{187} \mathrm{Os} /{ }^{188}$ Os enrichments in the mantle.

I have already shown that recycling of mantle sulfides of pyroxenitic parentage is unlikely to explain the enriched Pt-Re-Os isotope systematics of plume-derived lavas (Sen et al., 2010) and here I explicitly test the role of recycled pyroxenites in the generation of ${ }^{186}$ Os - ${ }^{187}$ Os enrichment in oceanic basalts ( Brandon et al., 1998; Brandon et al., 1999) .

Using the measured $\mathrm{Pt} / \mathrm{Os}$ and $\mathrm{Re} / \mathrm{Os}$ ratios of these pyroxenites I calculated the range of ${ }^{187} \mathrm{Os} /{ }^{188} \mathrm{Os}$ and ${ }^{186} \mathrm{Os} /{ }^{188} \mathrm{Os}$ compositions that these pyroxenites could develop by "ageing" them over 1,2 and 3Ga from a chondritic earth and assuming the ratios will not change during the recycling process. Figure 5.12 shows the "aged" compositions of all the pyroxenites and it is compared with the ${ }^{186} \mathrm{Os} /{ }^{188} \mathrm{Os}-{ }^{187} \mathrm{Os} /{ }^{188} \mathrm{Os}$ enriched Hawaiian lavas and komatiites. These pyroxenites upon aging can generate relatively radiogenic ${ }^{187} \mathrm{Os} /{ }^{188} \mathrm{Os}$ and ${ }^{186} \mathrm{Os} /{ }^{188} \mathrm{Os}$ ratios, but do not generate the steep array required by the 
ocean basalts (Fig. 5.12). Out of the 12 samples, only SL-716 and SL-571 can generate a steep array in the ${ }^{187} \mathrm{Os} /{ }^{188} \mathrm{Os}-{ }^{186} \mathrm{Os} /{ }^{188} \mathrm{Os}$ space, however, it is not steep enough to overlap the Hawaiian lavas and komatiites field.

Brandon et al., 1999 calculated that in order to produce the steep slope of the Hawaiian picrites in ${ }^{187} \mathrm{Os} /{ }^{188} \mathrm{Os}$ vs. ${ }^{186} \mathrm{Os} /{ }^{188} \mathrm{Os}$ isotope space, their source should have a $\mathrm{Pt} / \mathrm{Re}$ ratio of 88-100 (Brandon et al., 1999). The pyroxenites analyzed here have a Pt/Re range from 0.12 to 13 , with only one sample with a $\mathrm{Pt} / \mathrm{Re}$ ratio of 77 (Table 5.2). It is also important to note that none of the 23 pyroxenites reported by Acken et al. 2010 has a $\mathrm{Pt} / \mathrm{Re}$ ratio $>15$ and out of the11 samples, only one sample (GP 87T) in the Luguet et al., 2008 b study has a high enough $\mathrm{Pt} / \mathrm{Re}$ ratio $(\sim 115)$ that can generate the observed ${ }^{187} \mathrm{Os} /{ }^{188} \mathrm{Os}$ vs. ${ }^{186} \mathrm{Os} /{ }^{188} \mathrm{Os}$ enrichments in plume lavas. Therefore, it seems very unlikely that the pyroxenites may posses a very high $\mathrm{Pt} / \mathrm{Re}$ ratio $(>88)$. Based on the present dataset I suggest that most recycled mantle-derived pyroxenites and perhaps eclogites do not possess the requisite $\mathrm{Pt} / \mathrm{Re}$ ratio to generate, over time, the coupled enrichment of ${ }^{187} \mathrm{Os} /{ }^{188} \mathrm{Os}$ and ${ }^{186} \mathrm{Os} /{ }^{188} \mathrm{Os}$ ratios in plume derived lavas. Therefore an outer core contribution to the Hawaiian and other komatiite plume volcanism may still be the strongest hypothesis.

The only possible workaround to the low $\mathrm{Pt} / \mathrm{Re}$ ratios of the pyroxenites would be the fortuitous involvement of Pt-rich alloys in the source of these plume lavas, in addition to a pyroxenitic component. The Pt-rich alloys from the Josephine ophiolite have extremely high $\mathrm{Pt} / \mathrm{Re}$ ratios $(>10,000$, Luguet et al., 2008) and will generate over time very radiogenic ${ }^{186} \mathrm{Os} /{ }^{188} \mathrm{Os}$ ratios. Mixing of high ${ }^{186} \mathrm{Os} /{ }^{188} \mathrm{Os}$ ratios with the pyroxenitegenerated high ${ }^{187} \mathrm{Os} /{ }^{188} \mathrm{Os}$ could theoretically produce the required radiogenic 
${ }^{186} \mathrm{Os} /{ }^{188} \mathrm{Os}-{ }^{187} \mathrm{Os} /{ }^{188} \mathrm{Os}$ end member seen in the Hawaiian and komatiite lavas. While such a fortuitous scenario may be theoretically possible, I consider how likely it could be, especially when the distribution of Pt-rich alloys in the mantle is virtually unknown and considering the Ireland et al. (2009) arguments that such a high Pt/Re source is not compatible with the PGE contents of the Hawaiian lavas, at least.

\subsection{Summary}

The radiogenic to unradiogenic variability in the ${ }^{187} \mathrm{Os} /{ }^{188} \mathrm{Os}$ ratios and their correlation with PGE ratios, major and trace elements suggests that the Os signature of the pyroxenites reflect a primary magmatic process. To explain the large variability in the ${ }^{187} \mathrm{Os} /{ }^{188} \mathrm{Os}$ ratios I propose that the plume-derived magma (similar to the HV lavas) is picking up radiogenic osmium along the grain boundaries of the peridotites, as it percolates through the Pacific lithosphere. I conclude that the sulfides get preferentially mobilized during the melt-rock reaction because of their low melting temperature. Such preferential mobilization of sulfide is conceivable to explain the large ${ }^{187} \mathrm{Os} /{ }^{188} \mathrm{Os}$ variation in the pyroxenites and also explains why Os is decoupled from the other elements. The sampled pyroxenites essentially represent crystallized melts from different stages of this reaction process at the base of the lithosphere. These metasomatized pyroxenites do not have the requisite Pt/Re ratio to generate enriched ${ }^{186} \mathrm{Os}^{-{ }^{187}} \mathrm{Os}$ isotope signature observed in some Hawaiian picrites and komatiites. 
Table 5.1 Bulk Rock Trace Element Concentrations (ppm) and Sulfur (wt. \%)

\begin{tabular}{|c|c|c|c|c|c|c|c|c|c|c|c|c|c|c|c|}
\hline Sample & 552 & 553 & 555 & 559 & 714 & 716 & 744 & 590 & 594 & 620 & 571 & 776 & $\begin{array}{l}\text { BIR -1 } \\
\text { Meas. }\end{array}$ & $\begin{array}{l}\text { BIR-1 } \\
\text { Report }\end{array}$ & $\begin{array}{c}\text { BHVO-2 } \\
\text { Std }\end{array}$ \\
\hline $\begin{array}{l}\text { Rock Type } \\
\qquad p x^{*}\end{array}$ & $\begin{array}{c}\mathrm{a} \\
95 \% \\
(0.69)\end{array}$ & $\begin{array}{c}\mathrm{a} \\
85 \% \\
(0.76)\end{array}$ & $\begin{array}{c}\mathrm{a} \\
80 \% \\
(0.77)\end{array}$ & $\begin{array}{c}\mathrm{a} \\
85 \% \\
(0.77)\end{array}$ & $\begin{array}{c}\mathrm{a} \\
80 \% \\
(0.75)\end{array}$ & $\begin{array}{c}\mathrm{a} \\
95 \% \\
(0.80)\end{array}$ & $\begin{array}{c}\mathrm{a} \\
60 \% \\
(0.68)\end{array}$ & $\begin{array}{c}\mathrm{b} \\
80 \% \\
(0.78)\end{array}$ & $\begin{array}{c}\mathrm{b} \\
85 \% \\
(0.78)\end{array}$ & $\begin{array}{c}\mathrm{b} \\
75 \% \\
(0.80)\end{array}$ & $\begin{array}{c}c \\
75 \% \\
(0.84)\end{array}$ & $\begin{array}{c}\mathrm{c} \\
50 \% \\
(0.84)\end{array}$ & & & \\
\hline $\begin{array}{c}\mathrm{Al}_{2} \mathrm{O}_{3} \dagger \\
\mathrm{Gt}^{*} \\
\mathrm{Opx}^{*}\end{array}$ & $\begin{array}{c}7.29 \\
5 \% \\
(0.62)\end{array}$ & $\begin{array}{c}5.96 \\
5 \% \\
(0.61) \\
10 \% \\
(0.78) \\
\end{array}$ & $\begin{array}{c}6.87 \\
20 \% \\
(0.68)\end{array}$ & $\begin{array}{c}7.39 \\
15 \% \\
(0.65)\end{array}$ & $\begin{array}{c}6.34 \\
20 \% \\
(0.63)\end{array}$ & $\begin{array}{c}5.69 \\
3 \% \\
(0.70) \\
5 \% \\
(0.78) \\
\end{array}$ & $\begin{array}{c}7.40 \\
40 \% \\
(0.62)\end{array}$ & $\begin{array}{c}6.70 \\
15 \% \\
(0.67) \\
2 \% \\
(0.79) \\
\end{array}$ & $\begin{array}{c}6.51 \\
10 \% \\
(0.69) \\
5 \% \\
(0.79) \\
\end{array}$ & $\begin{array}{c}6.52 \\
20 \% \\
(0.68) \\
5 \% \\
(0.81) \\
\end{array}$ & $\begin{array}{c}5.06 \\
5 \% \\
(0.75) \\
20 \% \\
(0.84) \\
\end{array}$ & $\begin{array}{c}50 \% \\
(0.84)\end{array}$ & & & \\
\hline Cs & 0.05 & 0.01 & 0.00 & 0.06 & 0.01 & 0.02 & 0.00 & 0.00 & 0.01 & 0.01 & 0.01 & 0.01 & 0.01 & 0.01 & 0.10 \\
\hline $\mathrm{Rb}$ & 13.17 & 0.96 & 0.80 & 3.86 & 1.47 & 1.18 & 0.95 & 1.02 & 0.62 & 1.92 & 0.58 & 0.38 & 0.20 & 0.20 & 9.11 \\
\hline $\mathrm{Ba}$ & 273.1 & 75.73 & 15.13 & 134.10 & 47.38 & 132.67 & 46.72 & 58.30 & 34.93 & 64.01 & 14.95 & 4.78 & 6.30 & 7.14 & 131.0 \\
\hline $\mathrm{Th}$ & 0.22 & 0.26 & 0.20 & 0.23 & 0.09 & 0.08 & 0.12 & 0.11 & 0.15 & 0.28 & 0.09 & 0.08 & 0.03 & 0.03 & 1.22 \\
\hline $\mathrm{U}$ & 0.09 & 0.07 & 0.06 & 0.09 & 0.04 & 0.03 & 0.04 & 0.04 & 0.05 & 0.16 & 0.02 & 0.02 & 0.01 & 0.01 & 0.40 \\
\hline $\mathrm{Nb}$ & 5.43 & 2.61 & 1.01 & 1.99 & 0.86 & 0.81 & 0.84 & 0.45 & 0.77 & 1.85 & 0.62 & 0.91 & 0.51 & 0.55 & 18.10 \\
\hline $\mathrm{Ta}$ & 0.43 & 0.18 & 0.13 & 0.11 & 0.09 & 0.08 & 0.10 & 0.10 & 0.06 & 0.19 & 0.06 & 0.06 & 0.04 & 0.04 & 1.14 \\
\hline $\mathrm{La}$ & 2.86 & 3.16 & 2.39 & 3.33 & 1.60 & 1.99 & 1.81 & 1.90 & 1.86 & 3.19 & 1.29 & 1.08 & 0.67 & 0.62 & 15.20 \\
\hline $\mathrm{Ce}$ & 8.13 & 6.97 & 6.50 & 7.52 & 4.71 & 4.02 & 5.79 & 6.11 & 4.72 & 8.45 & 3.52 & 3.11 & 2.01 & 1.92 & 37.50 \\
\hline $\mathrm{Pb}$ & 0.47 & 0.42 & 0.16 & 0.50 & 0.29 & 0.12 & 0.08 & 0.62 & 0.28 & 0.47 & 0.18 & 0.25 & 2.54 & 3.10 & 1.70 \\
\hline $\operatorname{Pr}$ & 1.36 & 1.02 & 1.07 & 1.26 & 0.80 & 0.70 & 1.04 & 1.04 & 0.75 & 1.23 & 0.60 & 0.49 & 0.37 & 0.37 & 5.35 \\
\hline $\mathrm{Sr}$ & 689.9 & 225.5 & 140.3 & 238.7 & 90.0 & 472.4 & 84.8 & 104.0 & 63.1 & 128.0 & 53.5 & 37.8 & 106.9 & 109.0 & 396.0 \\
\hline $\mathrm{Nd}$ & 7.54 & 5.03 & 5.65 & 6.61 & 4.32 & 3.93 & 6.04 & 5.37 & 3.96 & 5.99 & 3.40 & 2.56 & 2.37 & 2.38 & 24.50 \\
\hline $\mathrm{Zr}$ & 60.88 & 31.18 & 32.07 & 24.29 & 25.85 & 19.76 & 46.88 & 22.88 & 15.21 & 26.15 & 11.20 & 13.24 & 13.89 & 14.00 & 172.00 \\
\hline Hf & 2.43 & 1.02 & 1.08 & 1.03 & 1.11 & 0.77 & 1.83 & 0.73 & 0.67 & 0.85 & 0.55 & 0.48 & 0.58 & 0.58 & 4.36 \\
\hline $\mathrm{Sm}$ & 2.69 & 1.63 & 1.77 & 2.22 & 1.53 & 1.41 & 2.23 & 1.62 & 1.30 & 1.79 & 1.23 & 0.85 & 1.08 & 1.12 & 6.07 \\
\hline $\mathrm{Eu}$ & 1.09 & 0.63 & 0.65 & 0.85 & 0.59 & 0.58 & 0.87 & 0.60 & 0.48 & 0.67 & 0.45 & 0.31 & 0.51 & 0.53 & 2.07 \\
\hline $\mathrm{Ti}$ & 16315 & 4006 & 4815 & 4723 & 6315 & 3990 & 6406 & 3164 & 3398 & 3613 & 2967 & 2395 & 5159 & 5600 & 16300 \\
\hline $\mathrm{Gd}$ & 3.62 & 2.10 & 2.00 & 2.69 & 1.65 & 1.86 & 2.82 & 1.80 & 1.63 & 2.10 & 1.44 & 1.01 & 1.78 & 1.87 & 6.24 \\
\hline $\mathrm{Tb}$ & 0.53 & 0.33 & 0.29 & 0.43 & 0.28 & 0.30 & 0.45 & 0.27 & 0.23 & 0.35 & 0.23 & 0.16 & 0.33 & 0.36 & 0.92 \\
\hline
\end{tabular}




\begin{tabular}{|c|c|c|c|c|c|c|c|c|c|c|c|c|c|c|c|}
\hline Dy & 3.16 & 2.14 & 1.66 & 2.58 & 1.63 & 1.86 & 2.75 & 1.53 & 1.42 & 2.20 & 1.37 & 0.95 & 2.54 & 2.51 & 5.31 \\
\hline Ho & 0.55 & 0.41 & 0.29 & 0.48 & 0.29 & 0.36 & 0.51 & 0.28 & 0.25 & 0.41 & 0.24 & 0.17 & 0.56 & 0.56 & 0.98 \\
\hline $\mathrm{Y}$ & 14.13 & 10.68 & 7.48 & 12.39 & 7.18 & 9.57 & 13.19 & 7.09 & 6.45 & 10.86 & 6.24 & 4.50 & 15.33 & 15.60 & 26.00 \\
\hline $\mathrm{Er}$ & 1.29 & 1.11 & 0.72 & 1.20 & 0.70 & 0.93 & 1.30 & 0.69 & 0.62 & 1.07 & 0.60 & 0.45 & 1.69 & 1.66 & 2.54 \\
\hline $\mathrm{Yb}$ & 0.93 & 0.91 & 0.52 & 0.90 & 0.48 & 0.70 & 1.02 & 0.53 & 0.45 & 0.82 & 0.42 & 0.36 & 1.62 & 1.65 & 2.00 \\
\hline $\mathrm{Lu}$ & 0.13 & 0.13 & 0.07 & 0.12 & 0.06 & 0.10 & 0.14 & 0.07 & 0.06 & 0.11 & 0.05 & 0.05 & 0.24 & 0.25 & 0.27 \\
\hline $\mathrm{Sc}$ & 20.98 & 32.60 & 29.41 & 27.69 & 21.68 & 27.36 & 21.46 & 26.96 & 26.09 & 30.26 & 30.61 & 20.17 & 41.64 & 43.00 & 32.00 \\
\hline V & 389.7 & 279.5 & 316.4 & 297.1 & 305.3 & 262.3 & 283.2 & 215.0 & 247.4 & 269.1 & 243.1 & 166.2 & 307.3 & 319.0 & 317.0 \\
\hline $\mathrm{Cr}$ & 444.3 & 1072.2 & 907.0 & 912.1 & 990.7 & 1100.7 & 304.7 & 2311.7 & 1741.9 & 1447.8 & 2337.2 & 2349.4 & 363.6 & 391.0 & 280.0 \\
\hline Co & 70.07 & 62.45 & 60.16 & 59.16 & 71.49 & 57.49 & 78.90 & 61.00 & 57.85 & 60.90 & 50.67 & 51.29 & 50.43 & 52.0 & 45.00 \\
\hline $\mathrm{Ni}$ & 341.3 & 434.26 & 488.64 & 473.54 & 501.61 & 486.32 & 490.22 & 711.90 & 615.61 & 635.77 & 565.61 & 572.78 & 159.8 & 166.0 & 119.0 \\
\hline $\mathrm{Cu}$ & 74.34 & 126.53 & 63.12 & 152.67 & 77.78 & 90.88 & 101.17 & 74.11 & 111.73 & 97.58 & 45.35 & 44.52 & 114.9 & 119.0 & 127.0 \\
\hline $\mathrm{Zn}$ & 26.22 & 37.12 & 38.14 & 24.66 & 48.40 & 33.85 & 33.20 & 43.12 & 23.69 & 36.15 & 20.80 & 23.84 & 41.12 & 72.0 & 103.0 \\
\hline $\mathrm{Ga}$ & 17.51 & 12.80 & 14.00 & 13.24 & 15.59 & 12.16 & 14.86 & 10.45 & 9.83 & 15.00 & 9.26 & 6.70 & 15.46 & 15.3 & 22.0 \\
\hline $\mathrm{Cd}$ & 0.04 & 0.04 & 0.04 & 0.04 & 0.03 & 0.03 & 0.04 & 0.04 & 0.03 & 0.03 & 0.03 & 0.02 & 0.03 & 0.10 & 0.06 \\
\hline $\mathrm{Sn}$ & 1.23 & 0.35 & 0.47 & 0.62 & 0.66 & 0.36 & 1.14 & 0.52 & 0.35 & 0.41 & 0.28 & 1.49 & 0.67 & 0.60 & 1.70 \\
\hline ulfur & 0.188 & 0.028 & 0.117 & 0.118 & 0.117 & .009 & 0.281 & 0.102 & 0.06 & 0.054 & 0.04 & 0.044 & & & \\
\hline
\end{tabular}

Note: $\mathrm{Mg} \#=\mathrm{Mg} /(\mathrm{Mg}+\mathrm{Fe})$ and $\mathrm{Al}_{2} \mathrm{O}_{3}$ data from Bizimis et al. (Bizimis et al., 2005) and SL-594 from Sen et al. (Sen et al., 2010) $\mathrm{a}$ - garnet pyroxenite; $\mathrm{b}$-olivine bearing garnet pyroxenite; $\mathrm{c}$-websterite

* Mode wt.\%. (Mg\#); All the samples have a prefix of $77 \mathrm{SL}-; \uparrow$ Concentration in Clinopyroxene (wt. \%.) 
Table 5.2 Bulk Rock HSE Concentrations (ppb) and Os Isotope Ratios

\begin{tabular}{|c|c|c|c|c|c|c|c|c|c|c|c|}
\hline \multirow[b]{3}{*}{ Sample Nc } & \multicolumn{6}{|c|}{ HSE in Bulk Rock } & \multirow[b]{2}{*}{$\mathrm{Pd} / \mathrm{Ir}$} & \multirow[b]{2}{*}{$\mathrm{Re} / \mathrm{Os}$} & \multirow[b]{2}{*}{$\mathrm{Pt} / \mathrm{Re}$} & \multirow[b]{2}{*}{${ }^{187} \mathrm{Os} /{ }^{188} \mathrm{Os}$} & \multirow[b]{2}{*}{$2 \sigma$} \\
\hline & Os & Ir & $\mathrm{Ru}$ & $\mathrm{Pt}$ & $\mathrm{Pd}$ & $\operatorname{Re}$ & & & & & \\
\hline & & & & & & & & & & & \\
\hline 552 & 0.24 & 0.12 & 0.45 & 1.73 & 2.75 & 2.69 & 23.8 & 11.4 & 0.64 & 0.1643 & 7 \\
\hline 553 & 0.02 & 0.04 & 0.08 & 0.18 & 0.16 & 0.66 & 4.0 & 32.8 & 0.27 & n.d. & \\
\hline 555 & 0.08 & 0.05 & 0.08 & 0.68 & 0.35 & 4.18 & 7.6 & 49.3 & 0.16 & 0.1464 & 7 \\
\hline 559 & 1.19 & 0.35 & 1.37 & 8.17 & 3.51 & 2.16 & 10.0 & 1.8 & 3.78 & 0.1556 & 6 \\
\hline 714 & 0.29 & 0.09 & 0.63 & 1.51 & 0.82 & 2.02 & 8.8 & 7.1 & 0.75 & 0.1334 & 9 \\
\hline 716 & 0.08 & 0.04 & 0.14 & 26.21 & 0.15 & 0.34 & 3.6 & 4.1 & 76.55 & 0.1361 & 36 \\
\hline 744 & 0.21 & 0.09 & 0.20 & 1.04 & 1.29 & 3.88 & 15.0 & 18.3 & 0.27 & 0.1535 & 51 \\
\hline 590 & 0.95 & 0.62 & 1.19 & 3.85 & 2.41 & 2.47 & 3.9 & 2.6 & 1.56 & 0.1362 & 1 \\
\hline 594 & 0.68 & 0.43 & 1.21 & 3.44 & 4.20 & 2.91 & 9.7 & 4.3 & 1.18 & 0.1540 & 12 \\
\hline 620 & 0.52 & 0.35 & 0.74 & 2.17 & 1.27 & 2.26 & 3.6 & 4.4 & 0.96 & 0.1401 & 21 \\
\hline 571 & 0.24 & 0.07 & 0.26 & 19.92 & 0.28 & 1.51 & 4.3 & 6.2 & 13.18 & 0.1233 & 8 \\
\hline 776 & 0.66 & 0.42 & 0.99 & 2.88 & 3.44 & 1.11 & 8.3 & 1.7 & 2.59 & 0.1324 & 2 \\
\hline
\end{tabular}


Table 5.3 A Sulfide Mode Calculation

\begin{tabular}{|c|c|c|c|c|c|c|}
\hline \multicolumn{7}{|l|}{ Sample No. } \\
\hline SL-552 & $\begin{array}{l}\text { Phases } \\
\text { (Ni) ppm }\end{array}$ & $\begin{array}{c}\text { Bulk Rock } \\
341\end{array}$ & $\begin{array}{c}\text { Clinopyroxene } \\
139\end{array}$ & $\begin{array}{c}\text { Phlogopite* } \\
820\end{array}$ & $\begin{array}{c}\text { Garnet } \\
30\end{array}$ & $\begin{array}{l}\text { Sulfide } \\
47000\end{array}$ \\
\hline \multirow{3}{*}{ SL-744 } & Mode & & $94 \%$ & $1 \%$ & $5 \%$ & $0.42 \%$ * \\
\hline & (Ni) ppm & 490 & 169 & 0 & 23.4 & 51400 \\
\hline & Mode & & $60 \%$ & $0 \%$ & $40 \%$ & $0.74 \%$ \\
\hline \multirow[t]{2}{*}{ SL-559 } & (Ni) ppm & 473.5 & 201 & 0 & 30 & 58900 \\
\hline & Mode & & $85 \%$ & $0 \%$ & $15 \%$ & $0.51 \%$ \\
\hline
\end{tabular}

${ }^{\ddagger}$ Modal Abundance of sulfide obtained by mass balancing Ni between bulk rock and its constituent phases.

Table 5.3 B Mass Balance for HSE

\begin{tabular}{|c|c|c|c|c|c|c|}
\hline & Sulfides & Os & $\mathrm{Ir}$ & $\mathrm{Pt}$ & $\mathrm{Pd}$ & $\mathrm{Re}$ \\
\hline SL-552 & ppm (range) & $0.01-0.32$ & $0.01-0.19$ & $0.03-0.65$ & $0.1-1.01$ & $0.19-0.44$ \\
\hline SL-744 & ppm (range) & $0.01-0.06$ & $0.003-0.04$ & $0.03-0.13$ & $0.06-0.21$ & $0.14-0.41$ \\
\hline SL-559 & ppm (range) & $0.06-1.22$ & $0.03-1.38$ & $0.02-0.21$ & $0.09-0.35$ & $0.29-0.44$ \\
\hline \multirow[t]{2}{*}{ SL-552 } & BR Calculated (ppb) & $0.04-1.35$ & $0.03-0.82$ & $0.14-2.71$ & $0.42-4.23$ & $0.8-1.85$ \\
\hline & BR Measured (ppb) & 0.24 & 0.12 & 1.73 & 2.75 & 2.69 \\
\hline \multirow[t]{2}{*}{ SL-744 } & BR Calculated (ppb) & $0.06-0.46$ & $0.02-0.28$ & $0.2-0.96$ & $0.41-1.52$ & $1.03-3.03$ \\
\hline & BR Measured (ppb) & 0.21 & 0.09 & 1.04 & 1.29 & 3.88 \\
\hline \multirow[t]{2}{*}{ SL-559 } & BR Calculated (ppb) & $0.3-6.2$ & 0.13-6.99 & $0.11-1.07$ & $0.44-1.77$ & $1.48-2.24$ \\
\hline & BR Measured (ppb) & 1.19 & 0.35 & 8.17 & 3.51 & 2.16 \\
\hline
\end{tabular}

Ni content in Cpx and Garnet from Bizimis et al. 2005 and unpublished dataset for phlogopite; BR - Bulk Rock

Major and PGE concentrations for sulfides are from Sen et al. 2010 


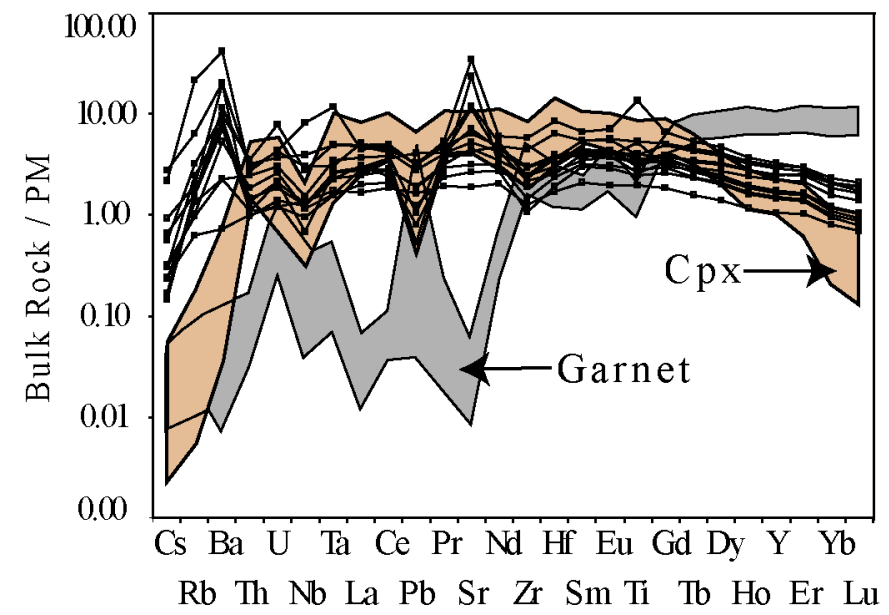

Figure 5.1 Primitive mantle normalized trace element concentrations in the bulk rock compared with concentrations in clinopyroxene and garnet concentrations from Bizimis et al. 2005. Primitive mantle normalization values from McDonough and Sun 1995. 

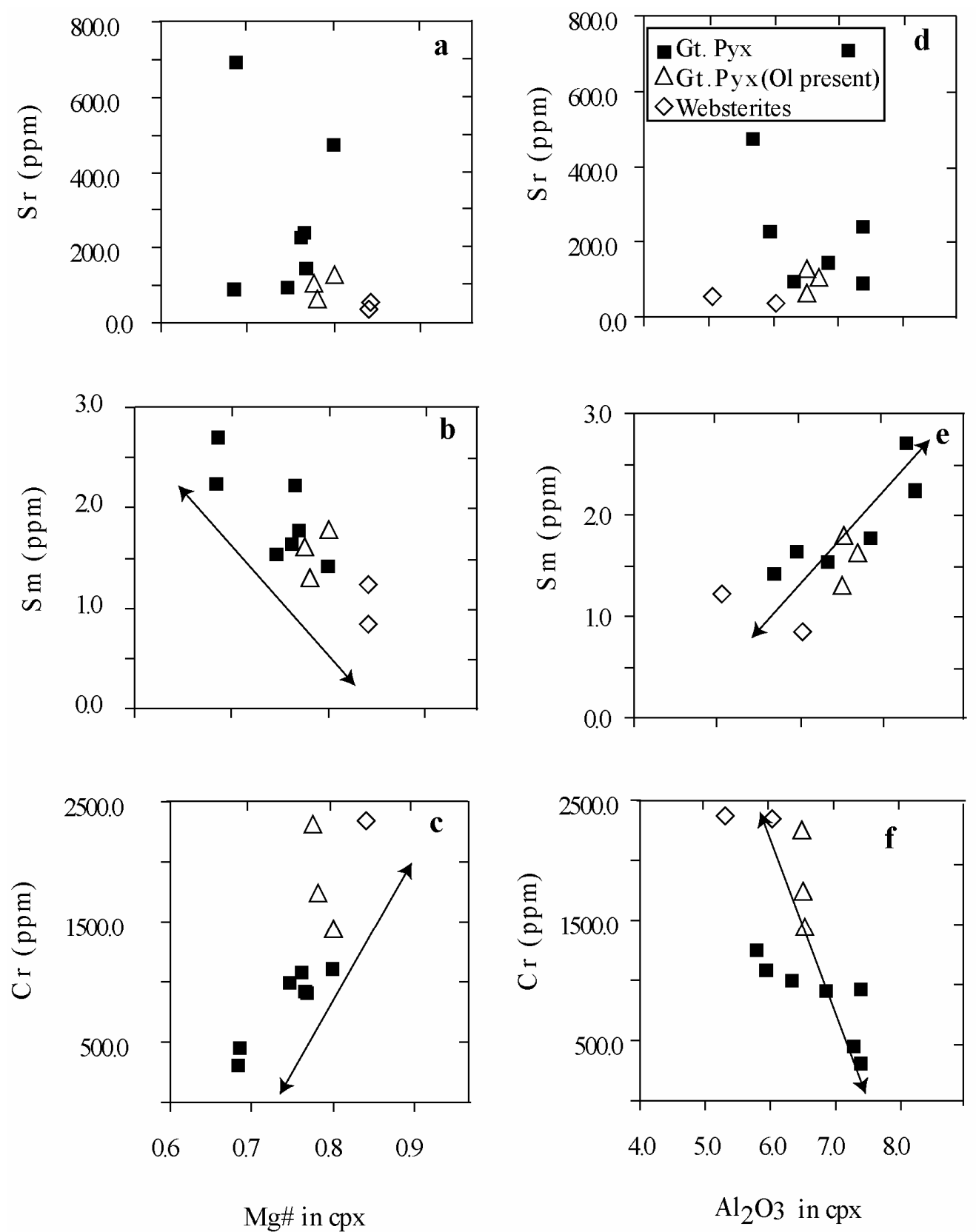

Figure 5.2 $\mathrm{Mg}$ number $(\mathrm{Mg} / \mathrm{Mg}+\mathrm{Fe})$ and $\mathrm{Al}_{2} \mathrm{O}_{3}$ content in clinopyroxenes vs. $\mathrm{Sr}, \mathrm{Sm}$ and $\mathrm{Cr}$ content of the bulk rock. Double headed arrows show strong correlation between $\mathrm{Mg} \#, \mathrm{Al}_{2} \mathrm{O}_{3}$ and $\mathrm{Sm}, \mathrm{Cr}$. 


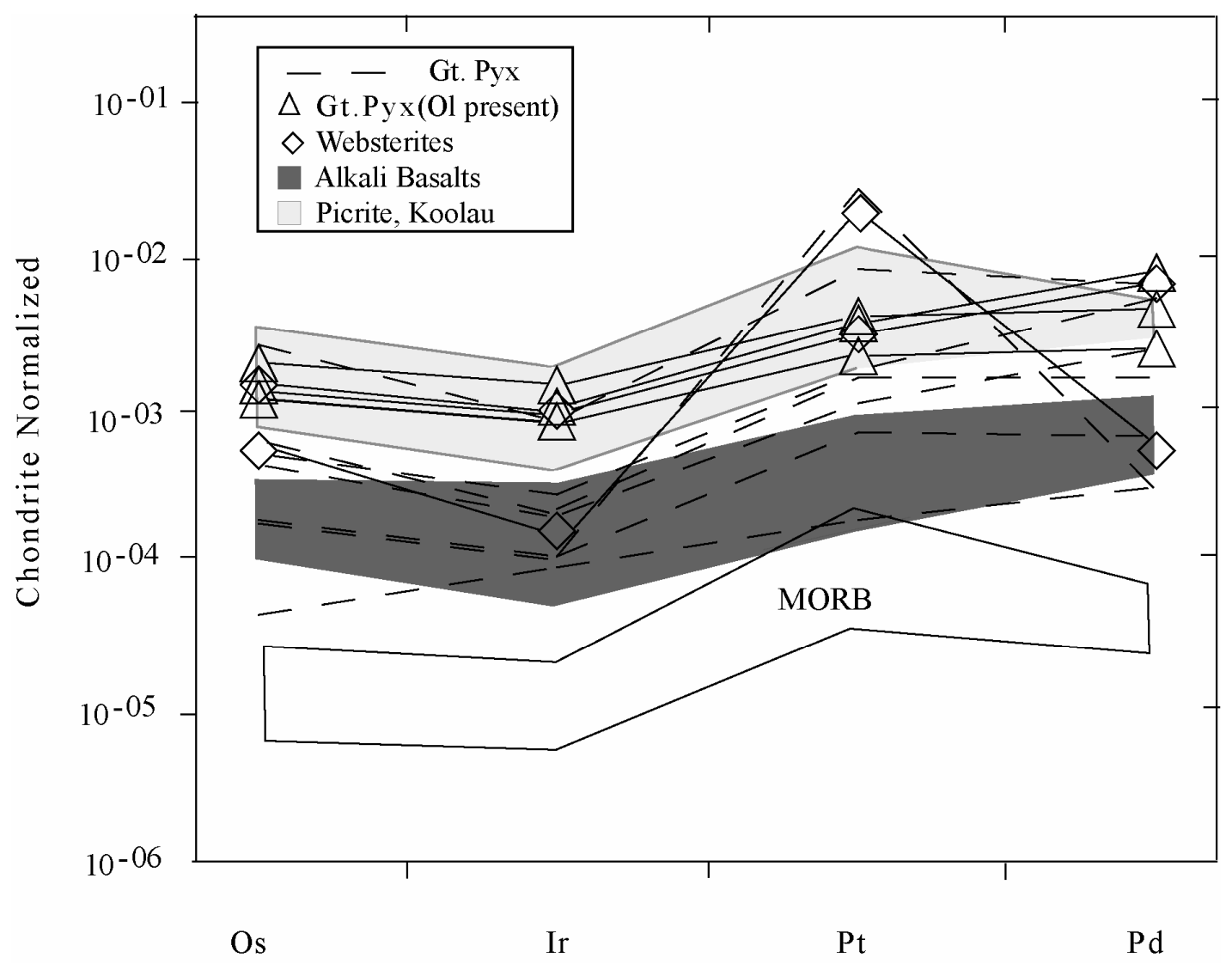

Figure 5.3 Chondrite normalized PGE pattern of garnet pyroxenites \pm olivine and websterites. Dark grey area, alkali basalts from Maui, Hawaii (Crocket, 2002); light grey area, picritic lava from Koolau, Hawaii (Ireland et al., 2009); MORB field is based on the data reported in Tatsumi et al. 1999 and Schiano et al. 1997 for Pacific MORB ). The garnet pyroxenites and the websterites have similar chondrite normalized PGE pattern with the enrichment of Pt and Pd over Os and Ir. In general, relative to the Pacific MORB, the pyroxenites have higher concentration of all the PGEs. CI normalized values from McDonough and Sun (McDonough and Sun, 1995) 

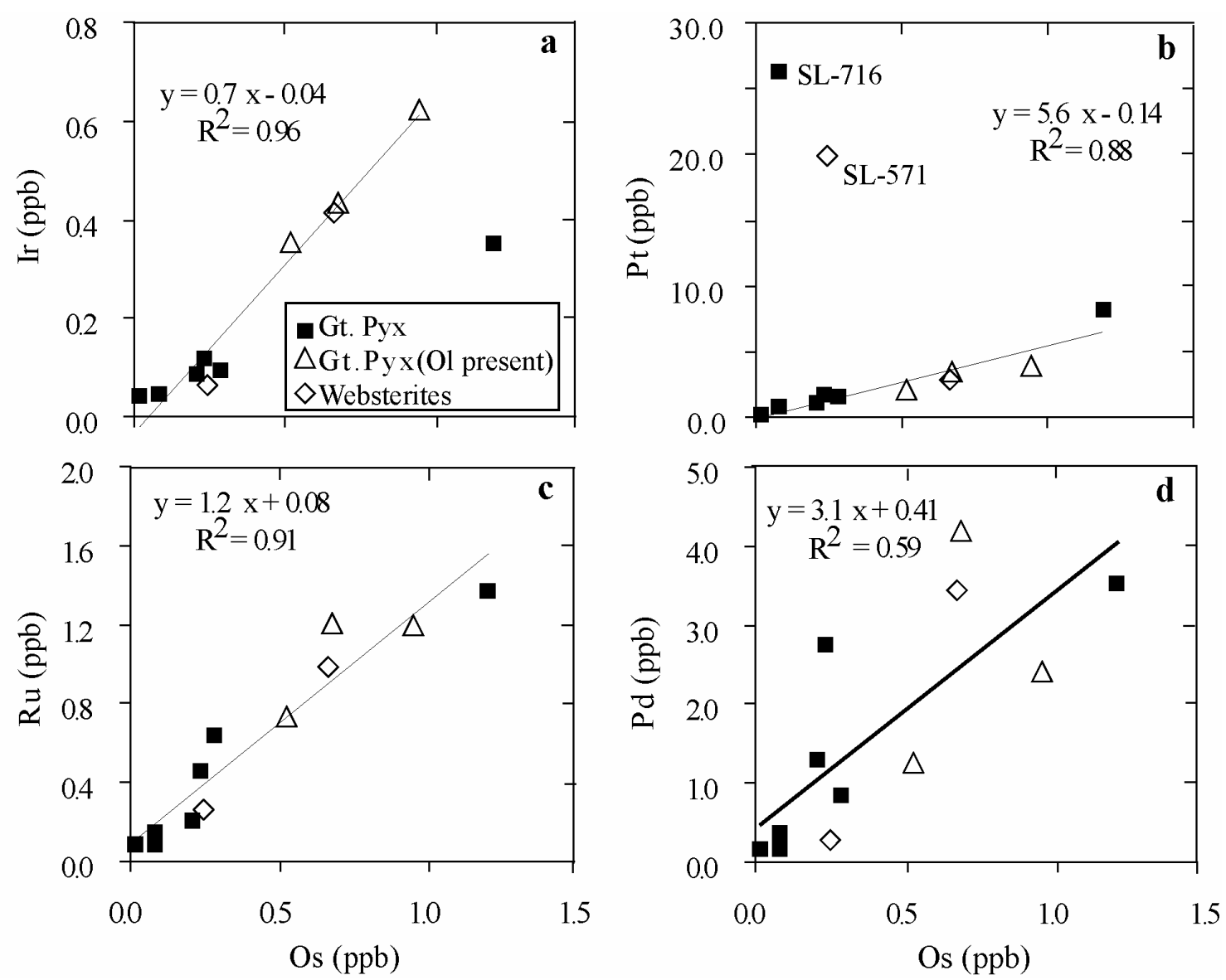

Figure 5.4 Plots of PGE abundances with Os concentration in bulk rocks. The sample shows strong PGE intra-correlations, likely reflecting variable modal abundance of sulfides. Gt Pyx and $\mathrm{Ol}$ are abbreviations for garnet pyroxenite and olivine respectively, and the error bars are smaller than the sample size. Filled square, garnet pyroxenites; open triangle, olivine bearing ( $1 \sim 5$ wt. $\%$.) garnet pyroxenites; open diamonds, websterites. 

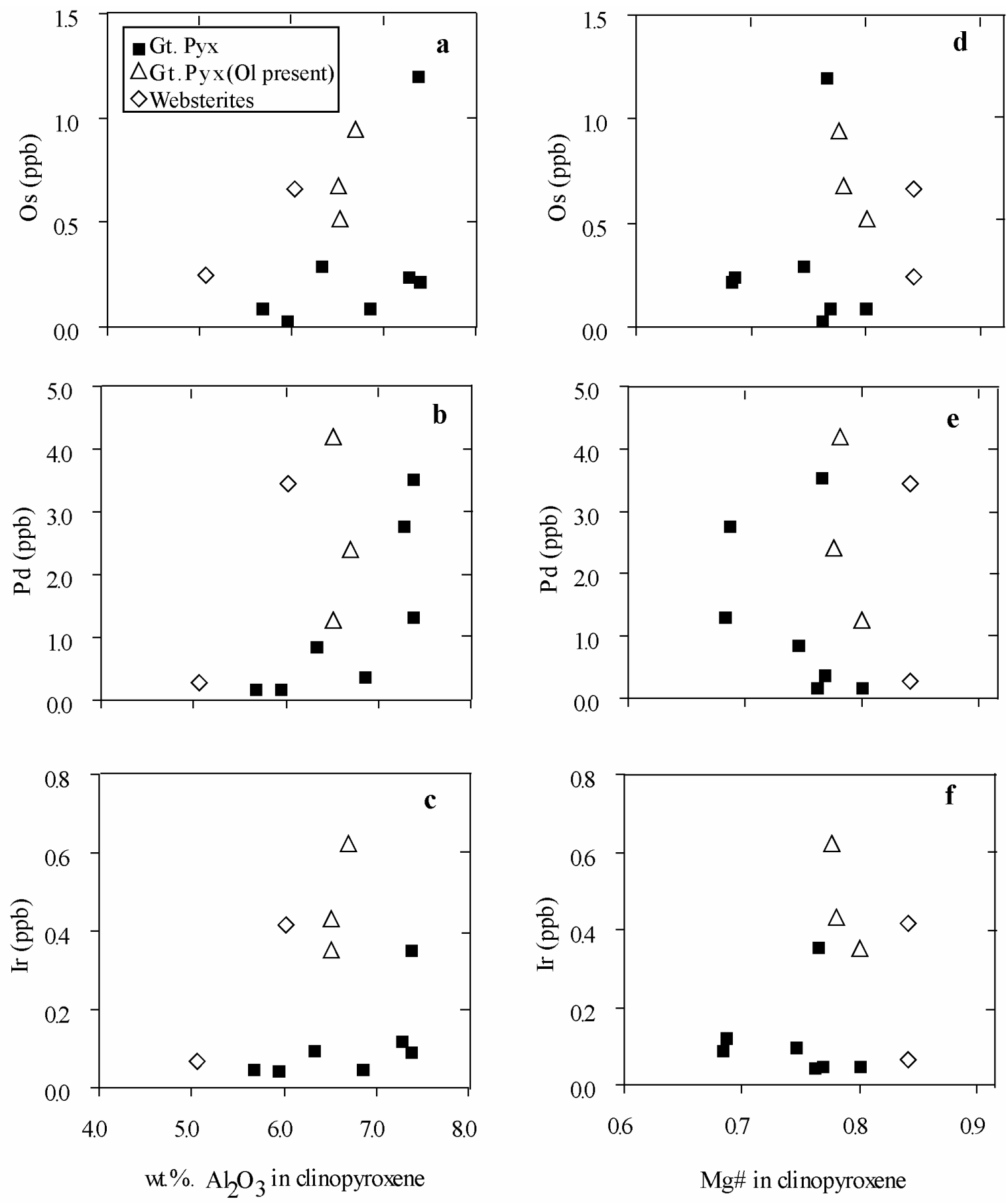

Figure 5.5 Plots of PGE abundances in bulk rock vs. $\mathrm{Al}_{2} \mathrm{O}_{3}$ and $\mathrm{Mg} \#$ (Molar $\mathrm{Mg} / \mathrm{Mg}+$ $\mathrm{Fe}_{\text {Total }}$ ) of clinopyroxenes. Bulk rock PGE data are from this study and most of the major element data for clinopyroxene from Bizimis et al. 2005 and SL-594 from Sen et al. 2010 (Supplementary table A3). The major element content of clinopyroxene shows no correlation with PGE contents. 

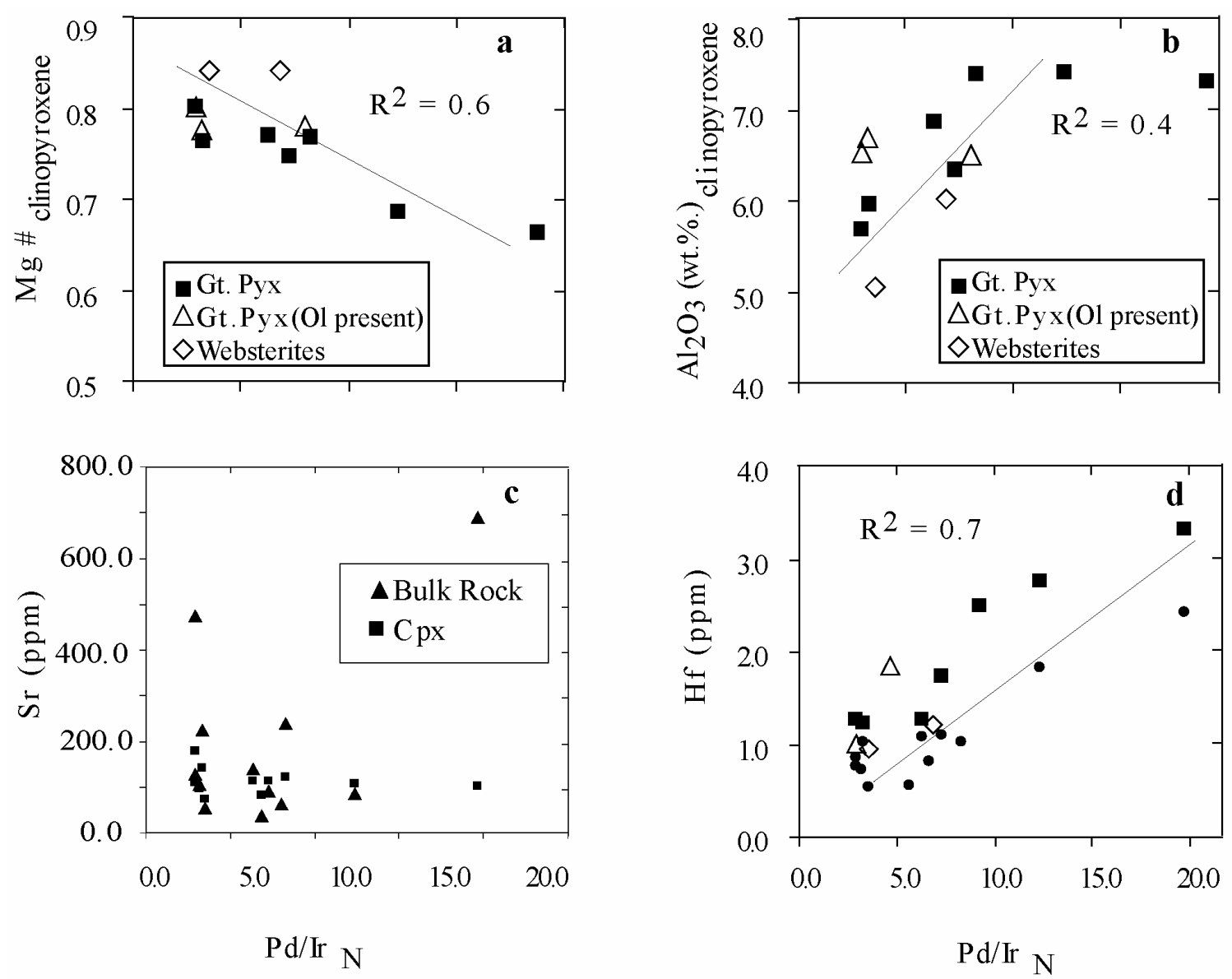

Figure 5.6 (a-d): Plots of CI normalized Pd/Ir ratio of the bulk rock vs. major and trace element content of clinopyroxenes and bulk rocks. Elemental data for clinopyroxenes are from Bizimis et al. 2005. The $\mathrm{Pd} / \mathrm{Ir}_{\mathrm{N}}$ ratio of the bulk rock shows positive correlation with $\mathrm{Al}_{2} \mathrm{O}_{3}$, Hf and negative correlations with $\mathrm{Mg}$ \#. $\mathrm{Pd} / \mathrm{Ir}$ ratios do not show any correlations with incompatible element content of the bulk rock or clinopyroxenes. The solid circles in Fig 6d are bulk rock data. CI normalized values from McDonough and Sun 1995. 

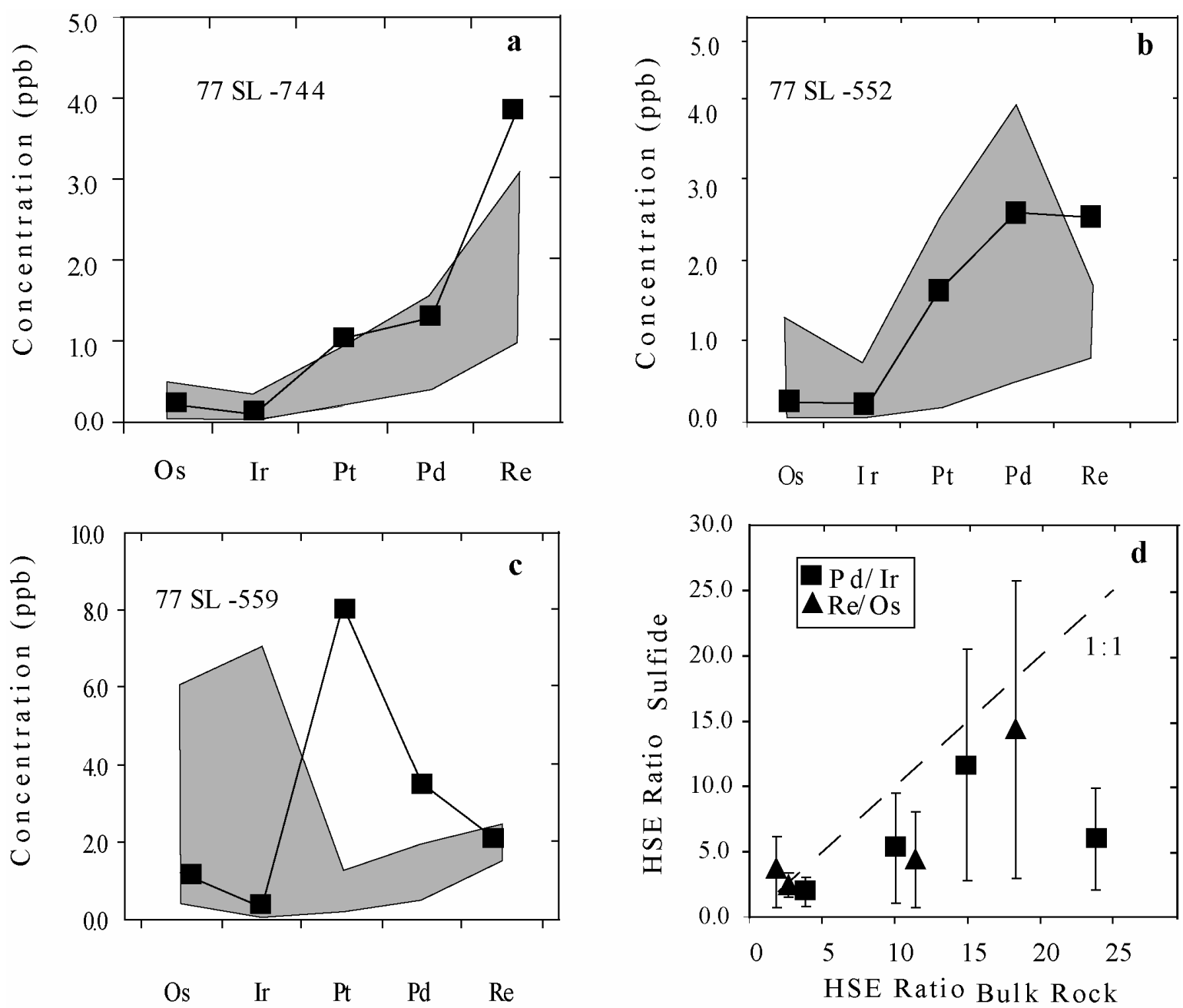

Figure 5.7 (a-c): Mass balance estimate of the contribution of sulfide to the HSE budget of garnet pyroxenites for sample number SL-744, 552 and 559. Filled square: measured bulk rock HSE abundances; shaded region: calculated HSE abundances in bulk rock, assuming no HSE in the silicates (Table 4.3). Calculated bulk rock data were estimated on the range of sulfide composition reported on the samples (Sen et al., 2010). The measured Os and Ir values are within the range of calculated values; this suggests that sulfides are the major repository of Os and Ir in these rocks. However Pt and Pd are outside the range for sample number SL-559, there may be smaller sulfide grains enriched in Pt and Pd (further discussed in the text). Note measured Re abundances is greater than the estimated one. (d) Comparison between HSE ratios in bulk rock and the sulfides for sample number SL-744, 552, 559 and 590. The error bar for HSE ratios in the sulfides are $1 \sigma$ standard deviation on the measured concentration. The $\mathrm{Pd} / \mathrm{Ir}$ and the $\mathrm{Re} / \mathrm{Os}$ ratio are higher in the bulk rock than the sulfides. 1:1 denotes a line of slope 1 . Note that we did not do any mass balance calculations for SL-590 (the only other sample where we have HSE data on sulfides and bulk rock), as the sample has $5 \%$ Olivine and we do not have the Ni concentrations for the Olivine to do Ni mass balance. 


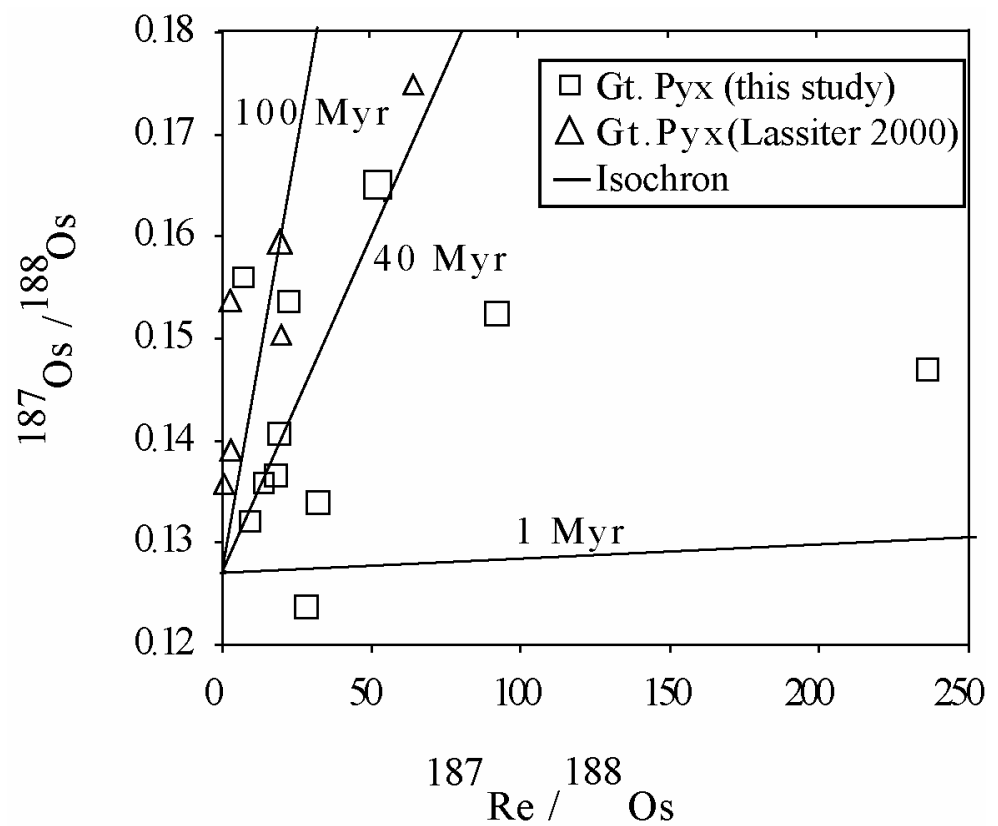

Figure 5.8 Plot of ${ }^{187} \mathrm{Os} /{ }^{188}$ Os versus ${ }^{187} \mathrm{Re} /{ }^{188} \mathrm{Os}$; No isochronous relationship exists in the pyroxenites xenoliths from Hawaii. 

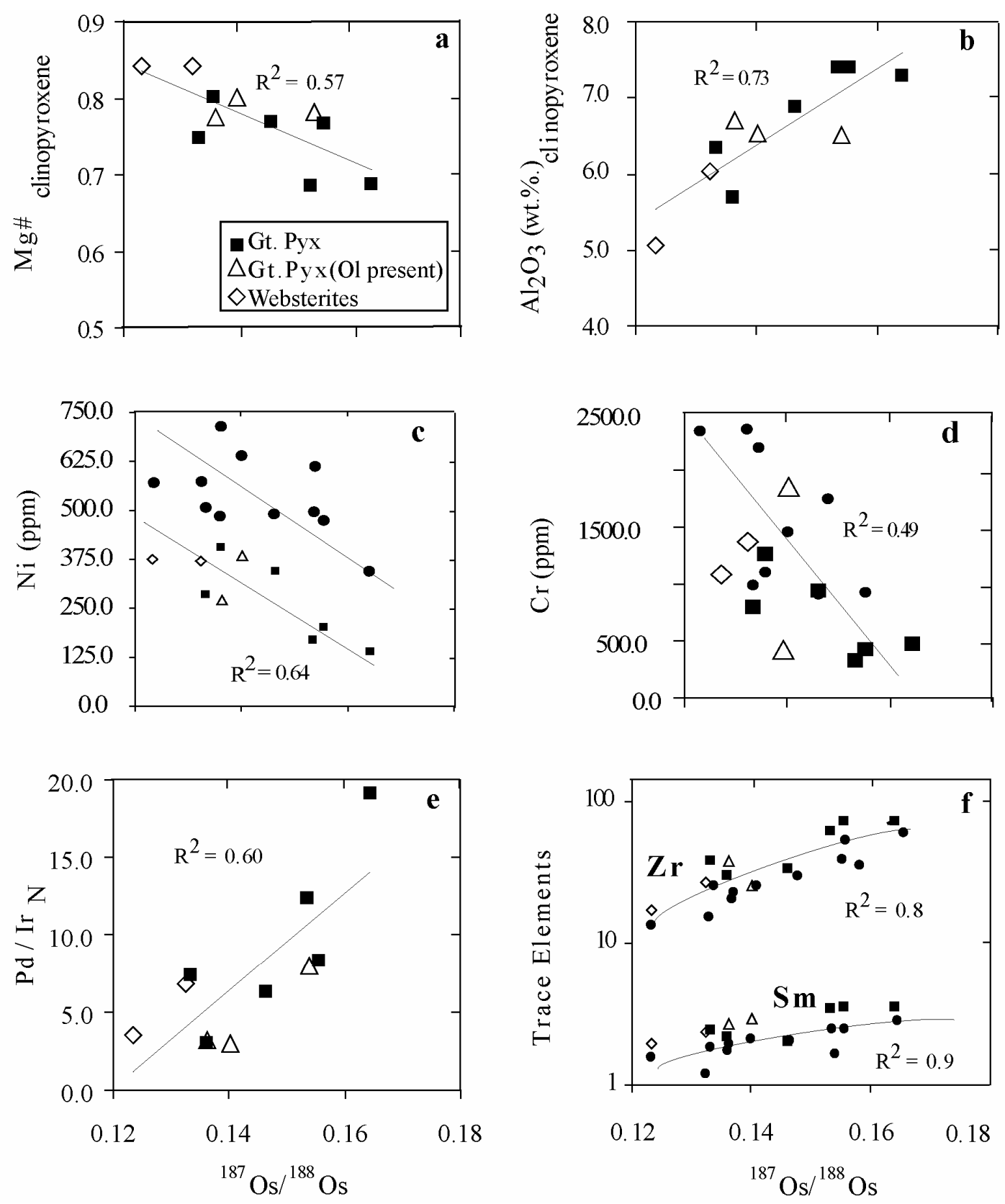

Figure 5.9 Plots of ${ }^{187} \mathrm{Os} /{ }^{188}$ Os ratio of the bulk rock vs. major and trace element content of clinopyroxenes and bulk rocks. Elemental data for clinopyroxenes are from Bizimis et al. 2005. The ${ }^{187} \mathrm{Os} /{ }^{188} \mathrm{Os}$ ratio of the bulk rock shows positive correlation with $\mathrm{Al}_{2} \mathrm{O}_{3}$, $\mathrm{Sm}$, Hf and $\mathrm{Pd} / \mathrm{Ir}$ and negative correlations with $\mathrm{Mg \#}$, $\mathrm{Ni}$ and $\mathrm{Cr}$ content of the clinopyroxene and bulk rock. The solid circles in Fig 6c-d-f and Fig e shows bulk rock data. CI normalized values from McDonough and Sun 1995. 


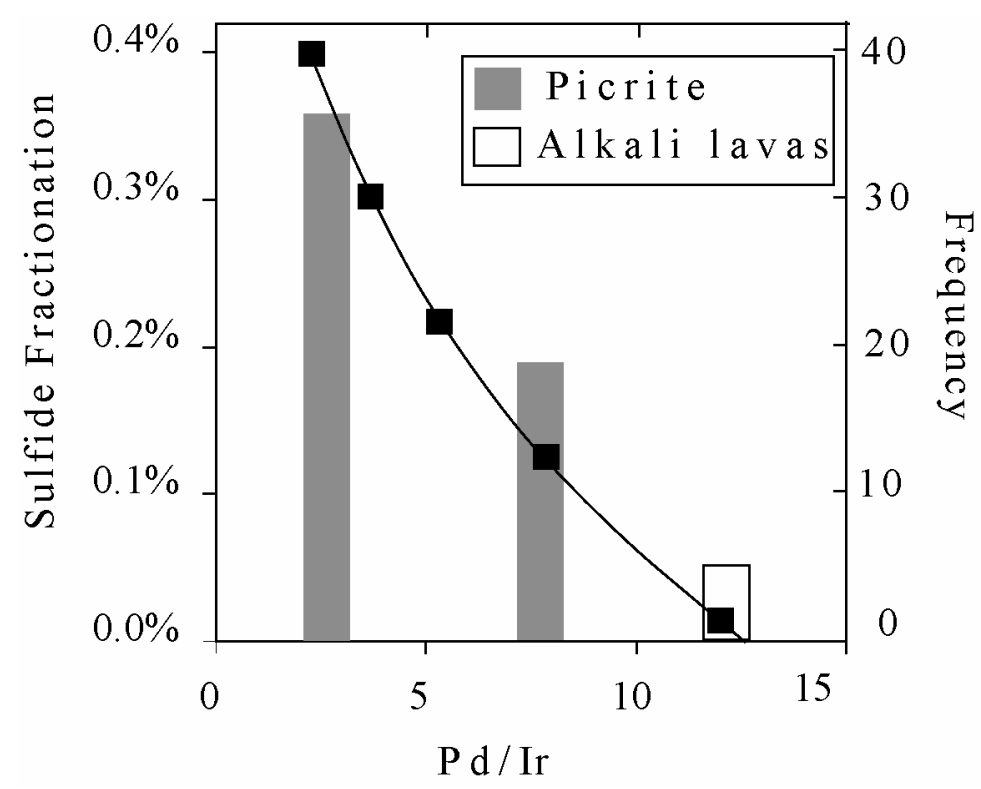

Figure 5.10 Effect of sulfide fractionation on the $\mathrm{Pd} / \mathrm{Ir}$ ratio of the silicate melt. For the starting silicate melt we used $4 \mathrm{ppb}$ of Pd and $0.25 \mathrm{ppb}$ of Ir (some of the most primitive Hawaiian picrites (Ireland et al., 2009)) and from the parental melt we fractionated sulfides using the sulfide/silicate partition coefficients of 3.2 and 5 x1000 for Ir and Pd (Fleet et al., 1999). Pd/Ir ratios of the silicate melt decreases with progressive sulfide fractionation. The rectangular bars corresponds to the right vertical axis; it represents the $\mathrm{Pd} / \mathrm{Ir}$ ratio of the Hawaiian picrites (Ireland et al., 2009) and post shield stage alkalic lavas (Crocket, 2002) The Pd/Ir ratio in the pyroxenites varies from 4-24 (see inset figure on $5.11 b)$ 

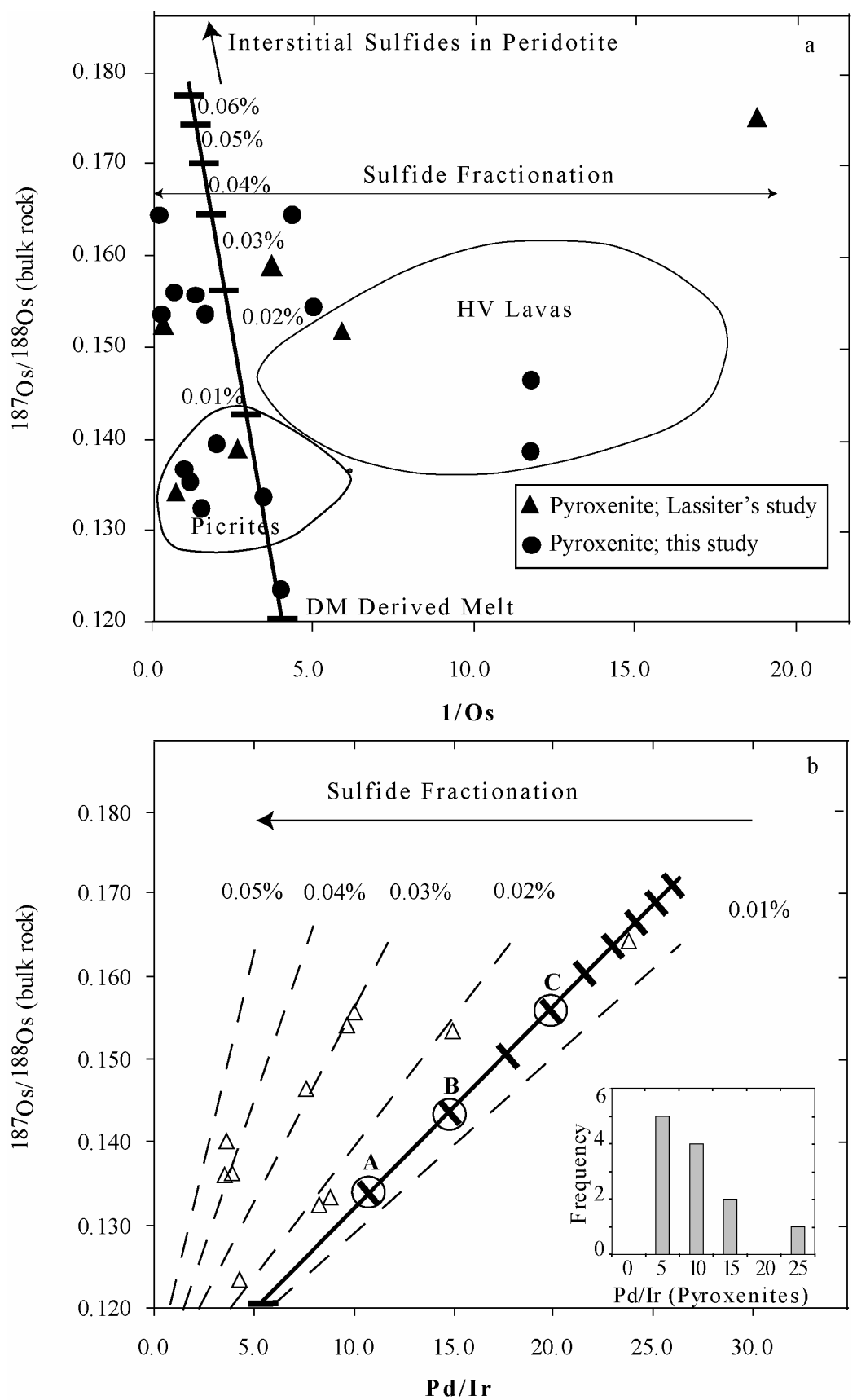

Figure 5.11 (a) Plot of $1 / \mathrm{Os}$ and $\mathrm{Pd} / \mathrm{Ir}$ ratios vs. ${ }^{187} \mathrm{Os} /{ }^{188} \mathrm{Os}$ ratios in the bulk rock pyroxenite. The solid bold line with tick marks in both the figures represent the mixing line between depleted mantle (DM) derived melt and interstitial sulfides from peridotites. Mixing parameters are as follows: depleted mantle (DM) derived melt ${ }^{187} \mathrm{Os} /{ }^{188} \mathrm{Os}=0.12$, Os $=250 \mathrm{ppt}, \mathrm{Ir}=250 \mathrm{ppt}, \mathrm{Pd}=1 \mathrm{ppb}$; Interstitial sulfides: ${ }^{187} \mathrm{Os} /{ }^{188} \mathrm{Os}=0.18, \mathrm{Os}=1$ $\mathrm{ppm}$; $\mathrm{Ir}=1 \mathrm{ppm}, \mathrm{Pd}=35 \mathrm{ppm}$ ( $\mathrm{PGE}$ and $\mathrm{Os}$ isotopic composition of interstitial sulfides are reported by Alard et al. 2000; 2002 (a) the figure shows that the pyroxenites from this study and the Lassiter et al. 2000 study plots scattered along the mixing line between the DM derived melt and interstitial sulfide within peridotite. We envision a process; 
where the percolating silicate melt is picking up radiogenic interstitial sulfides from the Pacific lithosphere.

(b) Variation of $\mathrm{Pd} / \mathrm{Ir}$ ratios in the pyroxenites as a result of sequential sulfide fractionation from the mixed melt composition. We separated out sulfides (using the same parameters as described in the Fig 10 caption) from different parental melt compositions; $\mathrm{A}(\mathrm{Pd}=2.7 \mathrm{ppb} ; \mathrm{Ir}=0.25 \mathrm{ppb}), \mathrm{B}(\mathrm{Pd}=4.5 \mathrm{ppb}, \mathrm{Ir}=0.3 \mathrm{ppb})$ and $\mathrm{C}(\mathrm{Pd}=$ $6.25 \mathrm{ppb}, \mathrm{Ir}=0.35 \mathrm{ppb}$ ) and calculated the melt composition at each step. The dashed line shows sulfide fractionation lines. Our calculation shows that the range of $\mathrm{Pd} / \mathrm{Ir}$ ratio (inset figure) and Os isotope in the bulk pyroxenite can be explained with $\sim 0.4 \%$ sulfide fractionation from a parental melt which is a mixture of DM derived melt with $0.5 \%$ interstitial sulfides in the peridotites. 


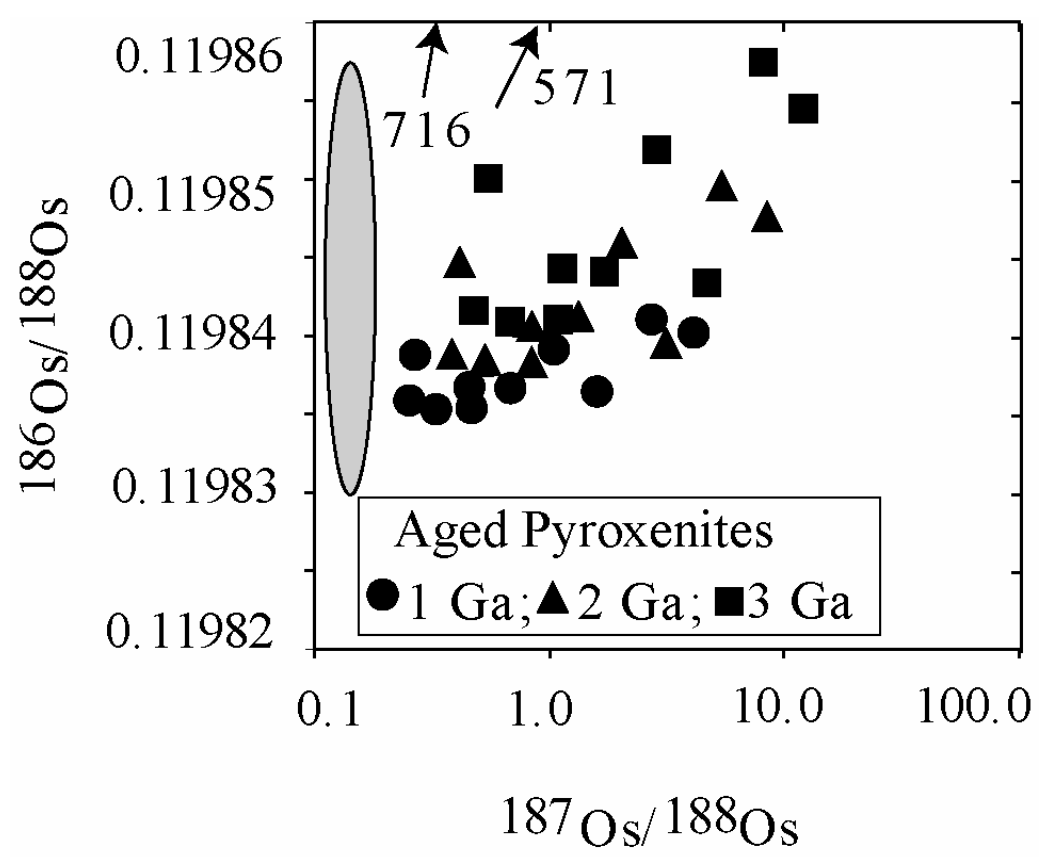

Figure 5.12 ${ }^{186} \mathrm{Os}-{ }^{187} \mathrm{Os}$ isotope systematics of 1-2-3 Ga evolved pyroxenites compared with reported high ${ }^{186} \mathrm{Os}-{ }^{187}$ Os plume derived lavas (picritic lavas and komatiites) ( Brandon et al., 1998; Brandon et al., 1999). The pyroxenites are assumed to have chondritic ${ }^{186} \mathrm{Os} /{ }^{188} \mathrm{Os}$ and ${ }^{187} \mathrm{Os} /{ }^{188} \mathrm{Os}$ ratios at $1-2-3 \mathrm{Ga}$ ago, calculated using present day ${ }^{186} \mathrm{Os} /{ }^{188} \mathrm{Os}=0.119834 ;{ }^{187} \mathrm{Os} /{ }^{188} \mathrm{Os}=0.127$, chondritic ${ }^{190} \mathrm{Pt} /{ }^{188} \mathrm{Os}=0.001692$; ${ }^{187} \mathrm{Re}^{188} \mathrm{Os}=0.40186$, and decay constants $\lambda^{190} \mathrm{Pt}=1.417 \times 10^{-12} /$ year and $\lambda^{187} \mathrm{Re}=$ $1.67 \times 10^{-11}$ /year (Brandon and Walker, 2005). The pyroxenites are then evolved to present day using the measured $\mathrm{Pt} / \mathrm{Os}$ and $\mathrm{Re} / \mathrm{Os}$ ratios. My calculations show that these pyroxenites will develop radiogenic ${ }^{186} \mathrm{Os}-{ }^{187} \mathrm{Os}$ compositions but at much shallower slope (exception SL-716) than observed in Hawaiian lavas and komatiites. 


\section{CHAPTER 6}

\section{PLUME DYNAMICS: SUMMARY AND CONCLUSIONS}

Chapter 2 of this dissertation pointed out that there were two principal questions I wished to address with this study: (1) whether or not the Hawaiian plume shows any geochemical signal of receiving materials from the Earth's Outer Core, and (2) how the plume interacts with the lithosphere. In contrast to many previous studies of Hawaiian lavas, I primarily focused on the sulfides that occur in the deep-seated garnet pyroxenite xenoliths and analyzed their platinum group element (PGE) concentrations and also the bulk rock Os isotope compositions of the xenoliths that host the sulfides. Here I summarize my observations on the sulfides:

\section{SUMMARY OF OBSERVATIONS}

1. Sulfides in Hawaiian garnet pyroxenite xenoliths compositionally belong to the monosulfide solid solution or MSS variety. Their composition range is as follows: $\mathrm{Fe}=55-57 \%, \mathrm{Ni}=3-10 \%, \mathrm{Cu}=0.5-2.0 \%, \mathrm{~S}=35-37 \%$ and $\mathrm{Zn}=0.01-0.5 \%$.

2. Petrographically, the sulfides are of two types - Type I occurs as globular, poikilitic inclusions only in clinopyroxenes, and Type II occurs interstitially between silicate phases. There is no chemical difference between the two types.

3. Hawaiian xenolith sulfides have a factor of 10 to 1000 lower PGE contents than those (e.g. Os $\sim 1$ to $<0.01 \mathrm{ppm}$ ) found in peridotites from elsewhere in the world.

4. Hawaiian sulfides show fractionated PGE patterns $\left(\mathrm{Pd}{ }_{(\mathrm{n})} / \mathrm{Ir}_{(\mathrm{n})} \sim 1-35\right)$ and very high $\operatorname{Re}_{(\mathrm{n})} / \mathrm{Os}_{(\mathrm{n})}$ ratios $(\sim 10-400)$.

5. They originated as immiscible liquids whose separation from the host silicate melts occurred at $1530 \pm 100^{\circ} \mathrm{C}$ and $3.1 \pm 0.6 \mathrm{GPa}$. 
6. Mineral/melt partition calculations suggest that the parental silicate melts (prior to immiscibility) were similar to the Honolulu Volcanics (HV) alkali lavas that host the xenoliths, and that limited $(0.1-0.3 \%)$ sulfide fractionation from a parental HV-type melt can account for the observed HSE variability in the sulfides.

7. Sulfides are the major carrier of PGEs in the bulk rock.

\section{"Leaky" Outer Core Hypothesis}

The relatively low $\mathrm{Pt} / \mathrm{Re}$ ratios of the Hawaiian sulfides and the bulk rock pyroxenites suggest that, upon "ageing", such sulfides and the pyroxenites cannot generate the coupled ${ }^{186} \mathrm{Oss}^{187}$ Os isotope enrichments observed in Hawaiian lavas. Therefore, recycling of mantle sulfides of pyroxenitic parentage is unlikely to explain the enriched Pt-Re-Os isotope systematics of plume-derived lavas. Therefore, the hypothesis that Os enrichment in the Hawaiian shield lavas owes its origin to mass contributions from a "leaky" Outer Core is supported. This, in turn, supports the hypothesis that the Hawaiian plume is anchored to the Core-Mantle Boundary layer (Helmberger et al., 1998; Russell et al., 1998; Bijwaard and Spakman, 1999; Humayun et al., 2004; Montelli et al., 2004).

Plume- Lithosphere Interaction Hypothesis

Earlier study by Lassiter et al. 2000 presented an interesting observation, that is, on an ${ }^{87} \mathrm{Sr} /{ }^{86} \mathrm{Sr}$ versus ${ }^{187} \mathrm{Os} /{ }^{188} \mathrm{Os}$, the Hawaiian pyroxenites and the Honolulu Volcanics that host the mantle xenoliths, cut across the calculated mixing trends between two sources - the plume and a depleted Mid-Ocean Ridge mantle source. Lassiter et al. 2000 suggested that this was due to "in growth" of ${ }^{187}$ Os from ${ }^{188} \mathrm{Re}$. In this dissertation I showed that the pyroxenites have ${ }^{187} \mathrm{Os} /{ }^{188}$ Os ratios $(0.123-0.164)$ that correlate with bulk 
rock major and trace elements: the most radiogenic samples have the highest $\mathrm{Al}_{2} \mathrm{O}_{3}$, $\mathrm{REE}$, $\mathrm{Pd} / \mathrm{Ir}$ and lowest $\mathrm{Ni}, \mathrm{Cr}$ and $\mathrm{Mg} \#$ contents. However, bulk rock ${ }^{187} \mathrm{Os} /{ }^{188} \mathrm{Os}$ ratios do not correlate with the Hf-Nd-Sr isotope compositions of clinopyroxene, nor with bulk rock $\mathrm{Re} / \mathrm{Os}$ or $1 / \mathrm{Os}$ ratios. This observation does not support an origin of these ${ }^{187} \mathrm{Os} /{ }^{188} \mathrm{Os}$ ratios from mixtures of melts or having resulted from in-situ ${ }^{187}$ Os ingrowth: instead it suggests that PGE concentrations and Os isotope ratios reflect primary mantle processes and not secondary (e.g., metasomatism) effects.

I show here that the major element, trace element and PGE correlations are a result of fractionation of magma from primary melts with variable Os isotope ratios. I suggest that the parental melts that crystallized the pyroxenites selectively picked up radiogenic Os from the grain boundary sulfides in the Pacific lithosphere while percolating through the lithosphere. The sampled pyroxenites essentially represent crystallized melts from different stages of this melt-mantle reaction process at the base of the lithosphere. My data strongly suggest that during the melt rock reaction process, lithospheric sulfides could preferentially enter into the melts, which is quite plausible as such sulfides have $\sim 75^{\circ} \mathrm{C}$ (Bockrath et al., 2004)) lower melting temperature than the solidus temperatures of the xenoliths (Keshav et. al., 2004)

\section{Final Model}

Figure 6.1 shows a schematic model of mantle dynamics as viewed from the results and conclusions drawn from this dissertation. The Hawaiian plume originates at the CoreMantle Boundary layer and is thought to entrain materials from the Outer Core. My result supports the earlier geophysical and geochemical observation that says that the plume originates at the Core-Mantle Boundary layer (Helmberger et al., 1998; Russell et al., 
1998; Bijwaard and Spakman, 1999; Humayun et al., 2004; Montelli et al., 2004;). I also conclude that the Os enrichment in the Hawaiian shield lavas owes its origin to mass contributions from a "leaky" Outer Core. The plume-derived melt that crystallized the pyroxenites selectively picked up radiogenic Os from the grain boundary sulfides in the Pacific lithosphere while percolating through the lithosphere prior to crystallization. I conclude that sulfides can be preferentially mobilized during the melt-rock reaction. This process can explain the reason for which Os is decoupled from other lithophile element isotopic systems in the oceanic mantle. 


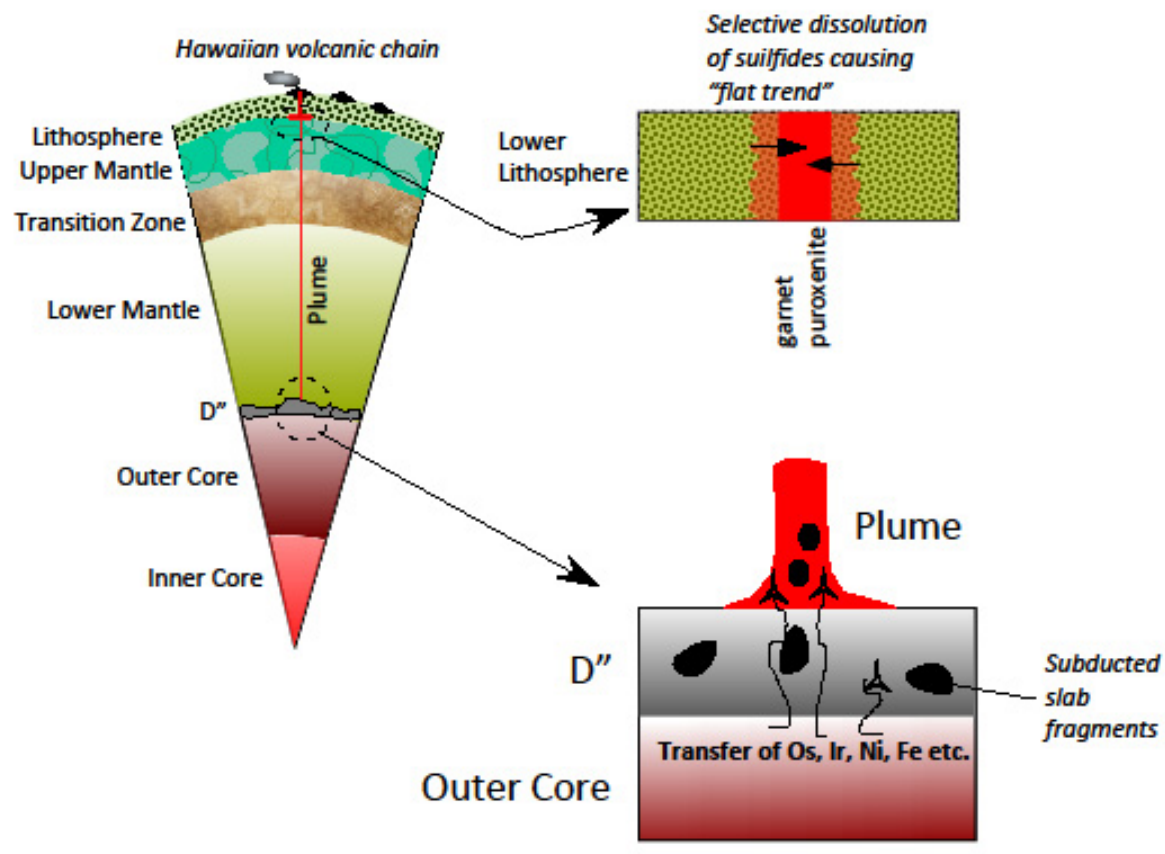

Figure 6.1 Final Model - Hawaiian plume originates at the Core-Mantle Boundary layers and while passing through the lithosphere it selectively picks up radiogenic grain boundary Osmium from the lithosphere. 


\section{LIST OF REFERENCES}

Acken, D.V., Becker, H., Walker, R.J, McDonough, W.F., Wombacher, F., Ash, R.D. and Piccoli, P.H., 2010. Formation of pyroxenite layers in the Totalp ultramafic massif (Swiss Alps) - Insights from highly siderophile elements and Os isotopes. Geochimica et Cosmochimica Acta, 74(2): 661-683.

Ackerman, L., Walker, R.J., Puchtel, I.S., Pitcher, L., Jelinek, E., Strnad, L., 2009. Effects of melt percolation on highly siderophile elements and Os isotopes in subcontinental lithospheric mantle; a study of the upper mantle profile beneath Central Europe. Geochimica et Cosmochimica Acta, 73(8): 2400-2414.

Alard, O., Griffin, W.L., Lorand, J.-P., Jackson, S.E. and O'Reilly, S.Y., 2000. Nonchondritic distribution of the highly siderophile elements in mantle sulphides. Nature, 407(6806): 891-894.

Alard, O., Griffin, W.L., Pearson, N.J., Lorand, J.-P. and O'Reilly, S.Y., 2002. New insights into the Re-Os systematics of sub-continental lithospheric mantle from in situ analysis of sulphides. Earth and Planetary Science Letters, 203(2): 651-663.

Alard, O., Luguet, A., Griffin, W.L., Lorand, J.P., Gunnoun, A., Burton, K.W. and O'Reilly, S.Y., 2005. In situ Os isotopes in abyssal peridotites bridge the isotopic gap between MORBs and their source mantle. Nature, 436(7053): 1005-1008.

Ballhaus, C., Bockrath, C., Wohlgemuth-Ueberwasser, C., Laurenz, V. and Berndt, J., 2006. Fractionation of the noble metals by physical processes. Contributions to Mineralogy and Petrology, 152(6): 667-684.

Baker, J.A. and Jensen, K.K., 2004. Coupled ${ }^{186}$ Os- ${ }^{187}$ Os enrichments in the Earth's mantle-core-mantle interaction or recycling of ferromanganese crusts and nodules? Earth and Planetary Science Letters, 220: 277-286.

Becker, H., Horan, M.F., Walker, R.J., Gao, S., Lorand, J.P. and Rudnick, R.J. 2006. Highly siderophile element composition of the Earth's primitive upper mantle; constraints from new data on peridotite massifs and xenoliths. Geochimica et Cosmochimica Acta, 70(17): 4528-4550.

Bennett, V.C., Norman, M.D. and Garcia, M.O., 2000. Rhenium and platinum group element abundances correlated with mantle source components in Hawaiian picrites; sulphides in the plume. Earth and Planetary Science Letters, 183(3-4): 513-526.

Bijwaard, H. and Spakman, W., 1999. Tomographic evidence for a narrow whole mantle plume below Iceland. Earth and Planetary Science Letters, 166(3-4): 121-126. 
Birck, J.L., Roy-Barman, M. and Capmas, M., 1997. Re-Os isotopic measurements at the femtomole level in natural samples. Geostand. Newsl., 21: 19-27.

Bizimis, M., Griselin, M., Lassiter, J.C., Salters, V.J.M. and Sen, G., 2007. Ancient recycled mantle lithosphere in the Hawaiian Plume; osmium-hafnium isotopic evidence from peridotite mantle xenoliths. Earth and Planetary Science Letters, 257(1-2): 259-273.

Bizimis, M., Sen, G. and Salters, V.J.M., 2004. Hf-Nd isotope decoupling in the oceanic lithosphere; constraints from spinel peridotites from Oahu, Hawaii. Earth and Planetary Science Letters, 217(1-2): 43-58.

Bizimis, M., Sen, G., Salters, V.J.M. and Keshav, S., 2005. Hf-Nd-Sr isotope systematics of garnet pyroxenites from Salt Lake Crater, Oahu, Hawaii; evidence for a depleted component in Hawaiian volcanism. Geochimica et Cosmochimica Acta, 69(10): 2629-2646.

Bock, G., 1991a. Long-period S to P converted waves and the onset of partial melting beneath Oahu, Hawaii. Geophysical Research Letters, 18(5): 869-872.

Bock, G., 1991b. Long - period S to P converted waves and the onset of partilal melting beneath Oahu, Hawaii. Geophysical Research Letters, 18(5): 869-872.

Bockrath, C., Ballhaus, C. and Holzheid, A., 2004. Fractionation of the platinum-group elements during mantle melting. Science, 305(5692): 1951-1953.

Brandon, A.D., Norman, M.D., Walker, R.J. and Morgan, J.W., 1999. (super 186) Os(super 187) Os systematics of Hawaiian picrites. Earth and Planetary Science Letters, 174(1-2): 25-42.

Brandon, A.D., Snow, J.E., Walker, R.J., Morgan, J.W. and Mock, T.D., 2000. (super 190) Pt- (super 186) Os and (super 187) Re- (super 187) Os systematics of abyssal peridotites. Earth and Planetary Science Letters, 177(3-4): 319-335.

Brandon, A.D. and Walker, R.J., 2005. The debate over core-mantle interaction. Earth and Planetary Science Letters, 232(3-4): 211-225.

Brandon, A.D., Walker, R.J., Morgan, J.W., Norman, M.D. and Prichard, H.M., 1998. Coupled (super 186) Os and (super 187) Os evidence for core-mantle interaction. Science, 280(5369): 1570-1573. 
Brandon, A.D., Walker, I.S., Puchtel, I.S., Becker, H., Humayun, M., and Revillion, S., 2003. (super 186) Os- (super 187) Os systematics of Gorgona Island komatiites; implications for early growth of the inner core. Earth and Planetary Science Letters, 206(3-4): 411-426.

Brenan, J.M., Haider, N. and Andrews, D., 2008. Experimental Evaluation of liquid immiscibility in a portion of the system $\mathrm{Fe}-\mathrm{Ni}-\mathrm{Cu}-\mathrm{S}$ using high gravitational acceleration. Economic Geology, 103: 1563-1570.

Bryce, J.G., DePaolo, D.J. and Lassiter, J.C., 2005. Geochemical structure of the Hawaiian plume; $\mathrm{Sr}, \mathrm{Nd}$, and Os isotopes in the $2.8 \mathrm{~km}$ HSDP-2 section of Mauna Kea volcano. Geochem. Geophys. Geosyst., 6, Q09G18, doi:10.1029/2004GC000809.

Campbell, J.A., Humayun, M. and Weisberg, K.M., 2002. Siderophile element constraints on the formation of metal in the metal-rich chondrites Bencubbin, Weatherford, and Gujba. Geochimica et Cosmochimica Acta, 66(4): 647-660.

Clague, D., 1987. Hawaiian alkaline volcanism, in: J.G Fiton and B.G.J Upton (Eds), Alkaline Igneous Rocks. Geological Society Special Publication 30: 227-252.

Clague, D.A. and Frey, F.A., 1982. Petrology and trace element geochemistry of the Honolulu Volcanics, Oahu; implications for the oceanic mantle below Hawaii. Journal of Petrology, 23(3): 447-504.

Class, C. and Goldstein, S.L., 1997. Plume-lithosphere interactions in the ocean basins; constraints from the source mineralogy. Earth and Planetary Science Letters, 150(3-4): 245-260.

Collins, J., Vernon, F., Orcutt, J. and Stephen, R., 2002. Upper mantle structure beneath the Hawaiian swell: constraints from the OSNPE. Geophysical Research Letters, 29: 171-174.

Constable, S.C. and Heinson, G.S., 2005. Magnetotelluric sounding of the Hawaiian hotspot swell. Tectonophysics, 389: 111-124.

Cook, D.L., Walker, R.J., Horan, M.F., Wasson, J.T. and Morgan, J.W., 2004. Pt-Re-Os systematics of group IIAB and IIIAB meteorites. Geochimica et Cosmochimica Acta, 68: 1413-1431.

Crocket, J.H., 2002. Platinum-group elements in basalts from Maui, Hawai'i; low abundances in alkali basalts. The Canadian Mineralogist, 40(2): 595-610. 
Crocket, J.H., Fleet, M.E. and Stone, W.E., 1997. Implications of composition for experimental partitioning of platinum-group elements and gold between sulfide liquid and basalt melt; the significance of nickel content. Geochimica et Cosmochimica Acta, 61(19): 4139-4149.

Davis, A.S. and Clague, D., 2006. Volcaniclastic deposits from the North Arch volcanic field, Hawaii: explosive fragmentation of alkalic lava at abyssal depths. Bulletin of Volcanology, 68(3): 294-307.

De Waal, S.A. and Calk, L.C., 1975. The sulfides in the garnet pyroxenite xenoliths from Salt Lake Crater, Oahu. Journal of Petrology, 16(1): 134-153.

Deines, P. and Harris, J.W., 1995. Sulfide inclusion chemistry and carbon isotopes of African diamonds. Geochimica et Cosmochimica Acta, 59(15): 3173-3188.

Dixon, J.E., Clague, D., Wallace, P. and Poreda, R., 1997. Volatiles in Alkalic Basalts form the North Arch Volcanic Field, Hawaii: Extensive Degassing of Deep Submarine-erupted Alkalic Series Lavas. Journal of Petrology 38(7): 911-939.

Ellam, R.M., Carlson, R.W. and Shirey, S.B., 1992. Evidence from Re-Os isotopes for plume-lithosphere mixing in Karoo flood basalt genesis. Nature, 359(6397): 718721.

Fleet, M.E., Crocket, J.H., Liu, M. and Stone, W.E., 1999. Laboratory partitioning of platinum-group elements (PGE) and gold with application to magmatic sulfidePGE deposits. Lithos, 47(1-2): 127-142.

Frey, F.A., 1980. The origin of pyroxenites and garnet pyroxenites from Salt Crater, Oahu, Hawaii; trace element evidence. American Journal of Science, Vol. 280A(Part 2): 427-449.

Green, D.H., 1966. The origin of the "eclogites" from Salt Lake Crater, Hawaii. Earth and Planetary Science Letters 1(6): 414-420

Griffin, W.L., Graham, S., O'Reilly, S.Y. and Pearson, N.J., 2004. Lithosphere evolution beneath the Kaapvaal Craton; Re-Os systematics of sulfides in mantle-derived peridotites. Chemical Geology, 208(1-4): 89-118.

Griffin, W.L., Spetsius, Z.V., Pearson, N.J. and O'Reilly, S.Y., 2002. In situ Re-Os analysis of sulfide inclusions in kimberlitic olivine; new constraints on depletion events in the Siberian lithospheric mantle. Geochemistry, Geophysics, Geosystems - G (super 3), 3: no.11, 25. 
Guo, J., Griffin, W.M. and Y., O.R.S., 1999. Geochemistry and origin of sulfide minerals in mantle xenoliths: Qilin, southeastern China. Journal of Petrology, 40(7): 11251149.

Hart, S.R. and Gaetani, G.A., 2006. Mantle Pb paradoxes; the sulfide solution. Contributions to Mineralogy and Petrology, 152(3): 295-308.

Hart, S.R. and Ravizza, G.E., 1996. Reading the istopic code (eds Basu, A \& Hart, S.R). American Geophysical Union, Washington DC: 123-134.

Harvey, J., Ganoun, A., Burton, K.W., Roger, N.W., Alard, O. and Parkinson, I.J., 2006. Ancient melt extraction from the oceanic upper mantle revealed by Re-Os isotopes in abyssal peridotites from the Mid-Atlantic Ridge. Earth and Planetary Science Letters, 244(3-4): 606-621.

Hauri, E.H. and Kurz, M.D., 1997. Melt migration and mantle chromatography; 2, A time-series Os isotope study of Mauna Loa Volcano, Hawaii. Earth and Planetary Science Letters, 153(1-2): 21-36.

Helmberger, D.V., Wen, L. and Ding, X., 1998. Seismic evidence that the source of the Iceland hotspot lies at the core-mantle boundary. Nature, 396(6708): 251-255.

Hofmann, A.W., 1997. Mantle Geochemistry: the message from oceanic volcanism. Nature, 385: 219-229.

Huang, S. and Frey, F.A., 2003. Trace element abundances of Mauna Kea basalts from Phase 2 of the Hawaii Scientific Drilling Project; petrogenetic implications of correlations with major element content and isotopic ratios. Geochem. Geophys. Geosyst., 4(6), 8711, doi:10.1029/2002GC000322. .

Humayun, M., Qin, L. and Norman, M.D., 2004. Geochemical evidence for excess iron in the mantle beneath Hawaii. Science, 306(5693): 91-94.

Ireland, T.J., Walker, R.J. and Garcia, M.O., 2009. Highly siderophile element and 187Os isotope systematics of Hawaiian picrites: Implications for parental melt composition and source heterogeneity Chemical Geology, 260: 112-128.

Jackson, E.D. and Wright, T.L., 1970. Xenoliths in the Honolulu volcanic series, Hawaii. Journal of Petrology, 11(2): 405-430.

Jamais, M., Lassiter, J.C. and Bruegmann, G., 2008. PGE and Os isotopic variations in lavas from Kohala Volcano, Hawaii; constraints on PGE behavior and melt/crust interaction. Chemical Geology, 250(1-4): 16-28. 
Jochum, K.P. and Nehring, F., (Max-Plank- Institute fuer Chemie) 2006. USGS BHVO2: GeoReM preferred values (11/2006). GeoReM (http://georem.mpchmainz.gwdg.de).

Jochum, K.P., Nehring, F. and Stoll, B., (Max-Plank-Institut fuer Chemie, 2006. BIR-1: GeoReM preferred values (11/2006). GeoReM (http://georem.mpchmainz.gwdg.de).

Jochum, K.P. and Stoll, B., 2008. Reference materials for elemental and isotopic analyses by LA-(MC)-ICP-MS: Success and outstanding needs. Minerological Association of Canada Short Course 40, Vancouver, B.C: 147-168.

Keshav, S., Gudfinnsson, G.H., Sen, G. and Fei, Y., 2004. High-pressure melting experiments on garnet clinopyroxenite and the alkalic to tholeiitic transition in ocean-island basalts. Earth and Planetary Science Letters, 223(3-4): 365-379.

Keshav, S. and Sen, G., 2001. Majoritic garnets in Hawaiian xenoliths; preliminary results. Geophysical Research Letters, 28(18): 3509-3512.

Keshav, S., Sen, G. and Presnall, D.C., 2007. Garnet-bearing xenoliths from salt lake crater, Oahu, Hawii; high-pressure fractional crystallization in the oceanic mantle. Journal of Petrology, 48(8): 1681-1724.

Kullerud, G., Yund, R.A. and Moh, G.H., 1969. Phase relations in the Cu-Fe-S, Cu-Ni-S, and Fe-Ni-S systems. Economic Geology Monograph 4: 323-343.

Kumar, N., Reisberg, L. and Zindler, A., 1996. A major and trace element and strontium, neodymium, and osmium isotopic study of a thick pyroxenite layer from the Beni Bousera ultramafic complex of northern Morocco. Geochimica et Cosmochimica Acta, 60(8): 1429-1444.

Laske, G., Orcutt, J.A., Phipps Morgan, J. and Anonymous, 2000. Imaging the Hawaiian swell using ocean bottom instruments. Seismological Research Letters, 71(2): 215.

Lassiter, J.C., 2003. Rhenium volatility in subaerial lavas; constraints from subaerial and submarine portions of the HSDP-2 Mauna Kea drillcore. Earth and Planetary Science Letters, 214(1-2): 311-325.

Lassiter, J.C. and Hauri, E.H., 1998. Osmium-isotope variations in Hawaiian lavas; evidence for recycled oceanic lithosphere in the Hawaiian Plume. Earth and Planetary Science Letters, 164(3-4): 483-496. 
Lassiter, J.C., Hauri, E.H., Reiners, P.W. and Garcia, M.O., 2000. Generation of Hawaiian post-erosional lavas by melting of a mixed lherzolite/pyroxenite source. Earth and Planetary Science Letters, 178(3-4): 269-284.

Lauer, H.V., and Jones, J.H., 1998. Partitioning of Pt and Os between solid-liquid metal in the Fe-Ni-S system, Proceeding of Lunar Planetary Science Conference: $\mathrm{p}$. 1796

Li, X., Kind, R., Priestley, K., Sobolev, S.V., Tilmann, F., Yuan, X. and Weber, M. 2000. Mapping the Hawaiian plume conduit with converted seismic waves. Nature, 405: 938-941.

Li, X., Kind, R., Yuan, X., Woelbern, I. and Hanka, W., 2004. Rejuvenation of the lithosphere by the Hawaiian Plume. Nature, 427(6977): 827-829.

Liu, C.Z., Snow, J.E., Brugmann, G., Hellebrand, E. and Hofmann, A., 2009. Nonchondritic HSE budget in Earth's upper mantle evidenced by abyssal peridotites from Gakkel ridge (Arctic Ocean). Earth and Planetary Science Letters, 283: 122132.

Lorand, J.-P. and Alard, O., 2001. Platinum-group element abundances in the upper mantle; new constraints from in situ and whole-rock analyses of Massif Central xenoliths (France). Geochimica et Cosmochimica Acta, 65(16): 2789-2806.

Lorand, J.P., 1989. Sulfide petrology of spinel and garnet pyroxenite layers from mantlederived spinel lherzolite massifs of Ariege (northeastern Pyrenees, France). Journal of Petrology, 30(4): 987-1015.

Lorand, J.P., Alard, A., Luguet, A. and Keays, R.R. 2003. Sulfur and selenium systematics of the subcontinental lithospheric mantle: Inferences from the Massif Central xenolith suite (France); Geochimica et Cosmochimica Acta 67(21): 41374151.

Luguet, A., Alard, O., Lorand, J.P., Pearson, N.J., Ryan, C. and O'Reilly, S.Y., 2001. Laser-ablation microprobe (LAM)-ICPMS unravels the highly siderophile element geochemistry of the oceanic mantle. Earth and Planetary Science Letters, 189(3-4): 285-294.

Luguet, A., Lorand, J.-P. and Seyler, M., 2003. A coupled study of sulfide petrology and highly siderophile element geochemistry in abyssal peridotites from the Kane Fracture Zone (MARK area, Mid-Atlantic ridge). geochimica et Cosmochimica Acta, 67: 1553-1570. 
Luguet, A., Pearson, D.G., Nowell, G.M., Dreher, S.T., Coggon, J.A., Spetsius, Z.V. and Parman S.W., 2008. Enriched Pt-Re-Os Isotope Systematics in Plume Lavas Explained by Metasomatic Sulfides. Science, 319(5862): 453-456.

Luguet, A., Shirey, S.B., Lorand, J.-P., Horan, M.F. and Carlson, R.W., 2007. Residual platinum-group minerals from highly depleted harzburgites of the Lherz Massif (France) and their role in HSE fractionation of the mantle. Geochimica et Cosmochimica Acta, 71(12): 3082-3097.

MacLean, W.H., 1969. Liquidus phase relations in the FeS-FeO-Fe (sub 3) O (sub 4) $\mathrm{SiO}$ (sub 2) system, and their application in geology. Economic Geology and the Bulletin of the Society of Economic Geologists, 64(8): 865-884.

Maier, W.D., Barnes, S.-J. and van der Merwe, M.J., 2001. Platinum-group elements in the Pyroxenite Marker, Bushveld Complex; implications for the formation of the Main Zone. South African Journal of Geology, 104(4): 301-308.

Marske, J.P., Garcia, M.O., Pietruszka, A.J., Rhodes, J.M. and Norman, M.D., 2008. Geochemical variations during Kilauea's Pu'u 'O'o eruption reveal a fine-scale mixture of mantle heterogeneities within the Hawaiian Plume. Journal of Petrology, 49(7): 1297-1318.

Martin, C.E., Carlson, R.W., Shirey, S.B., Frey, F.A. and Chen, C.-Y., 1994. Os isotopic variation in basalts from Haleakala Volcano, Maui, Hawaii; a record of magmatic processes in oceanic mantle and crust. Earth and Planetary Science Letters, 128(34): 287-301.

Mathez, E.A., 1976. Sulfur solubility and magmatic sulfides in submarine basalt glass. Journal of Geophysical Research, 81(23, The nature of the oceanic crust): 42694276.

Mavrogenes, J.A. and O'Neill, H., 1999. The relative effects of pressure, temperature and oxygen fugacity on the solubility of sulfide in mafic magmas. Geochimica et Cosmochimica Acta 63: 1173-1180

McDonough, W.F. and Sun, S.S., 1995. The composition of the Earth. Chemical Geology, 120(3-4): 223-253.

Meisel, T., Walker, R.J., Irving, A.J. and Lorand, J.-P., 2001. Osmium isotopic compositions of mantle xenoliths; a global perspective. Geochimica et Cosmochimica Acta, 65(8): 1311-1323.

Montelli, R., Nolet, G., Dahlen, F.A., Masters, G., Engdahl, E.R. and Hung, S.H.2004. Finite-frequency tomography reveals a variety of plumes in the mantle. Science, 303(5656): 338-343. 
Morgan, W.J., 1971. Convection plumes in the lower mantle. Nature (London), 230(5288): 42-43.

Nielsen, S.G., Rehkaemper, M., Norman, M.D., Halliday, A.N. and Harrison, D., 2006. Thallium isotopic evidence for ferromanganese sediments in the mantle source of Hawaiian basalts. Nature, 439(7074): 314-317.

Niu, Y. and O'Hara, M.J., 2003. Origin of ocean island basalts: A new perspective from petrology,geochemistry, and mineral physics considerations. Journal of Geophysical Research, 108, doi:10.1029/2002JB002048.

Norman, M.D. and Garcia, M.O., 1999. Primitive magmas and source characteristics of the Hawaiian Plume; petrology and geochemistry of shield picrites. Earth and Planetary Science Letters, 168(1-2): 27-44.

Pattou, L., Lorand, J.P. and Gros, M., 1996. Non-chondritic platinum-group element ratios in the Earth's mantle. Nature, 379(6567): 712-715.

Pearson, D.G. and Nowell, G.M., 2004. Re-Os and Lu-Hf isotope constraints on the origin and age of pyroxenites from the Beni Bousera peridotite massif; implications for mixed peridotite-pyroxenite mantle sources. Journal of Petrology, 45(2): 439-455.

Pearson, D.G., Shirey, S.B., Harris, J.W. and Carlson, R.W., 1998. Sulphide inclusions in diamonds from the Koffiefontein kimberlite, S Africa; constraints on diamond ages and mantle Re-Os systematics. Earth and Planetary Science Letters, 160(34): 311-326.

Pearson, N.J., Alard, O., Griffin, W.L., Jackson, S.E. and O'Reilly, S.Y., 2002. In situ measurement of Re-Os isotopes in mantle sulfides by laser ablation multicollector-inductively coupled plasma mass spectrometry; analytical methods and preliminary results. Geochimica et Cosmochimica Acta, 66(6): 1037-1050.

Peregoedova, A., Barnes, S.-J. and Baker, D.R., 2006. An experimental study of mass transfer of platinum-group elements, gold, nickel and copper in sulfur-dominated vapor at magmatic temperatures. Chemical Geology, 30(1-2): 59-75.

Peucker-Ehrenbrink, B., Bach, W., Hart, S.R., Blusztajn, J.S. and Abbruzzese, T., 2003. Rhenium-osmium isotope systematics and platinum group element concentrations in oceanic crust from DSDP/ODP sites 504 and 417/418. Geochem. Geophys. Geosyst., 4(7), 8911, doi:10.1029/2002GC000414. 
Priestley, K. and Tilman, F., 1999. Shear-wave structure of the lithosphere above the Hawaiian hot spot from two-station Rayleigh wave phase velocity measurements. Geophysical Research Letters, 26(10): 1493-1496.

Puchtel, I.S., Brandon, A.D. and Humayun, M., 2004a. Precise Pt-Re-Os isotope systematics of the mantle from $2.7 \mathrm{Ga}$ komatiites. Earth and Planetary Science Letters, 224(1-2): 157-174.

Puchtel, I.S., Brandon, A.D., Humayun, M. and Walker, R.J., 2005a. Evidence for the early differentiation of the core from Pt-Re-Os isotope systematics of 2.8-Ga komatiites. Earth and Planetary Science Letters, 237(1-2): 118-134.

Puchtel, I.S., Brandon, A.D., Humayun, M., Walker, R.J. and Anonymous, 2005b. Pt-ReOs isotope and HSE systematics of $2.8 \mathrm{Ga}$ komatiites. Geochimica et Cosmochimica Acta, 69(10, Suppl.): 392.

Puchtel, I.S. and Humayun, M., 2000. platinum group elements in Kostomuksha komatiites and basalts: implications for oceanic crust recycling and core-mantle interaction Geochimica et Cosmochimica Acta, 64(24): 4227-4242.

Puchtel, I.S., Humayun, M., Campbell, A.J., Sproule, R.A. and Lesher, C.M., 2004b. Platinum group element geochemistry of komatiites from the Alexo and Pyke Hill areas, Ontario, Canada. Geochimica et Cosmochimica Acta, 68(6): 1361-1383.

Rehkamper, M., Halliday, A.N., Fitton, J.G., Lee, D.C., Wieneke, M. and Arndt, N.T., 1999. $\mathrm{Ir}, \mathrm{Ru}, \mathrm{Pt}$, and Pd in basalts and komatiites: new constraints for the geochemical behavior of the platinum-group elements in the mantle. Geochimica et Cosmochimica Acta 63(22): 3915-3934.

Ribe, N.M. and Christensen, U.R., 1999. The dynamical origin of Hawaiian volcanism. Earth and Planetary Science Letters, 171(4): 517-531.

Richardson, S.H., Shirey, S.B., Harris, J.W. and Carlson, R.W., 2001. Archean subduction recorded by Re-Os isotopes in eclogitic sulfide inclusions in Kimberley diamonds. Earth and Planetary Science Letters, 191(3-4): 257-266.

Righter, K., Hauri, E.H. and . 1998. Compatibilty of Rhenium in garnet during mantle melting and magma genesis. Science, 280: 1737-1741.

Roy-Barman, M., Wasserburg, G.J., Papanastassiou, D.A. and Chaussidon, M., 1998a. Osmium isotopic compositions and Re-Os concentrations in sulfide globules from basaltic glasses. Earth and Planetary Science Letters, 154(1-4): 331-347. 
Roy-Barman, M., Wasserburg, G.J., Papanastassiou, D.A. and Chaussidon, M., 1998 b. Osmium isotopic compositions and Re-Os concentrations in sulfide globules from basaltic glasses Earth and Planetary Science Letters, 154(1-4): 331-347.

Rudnick, R.L. and Walker, R.J., 2009. Interpreting ages from Re/Os isotopes in peridotites. Lithos, 112(SUPPL. 2): 1083-1095.

Russell, S.A., Lay, T. and Garnero, E.J., 1998. Seismic evidence for small-scale dynamics in the lowermost mantle at the root of the Hawaiian hotspot. Nature, 396(6708): 255-258.

Salters, V.J.M., Longhi, J.E. and Bizimis, M., 2002. Near mantle solidus trace element partitioning at pressures up to $3.4 \mathrm{GPa}$. Geochemistry, Geophysics, Geosystems G (super 3), 3: no.7, 15.

Sattari, P., Brenan, J.M., Horn, I. and McDonough, W.F., 2002. Experimental constraints on the sulfide- and chromite-silicate melt partitioning behavior of rhenium and platinum-group elements. Economic Geology and the Bulletin of the Society of Economic Geologists, 97(2): 385-398.

Schersten, A., Elliott, T., Hawkesworth, C. and Norman, M., 2004. Tungsten isotope evidence that mantle plumes contain no contribution from the Earth's core. Nature, 427(6971): 234-237.

Schiano, P., Birck, J.-L. and Allegre, C.J., 1997. Osmium-strontium-neodymium-lead isotopic covariations in mid-ocean ridge basalt glasses and the heterogeneity of the upper mantle. Earth and Planetary Science Letters, 150(3-4): 363-379.

Sen, G., 1987. Xenoliths associated with the Hawaiian hot spot. In: P.H. Nixon, Editor, Mantle Xenoliths. Wiley.: 359-375

Sen, G., 1983. A petrologic model for the constitution of the upper mantle and crust of the Koolau shield, Oahu, Hawaii, and Hawaiian magmatism: Earth and Planetary Science Letters, 62: 215-228.

Sen, G., 1988. Petrogenesis of spinel lherzolite and pyroxenite suite xenoliths from the Koolau Shield, Oahu, Hawaii; implications for petrology of the post-eruptive lithosphere beneath Oahu. Contributions to Mineralogy and Petrology, 100(1): 61-91.

Sen, G., Frey, F.A., Shimizu, N. and Leeman, W.P., 1993. Evolution of the lithosphere beneath Oahu, Hawaii: Rare earth element abundances in mantle xenoliths. Earth and Planetary Science Letters, 119: 53-69. 
Sen, G., Keshav, S., Bizimis, M., Sorensen, S.S. and Carlson, W., 2005. Hawaiian mantle xenoliths and magmas; composition and thermal character of the lithosphere. American Mineralogist, 90(5-6): 871-887.

Sen, I.S., Bizimis, M. and Sen, G., 2010. Geochemistry of Sulfides in Hawaiian Garnet Pyroxenite Xenoliths: Implications for Highly Siderophile Elements in the Oceanic Mantle. Chemical Geology 273 (2010) pp.180-192

Snow, J.E. and Reisberg, L., 1995. Os isotopic systematics of altered abyssal peridotites. Earth and Planetary Science Letters, 135: 411-421.

Sobolev, A.V., Hofmann, A.W., Sobolev, S.V. and Nikogosian, I.K., 2005. An olivinefree mantle source of Hawaiian shield basalts. Nature, 434(7033): 590-597.

Sugaki, A., and Kitakaze, A., 1998. High form of pentlandite and its thermal stability. American Minerologist 83(1-2): 133-140

Sylvester, P.J., 2008. Mineralogical Association of Canada Short Course 40, Vancouver, B.C: $67-78$.

Szabo, C.S. and Bodnar, R.J., 1995. Chemistry and origin of mantle sulfides in spinel peridotite xenoliths from alkaline basaltic lavas, Nograd-Gomor Volcanic Field, northern Hungary and southern Slovakia. Geochimica et Cosmochimica Acta, 59(19): 3917-3927.

Tatsumi, Y., Oguri, K. and Shimoda, G., 1999. The behaviour of platinum-group elements during magmatic differentiation in Hawaiian tholeiites. Geochemical Journal, 33(4): 237-247.

Walker, D., 1997. Applications of the (super 190) Pt- (super 186) Os isotope system to geochemistry and cosmochemistry. Geochimica et Cosmochimica Acta, 61(22): 4799-4807.

Walker, R.J., 2000. Core participation in mantle geochemistry, Geochimica et Cosmochimica Acta,64: 2897-2911.

Walker, R.J., Prichard, H.M., Ishiwatari, A. and Pimentel, M., 2002. The osmium isotopic composition of convecting upper mantle deduced from ophiolite chromites. Geochimica et Cosmochimica Acta, 66(2): 329-345.

Walter, M.J., 1998. Melting of Garnet Peridotite and the Origin of Komatiite and Depleted Lithosphere. Journal of Petrology 39(1): 29-60. 
Wang, K.L., O'Reilly, S.Y., Griffin, W.L., Pearson, N.J. and Zhang, M., 2009. Sulfides in mantle peridotites from Penghu Islands, Taiwan: Melt percolation, PGE fractionation, and the lithospheric evolution of the South China block. Geochimica et Cosmochimica Acta, 73: 4531-4557.

White, R.W., 1966 Ultramafic inclusions in basaltic rocks from Hawaii, Contribution to Mineralogy and Petrology, 12: 245-314

Wilson, J.T., 1963. A possible origin of the Hawaiian Islands. Canadian Journal of Physics = Journal Canadien de Physique, 41(6): 863-870.

Wilson, S.A., Ridley, W.I. and Koenig, A.E., 2002. Development of sulfide calibration standards for the laser ablation inductively-coupled plasma mass spectrometry technique. Journal of Analytical Atomic Spectrometry, 17: 406-409.

Wirth, R. and Rocholl, A., 2003. Nanocrystalline diamond from the Earth's mantle underneath Hawaii. Earth and Planetary Science Letters, 211(3-4): 357-369.

Wolfe, C.J., Solomon, S.C., Collins, J.A., Detrick, R.S., Orcutt, J.A., Bercovici, D. and Hauri, E.H., 2009. Mantle Shear-Wave Velocity Structure Beneath the Hawaiian Hot Spot. Science, 326. no. 5958: 1388-1390.

Workman, R.K., Hart, S.R., Jackson, M., Regelous, M., Farley, K.A., Blusztajn, J., Kurz, M. and Staudigel, H., 2004. Recycled metasomatized lithosphere as the origin of the Enriched Mantle II (EM2) end-member : evidence from the Samoan Volcanic Chain. Geochemistry Geophysics Geosystems, 5(4). 


\section{APPENDIX}

Supplementary Table A1 (All analysis are $1 \mu \mathrm{m}$ EPMA Analysis)

Major Element Concentrations of Included Sulfides in Clinopyroxenes

\begin{tabular}{ccccccc}
\hline Sample No: & $\mathrm{Fe}$ & $\mathrm{Ni}$ & $\mathrm{Zn}$ & $\mathrm{Cu}$ & $\mathrm{S}$ & Total \\
\hline 552_1 & 57.14 & 3.62 & 0.40 & 1.49 & 37.59 & 100.23 \\
$552 \_2$ & 57.87 & 3.07 & 0.40 & 1.20 & 37.41 & 99.94 \\
$552 \_3$ & 57.56 & 3.01 & 0.39 & 1.63 & 37.01 & 99.58 \\
$552 \_4$ & 57.88 & 3.10 & 0.41 & 1.38 & 38.20 & 100.97 \\
$552 \_5$ & 58.21 & 3.11 & 0.39 & 1.41 & 37.48 & 100.59 \\
$552 \_6$ & 56.18 & 4.86 & 0.40 & 1.51 & 37.51 & 100.45 \\
552_7 & 57.42 & 4.24 & 0.39 & 1.03 & 37.73 & 100.81 \\
Average & $\mathbf{5 7 . 4 6}$ & $\mathbf{3 . 5 7}$ & $\mathbf{0 . 4 0}$ & $\mathbf{1 . 3 8}$ & $\mathbf{3 7 . 5 6}$ & $\mathbf{1 0 0 . 3 7}$ \\
1 $\sigma$ Error & 0.67 & 0.72 & 0.01 & 0.20 & 0.36 & 0.49
\end{tabular}

$\begin{array}{ccccccc}\text { 559_1 } & 53.83 & 5.84 & 0.44 & 1.84 & 37.24 & 99.17 \\ \text { 559_2 } & 53.31 & 5.67 & 0.43 & 1.95 & 37.53 & 98.89 \\ 559 \_3 & 53.63 & 6.26 & 0.44 & 1.62 & 39.03 & 100.97 \\ \text { 559_4 } & 51.12 & 7.49 & 0.41 & 3.09 & 37.82 & 99.93 \\ \text { 559_5 } & 54.45 & 6.24 & 0.41 & 1.07 & 37.62 & 99.78 \\ \text { 559_6 } & 55.27 & 5.43 & 0.42 & 0.62 & 38.24 & 99.98 \\ \text { 559_7 } & 52.54 & 6.98 & 0.40 & 1.41 & 37.85 & 99.19 \\ \text { 559_8 } & 53.32 & 7.02 & 0.43 & 1.12 & 37.97 & 99.86 \\ \text { 559_9 } & 53.64 & 5.39 & 0.42 & 0.76 & 38.07 & 98.27 \\ \text { 559_10 } & 54.03 & 7.90 & 0.42 & 0.76 & 37.75 & 100.86 \\ \text { Average } & \mathbf{5 3 . 5 1} & \mathbf{6 . 4 2} & \mathbf{0 . 4 2} & \mathbf{1 . 4 2} & \mathbf{3 7 . 9 1} & \mathbf{9 9 . 6 9} \\ \text { 1 \% Error } & 1.11 & 0.88 & 0.01 & 0.75 & 0.48 & 0.84 \\ & & & & & & \\ \text { 590_1 } & 48.57 & 11.20 & 0.40 & 2.03 & 38.60 & 100.78 \\ \text { 590_2 } & 49.82 & 9.70 & 0.43 & 2.09 & 38.37 & 100.41 \\ \text { 590_3 } & 51.16 & 8.50 & 0.42 & 1.39 & 39.22 & 100.69 \\ \text { 590_4 } & 48.41 & 11.58 & 0.41 & 2.74 & 37.76 & 100.89 \\ \text { 590_5 } & 49.76 & 11.18 & 0.40 & 1.73 & 37.31 & 100.38 \\ \text { 590_6 } & 49.68 & 9.90 & 0.39 & 1.54 & 38.31 & 99.81 \\ \text { 590_7 } & 49.76 & 11.22 & 0.40 & 1.54 & 38.37 & 101.29 \\ \text { 590_8 } & 48.98 & 12.60 & 0.40 & 1.10 & 38.54 & 101.62 \\ \text { Average } & \mathbf{4 9 . 5 2} & \mathbf{1 0 . 7 4} & \mathbf{0 . 4 1} & \mathbf{1 . 7 7} & \mathbf{3 8 . 3 1} & \mathbf{1 0 0 . 7 8} \\ \text { 1 6 Error } & 0.87 & 1.29 & 0.01 & 0.51 & 0.57 & 0.56 \\ \text { 744_1 } & 53.15 & 8.13 & 0.04 & 0.18 & 37.60 & 99.11\end{array}$




\begin{tabular}{|c|c|c|c|c|c|c|}
\hline $744 \_2$ & 55.42 & 6.26 & 0.02 & 0.29 & 37.68 & 99.66 \\
\hline $744 \_3$ & 56.33 & 5.76 & 0.00 & 0.08 & 38.04 & 100.20 \\
\hline $744 \_4$ & 55.32 & 7.05 & 0.00 & 1.58 & 37.47 & 101.42 \\
\hline $744 \_5$ & 55.07 & 6.65 & 0.02 & 0.81 & 36.89 & 99.44 \\
\hline 744_6 & 54.74 & 8.21 & 0.02 & 0.98 & 36.17 & 100.11 \\
\hline 744_7 & 55.37 & 6.53 & 0.00 & 0.62 & 37.64 & 100.15 \\
\hline 744_8 & 56.71 & 5.60 & 0.00 & 0.58 & 37.14 & 100.03 \\
\hline 744_9 & 56.01 & 5.93 & 0.00 & 0.64 & 36.26 & 98.84 \\
\hline $744 \_10$ & 56.54 & 5.32 & 0.00 & 0.89 & 36.93 & 99.68 \\
\hline $744 \_11$ & 55.67 & 6.46 & 0.00 & 0.83 & 37.12 & 100.07 \\
\hline $744 \_12$ & 55.55 & 5.89 & 0.02 & 1.15 & 36.42 & 99.03 \\
\hline $744 \_13$ & 53.61 & 9.68 & 0.00 & 0.48 & 36.15 & 99.92 \\
\hline $744 \_14$ & 54.39 & 5.86 & 0.00 & 1.07 & 36.73 & 98.05 \\
\hline $744 \_15$ & 55.87 & 7.38 & 0.00 & 0.47 & 37.18 & 100.90 \\
\hline $744 \_16$ & 56.92 & 5.52 & 0.00 & 0.28 & 36.91 & 99.63 \\
\hline Average & 55.42 & 6.64 & 0.01 & 0.68 & 37.02 & 99.76 \\
\hline $1 \sigma$ Error & 1.06 & 1.19 & 0.01 & 0.40 & 0.58 & 0.80 \\
\hline 774_1 & 56.20 & 3.33 & 0.42 & 1.05 & 37.38 & 98.37 \\
\hline $774 \_2$ & 55.87 & 3.06 & 0.42 & 1.50 & 35.82 & 96.66 \\
\hline 774_3 & 54.75 & 3.54 & 0.42 & 1.52 & 35.66 & 95.89 \\
\hline 774_4 & 56.01 & 3.44 & 0.43 & 1.90 & 37.12 & 98.91 \\
\hline $774 \_5$ & 55.49 & 4.41 & 0.41 & 1.57 & 37.48 & 99.36 \\
\hline 774_6 & 57.68 & 3.11 & 0.42 & 1.01 & 37.29 & 99.51 \\
\hline 774_7 & 56.35 & 3.43 & 0.45 & 1.28 & 37.75 & 99.25 \\
\hline 774_8 & 56.57 & 3.29 & 0.43 & 1.23 & 36.88 & 98.41 \\
\hline Average & 56.11 & 3.45 & 0.43 & 1.38 & 36.92 & 98.29 \\
\hline $1 \sigma$ Error & 0.85 & 0.42 & 0.01 & 0.30 & 0.77 & 1.33 \\
\hline 680_1 & 53.69 & 3.66 & 0.41 & 2.19 & 39.27 & 99.22 \\
\hline $680 \_2$ & 55.31 & 4.36 & 0.39 & 1.65 & 37.80 & 99.52 \\
\hline $680 \_3$ & 54.74 & 4.44 & 0.41 & 2.61 & 37.29 & 99.48 \\
\hline $680 \_4$ & 55.03 & 3.84 & 0.42 & 2.84 & 36.39 & 98.52 \\
\hline $680 \_5$ & 53.99 & 4.66 & 0.41 & 1.39 & 36.66 & 97.11 \\
\hline 680_6 & 54.53 & 3.86 & 0.47 & 1.47 & 38.20 & 98.53 \\
\hline Average & 54.55 & 4.14 & 0.42 & 2.03 & 37.60 & 98.73 \\
\hline $1 \sigma$ Error & 0.62 & 0.40 & 0.03 & 0.61 & 1.06 & 0.91 \\
\hline $555 \_1$ & 55.60 & 6.47 & 0.01 & 0.26 & 38.01 & 100.46 \\
\hline
\end{tabular}




\begin{tabular}{|c|c|c|c|c|c|c|}
\hline $555 \_2$ & 55.71 & 7.43 & 0.01 & 0.46 & 36.48 & 100.20 \\
\hline 555_3 & 53.96 & 8.56 & 0.00 & 0.88 & 35.14 & 98.68 \\
\hline Average & 55.09 & 7.49 & 0.01 & 0.53 & 36.55 & 99.78 \\
\hline $1 \sigma$ Error & 0.98 & 1.05 & 0.01 & 0.32 & 1.43 & 0.96 \\
\hline 594_1 & 51.72 & 6.72 & 0.44 & 1.88 & 39.41 & 100.16 \\
\hline $594 \_2$ & 52.54 & 7.39 & 0.41 & 1.08 & 39.53 & 100.94 \\
\hline $594 \_3$ & 51.36 & 8.25 & 0.41 & 1.61 & 38.98 & 100.62 \\
\hline 594_4 & 46.46 & 12.41 & 0.40 & 2.82 & 38.70 & 100.79 \\
\hline 594_5 & 49.88 & 8.95 & 0.42 & 1.64 & 39.90 & 100.79 \\
\hline Average & 50.39 & 8.74 & 0.42 & 1.80 & 39.30 & 100.66 \\
\hline $1 \sigma$ Error & 2.40 & 2.22 & 0.01 & 0.64 & 0.47 & 0.30 \\
\hline 776_1 & 55.09 & 6.34 & 0.45 & 0.95 & 38.98 & 101.81 \\
\hline $776 \_2$ & 47.08 & 10.58 & 0.41 & 3.57 & 38.76 & 100.39 \\
\hline $776 \_3$ & 50.33 & 8.79 & 0.42 & 1.10 & 38.67 & 99.31 \\
\hline $776 \_4$ & 50.19 & 9.11 & 0.41 & 1.53 & 38.83 & 100.07 \\
\hline $776 \_5$ & 49.73 & 7.92 & 0.42 & 2.61 & 39.11 & 99.79 \\
\hline Average & 50.48 & 8.55 & 0.42 & 1.95 & 38.87 & 100.27 \\
\hline $1 \sigma$ Error & 2.89 & 1.56 & 0.02 & 1.11 & 0.18 & 0.95 \\
\hline 620_1 & 54.85 & 9.268 & 0.299 & 0.29 & 36.69 & 101.40 \\
\hline $620 \_2$ & 54.2 & 7.6 & 0.02 & 0.4 & 38.2 & 100.42 \\
\hline Average & 54.53 & 8.43 & 0.16 & 0.35 & 37.45 & 100.91 \\
\hline $1 \sigma$ Error & 0.46 & 1.18 & 0.20 & 0.08 & 1.07 & 0.69 \\
\hline $567 \_1$ & 54.02 & 4.56 & 0.32 & 2.52 & 36.97 & 98.38 \\
\hline $567 \_2$ & 54.12 & 5.80 & 0.30 & 1.54 & 37.15 & 98.91 \\
\hline $567 \_3$ & 55.29 & 4.73 & 0.30 & 1.31 & 36.68 & 98.31 \\
\hline $567 \_4$ & 54.91 & 4.69 & 0.29 & 1.45 & 37.02 & 98.36 \\
\hline $567 \_5$ & 54.88 & 4.86 & 0.30 & 1.51 & 37.23 & 98.77 \\
\hline 567_6 & 54.72 & 4.94 & 0.29 & 1.34 & 37.69 & 98.98 \\
\hline $567 \_7$ & 53.58 & 5.23 & 0.29 & 0.89 & 37.45 & 97.44 \\
\hline $567 \_8$ & 55.18 & 4.91 & 0.30 & 1.13 & 37.01 & 98.52 \\
\hline 567_9 & 56.06 & 4.42 & 0.31 & 0.82 & 36.89 & 98.51 \\
\hline $567 \_10$ & 54.06 & 5.93 & 0.31 & 1.01 & 37.20 & 98.50 \\
\hline $567 \_11$ & 55.18 & 4.73 & 0.32 & 1.12 & 37.48 & 98.83 \\
\hline $567 \_12$ & 54.91 & 4.96 & 0.28 & 1.84 & 36.37 & 98.36 \\
\hline $567 \_13$ & 54.12 & 5.05 & 0.32 & 2.94 & 36.93 & 99.35 \\
\hline
\end{tabular}




\begin{tabular}{|c|c|c|c|c|c|c|}
\hline $567 \_14$ & 55.09 & 4.99 & 0.30 & 1.77 & 37.08 & 99.24 \\
\hline $567 \_15$ & 54.99 & 5.07 & 0.30 & 1.35 & 37.53 & 99.24 \\
\hline $567 \_16$ & 55.50 & 4.51 & 0.30 & 1.43 & 37.41 & 99.14 \\
\hline $567 \_17$ & 55.63 & 4.56 & 0.31 & 1.42 & 37.78 & 99.70 \\
\hline Average & 54.84 & 4.94 & 0.30 & 1.49 & 37.17 & 98.74 \\
\hline $1 \sigma$ Error & 0.66 & 0.41 & 0.01 & 0.55 & 0.36 & 0.53 \\
\hline $859 \_1$ & 45.39 & 17.03 & 0.00 & 0.98 & 36.11 & 99.67 \\
\hline $859 \_2$ & 44.14 & 17.79 & 0.00 & 1.96 & 36.10 & 100.10 \\
\hline $859 \_3$ & 43.70 & 17.78 & 0.00 & 1.16 & 36.18 & 98.98 \\
\hline $859 \_4$ & 35.19 & 14.87 & 0.00 & 15.85 & 34.20 & 100.21 \\
\hline $859 \_5$ & 43.98 & 18.83 & 0.00 & 1.17 & 36.46 & 100.60 \\
\hline $859 \_6$ & 45.06 & 19.00 & 0.00 & 1.03 & 36.39 & 101.61 \\
\hline $859 \_7$ & 44.85 & 18.65 & 0.01 & 1.54 & 35.71 & 100.88 \\
\hline $859 \_8$ & 44.81 & 18.87 & 0.01 & 1.43 & 36.16 & 101.41 \\
\hline 859_9 & 44.14 & 19.81 & 0.01 & 1.34 & 36.25 & 101.70 \\
\hline 859_10 & 44.53 & 18.80 & 0.00 & 1.21 & 36.23 & 100.88 \\
\hline Average & 43.58 & 18.14 & 0.00 & 2.77 & 35.98 & 100.60 \\
\hline $1 \sigma$ Error & 2.99 & 1.39 & 0.00 & 4.61 & 0.66 & 0.88 \\
\hline
\end{tabular}




\section{Supplementary Table A2}

Major Element Concentrations of Interstitial Sulfides

All analysis are $1 \mu \mathrm{m}$ EPMA analysis

\begin{tabular}{|c|c|c|c|c|c|c|}
\hline Sample No: & $\mathrm{Fe}$ & $\mathrm{Ni}$ & $\mathrm{Zn}$ & $\mathrm{Cu}$ & $\mathrm{S}$ & Total \\
\hline $552 \_1$ & 56.04 & 3.35 & 0.41 & 1.17 & 38.33 & 99.29 \\
\hline 5522 & 56.72 & 2.71 & 0.42 & 0.55 & 38.79 & 99.19 \\
\hline 5523 & 57.86 & 2.66 & 0.42 & 0.60 & 39.02 & 100.55 \\
\hline $552 \_4$ & 56.73 & 4.18 & 0.41 & 1.50 & 37.61 & 100.43 \\
\hline $552 \_5$ & 57.29 & 3.49 & 0.43 & 1.43 & 36.98 & 99.63 \\
\hline $552 \_6$ & 57.56 & 3.07 & 0.39 & 1.22 & 37.71 & 99.95 \\
\hline $552 \_7$ & 57.56 & 3.18 & 0.38 & 1.29 & 38.25 & 100.65 \\
\hline AVERAGE & 57.11 & 3.23 & 0.41 & 1.11 & 38.10 & 99.96 \\
\hline $1 \sigma$ Error & 0.64 & 0.52 & 0.02 & 0.38 & 0.71 & 0.61 \\
\hline $559 \_1$ & 55.43 & 5.15 & 0.42 & 1.10 & 37.14 & 99.24 \\
\hline 5592 & 55.36 & 4.35 & 0.42 & 1.09 & 37.12 & 98.35 \\
\hline $559 \_3$ & 56.66 & 3.82 & 0.42 & 0.80 & 37.39 & 99.09 \\
\hline $559 \_4$ & 55.89 & 4.73 & 0.41 & 0.83 & 37.59 & 99.45 \\
\hline 5595 & 54.64 & 4.99 & 0.41 & 2.04 & 37.58 & 99.66 \\
\hline $559 \_6$ & 54.81 & 4.66 & 0.40 & 1.11 & 37.71 & 98.69 \\
\hline $559 \_7$ & 56.34 & 3.56 & 0.40 & 0.61 & 38.01 & 98.92 \\
\hline $559 \_8$ & 54.78 & 5.05 & 0.42 & 1.59 & 37.95 & 99.80 \\
\hline $559 \_9$ & 55.69 & 3.80 & 0.44 & 1.29 & 37.89 & 99.12 \\
\hline 559_10 & 55.59 & 4.11 & 0.41 & 1.10 & 37.59 & 98.80 \\
\hline 559_11 & 53.35 & 4.21 & 0.42 & 2.65 & 37.95 & 98.58 \\
\hline 559-12 & 51.13 & 6.41 & 0.40 & 2.38 & 37.95 & 98.26 \\
\hline 559_13 & 52.82 & 5.61 & 0.41 & 1.59 & 38.56 & 98.99 \\
\hline AVERAGE & 54.81 & 4.65 & 0.41 & 1.40 & 37.73 & 99.00 \\
\hline $1 \sigma$ Error & 1.55 & 0.80 & 0.01 & 0.62 & 0.39 & 0.47 \\
\hline 590_1 & 48.95 & 9.90 & 0.40 & 1.76 & 38.12 & 99.12 \\
\hline 590_2 & 49.91 & 12.12 & 0.38 & 1.11 & 36.58 & 100.09 \\
\hline $590 \_3$ & 51.20 & 10.50 & 0.41 & 1.53 & 37.24 & 100.88 \\
\hline $590 \_4$ & 51.20 & 11.63 & 0.39 & 1.58 & 35.20 & 100.00 \\
\hline $590 \_5$ & 49.50 & 8.60 & 0.40 & 2.35 & 39.81 & 100.66 \\
\hline $590 \_6$ & 47.10 & 10.19 & 0.40 & 0.73 & 40.83 & 99.25 \\
\hline AVERĀGE & 49.64 & 10.49 & 0.40 & 1.51 & 37.96 & 100.00 \\
\hline $1 \sigma$ Error & 1.54 & 1.26 & 0.01 & 0.56 & 2.08 & 0.71 \\
\hline
\end{tabular}




\begin{tabular}{|c|c|c|c|c|c|c|}
\hline 744_1 & 54.08 & 7.06 & 0.00 & 0.93 & 37.00 & 99.07 \\
\hline 744_2 & 55.53 & 6.54 & 0.00 & 0.74 & 37.36 & 100.16 \\
\hline $744 \_3$ & 55.53 & 7.04 & 0.00 & 0.70 & 37.49 & 100.75 \\
\hline 744_4 & 53.86 & 6.55 & 0.01 & 0.55 & 37.67 & 98.64 \\
\hline $744 \_5$ & 54.37 & 7.56 & 0.00 & 0.83 & 38.03 & 100.79 \\
\hline 744_6 & 55.81 & 6.14 & 0.03 & 0.69 & 37.38 & 100.05 \\
\hline 744_7 & 54.42 & 6.47 & 0.00 & 0.79 & 37.30 & 98.97 \\
\hline $744 \_8$ & 55.03 & 7.61 & 0.01 & 0.74 & 37.40 & 100.79 \\
\hline 744_9 & 55.28 & 7.59 & 0.00 & 0.90 & 37.06 & 100.83 \\
\hline $744 \_10$ & 55.22 & 6.31 & 0.00 & 0.71 & 36.95 & 99.18 \\
\hline 744_11 & 54.92 & 7.19 & 0.00 & 0.93 & 37.01 & 100.04 \\
\hline $744 \_12$ & 54.42 & 7.43 & 0.00 & 1.20 & 36.77 & 99.81 \\
\hline $744 \_13$ & 54.95 & 6.25 & 0.00 & 1.00 & 37.02 & 99.22 \\
\hline $744 \_14$ & 55.01 & 4.73 & 0.02 & 0.29 & 37.07 & 97.11 \\
\hline $744 \_15$ & 49.85 & 5.95 & 0.00 & 0.48 & 36.76 & 93.05 \\
\hline $744 \_16$ & 51.04 & 6.62 & 0.00 & 0.44 & 31.73 & 89.83 \\
\hline $744 \_17$ & 54.04 & 8.15 & 0.00 & 1.30 & 36.00 & 99.49 \\
\hline $744 \_18$ & 56.47 & 8.04 & 0.05 & 0.21 & 37.40 & 102.16 \\
\hline $744 \_19$ & 56.03 & 6.32 & 0.00 & 0.52 & 37.00 & 99.86 \\
\hline 744_20 & 55.71 & 7.89 & 0.00 & 0.60 & 36.91 & 101.10 \\
\hline $744 \_21$ & 54.65 & 7.29 & 0.00 & 0.86 & 37.04 & 99.85 \\
\hline 744_22 & 55.43 & 7.37 & 0.00 & 1.20 & 36.87 & 100.86 \\
\hline 744_23 & 54.73 & 6.00 & 0.01 & 0.52 & 36.72 & 97.98 \\
\hline 744_24 & 54.81 & 6.43 & 0.03 & 1.23 & 33.09 & 95.59 \\
\hline 744_25 & 55.78 & 5.67 & 0.00 & 0.64 & 37.15 & 99.24 \\
\hline $744 \_26$ & 55.89 & 6.13 & 0.01 & 0.74 & 37.30 & 100.07 \\
\hline $744 \_27$ & 55.77 & 6.96 & 0.01 & 0.51 & 36.89 & 100.14 \\
\hline AVERAGE & 54.76 & 6.79 & 0.01 & 0.75 & 36.75 & 99.06 \\
\hline $1 \sigma$ Error & 1.42 & 0.80 & 0.01 & 0.28 & 1.32 & 2.59 \\
\hline 774_1 & 57.16 & 3.10 & 0.42 & 1.22 & 38.59 & 100.52 \\
\hline 774_2 & 57.58 & 2.93 & 0.43 & 0.95 & 38.82 & 100.71 \\
\hline 774_3 & 56.99 & 3.82 & 0.42 & 0.78 & 37.29 & 98.30 \\
\hline 774_4 & 53.40 & 3.92 & 0.42 & 1.15 & 37.86 & 98.66 \\
\hline $774 \_5$ & 54.20 & 3.80 & 0.41 & 1.15 & 37.89 & 99.33 \\
\hline 774_6 & 57.33 & 3.70 & 0.43 & 0.99 & 37.86 & 99.31 \\
\hline 774_7 & 57.22 & 3.60 & 0.40 & 0.82 & 37.52 & 98.55 \\
\hline 774_8 & 55.03 & 3.31 & 0.41 & 1.79 & 38.00 & 98.53 \\
\hline
\end{tabular}




\begin{tabular}{|c|c|c|c|c|c|c|}
\hline AVERAGE & 56.11 & 3.52 & 0.42 & 1.11 & 37.98 & 99.24 \\
\hline $1 \sigma$ Error & 1.64 & 0.37 & 0.01 & 0.32 & 0.51 & 0.93 \\
\hline $680 \_1$ & 58.00 & 4.17 & 0.41 & 1.60 & 36.24 & 100.42 \\
\hline $680 \_2$ & 58.32 & 3.81 & 0.40 & 1.36 & 37.04 & 100.91 \\
\hline $680 \_3$ & 57.48 & 4.14 & 0.40 & 1.44 & 36.88 & 100.35 \\
\hline $680 \_4$ & 56.81 & 4.37 & 0.42 & 1.58 & 37.15 & 100.34 \\
\hline $680 \_5$ & 57.79 & 3.91 & 0.39 & 1.23 & 37.15 & 100.47 \\
\hline 680_6 & 57.31 & 4.06 & 0.41 & 1.63 & 37.09 & 100.50 \\
\hline $680 \_7$ & 56.42 & 4.50 & 0.39 & 1.88 & 37.52 & 100.71 \\
\hline $680 \_8$ & 56.72 & 4.25 & 0.39 & 1.83 & 36.59 & 99.79 \\
\hline 680_9 & 57.49 & 3.71 & 0.42 & 1.45 & 37.43 & 100.50 \\
\hline $680 \_10$ & 56.37 & 4.22 & 0.40 & 1.73 & 37.48 & 100.20 \\
\hline $680 \_11$ & 57.47 & 4.07 & 0.40 & 1.27 & 36.89 & 100.09 \\
\hline AVERAGE & 57.29 & 4.11 & 0.40 & 1.55 & 37.04 & 100.39 \\
\hline $1 \sigma$ Error & 0.64 & 0.23 & 0.01 & 0.22 & 0.39 & 0.30 \\
\hline $555 \_1$ & 52.75 & 9.45 & 0.05 & 0.63 & 36.77 & 99.75 \\
\hline 555_2 & 53.31 & 8.28 & 0.00 & 0.63 & 36.50 & 98.86 \\
\hline AVERAGE & 53.03 & 8.86 & 0.02 & 0.63 & 36.63 & 99.31 \\
\hline $1 \sigma$ Error & 0.40 & 0.83 & 0.03 & 0.00 & 0.19 & 0.63 \\
\hline 594_1 & 54.11 & 8.54 & 0.43 & 1.24 & 36.20 & 100.51 \\
\hline 594_2 & 55.41 & 7.67 & 0.40 & 0.94 & 36.67 & 101.09 \\
\hline 594_3 & 53.20 & 6.71 & 0.40 & 1.82 & 36.93 & 99.06 \\
\hline 594_4 & 52.07 & 9.24 & 0.41 & 1.47 & 37.28 & 100.48 \\
\hline 594_5 & 53.53 & 8.46 & 0.42 & 1.20 & 36.45 & 100.05 \\
\hline 594_6 & 52.12 & 6.73 & 0.43 & 3.49 & 37.72 & 100.50 \\
\hline $594 \_7$ & 51.72 & 7.56 & 0.43 & 2.74 & 37.46 & 99.91 \\
\hline AVERAGE & 53.17 & 7.84 & 0.42 & 1.84 & 36.96 & 100.23 \\
\hline $1 \sigma$ Error & 1.32 & 0.95 & 0.01 & 0.94 & 0.56 & 0.64 \\
\hline $776 \_1$ & 53.72 & 7.70 & 0.42 & 0.50 & 37.90 & 100.25 \\
\hline $776 \_2$ & 54.38 & 8.35 & 0.40 & 0.80 & 36.43 & 100.36 \\
\hline $776 \_3$ & 54.78 & 6.61 & 0.42 & 0.72 & 38.95 & 101.48 \\
\hline $776 \_4$ & 53.81 & 7.18 & 0.39 & 0.86 & 38.45 & 100.69 \\
\hline AVERAGE & 54.17 & 7.46 & 0.41 & 0.72 & 37.93 & 100.69 \\
\hline $1 \sigma$ Error & 0.50 & 0.74 & 0.02 & 0.15 & 1.09 & 0.56 \\
\hline
\end{tabular}




\begin{tabular}{|c|c|c|c|c|c|c|}
\hline $620 \_1$ & 50.55 & 13.13 & 0.02 & 0.85 & 35.18 & 99.88 \\
\hline $620 \_2$ & 52.68 & 10.44 & 0.00 & 0.67 & 35.80 & 99.70 \\
\hline $620 \_3$ & 55.304 & 5.803 & 0.31 & 0.857 & 36.491 & 98.764 \\
\hline $620 \_4$ & 54.839 & 6.3 & 0.30 & 1.313 & 35.58 & 98.334 \\
\hline AVERAGE & 53.34 & 8.92 & 0.16 & 0.92 & 35.76 & 99.17 \\
\hline $1 \sigma$ Error & 2.19 & 3.49 & 0.17 & 0.28 & 0.55 & 0.74 \\
\hline $35 \_1$ & 49.80 & 8.76 & 0.30 & 2.96 & 36.87 & 98.69 \\
\hline $35 \_2$ & 50.11 & 8.75 & 0.30 & 3.04 & 36.93 & 99.12 \\
\hline $35 \_3$ & 50.14 & 8.90 & 0.30 & 2.77 & 36.86 & 98.97 \\
\hline $35 \_4$ & 50.13 & 8.74 & 0.29 & 2.82 & 36.24 & 98.21 \\
\hline $35 \_6$ & 50.30 & 8.63 & 0.30 & 3.00 & 35.89 & 98.12 \\
\hline AVERAGE & 50.09 & 8.76 & 0.30 & 2.92 & 36.56 & 98.62 \\
\hline $1 \sigma$ Error & 0.18 & 0.10 & 0.00 & 0.12 & 0.47 & 0.45 \\
\hline $62 \_1$ & 53.15 & 6.95 & 0.30 & 1.57 & 36.53 & 98.50 \\
\hline $62 \_2$ & 52.27 & 7.20 & 0.30 & 1.86 & 36.64 & 98.27 \\
\hline $62 \_3$ & 52.91 & 7.28 & 0.31 & 1.45 & 36.76 & 98.70 \\
\hline $62 \_4$ & 53.38 & 7.10 & 0.29 & 1.05 & 36.71 & 98.53 \\
\hline $62 \_5$ & 53.00 & 7.61 & 0.31 & 1.24 & 37.21 & 99.37 \\
\hline AVERAGE & 52.94 & 7.23 & $\mathbf{0 . 3 0}$ & 1.43 & 36.77 & 98.68 \\
\hline $1 \sigma$ Error & 0.41 & 0.25 & 0.01 & 0.31 & 0.26 & 0.42 \\
\hline $567 \_1$ & 39.55 & 2.05 & 0.32 & 23.01 & 34.01 & 98.94 \\
\hline $567 \_2$ & 48.20 & 7.84 & 0.29 & 6.52 & 35.46 & 98.31 \\
\hline $567 \_3$ & 55.57 & 5.35 & 0.29 & 0.89 & 36.55 & 98.65 \\
\hline AVERAGE & 47.77 & 5.08 & 0.30 & 10.14 & 35.34 & 98.63 \\
\hline $1 \sigma$ Error & 8.02 & 2.91 & 0.02 & 11.50 & 1.27 & 0.32 \\
\hline $859 \_1$ & 48.10 & 13.04 & 0.00 & 36.15 & 1.06 & 98.35 \\
\hline $859 \_2$ & 49.22 & 11.36 & 0.00 & 35.64 & 1.23 & 97.45 \\
\hline $859 \_3$ & 46.56 & 15.17 & 0.02 & 35.85 & 1.65 & 99.25 \\
\hline $859 \_4$ & 48.78 & 14.89 & 0.00 & 36.44 & 1.27 & 101.38 \\
\hline $859 \_5$ & 47.88 & 15.18 & 0.02 & 36.06 & 1.01 & 100.15 \\
\hline $859 \_6$ & 48.48 & 13.62 & 0.03 & 35.78 & 1.13 & 99.05 \\
\hline $859 \_7$ & 47.60 & 16.13 & 0.00 & 36.08 & 1.00 & 100.80 \\
\hline $859 \_8$ & 48.71 & 15.31 & 0.00 & 35.75 & 0.65 & 100.42 \\
\hline AVERAGE & 48.17 & 14.34 & 0.01 & 35.97 & 1.13 & 99.61 \\
\hline
\end{tabular}




\section{Supplementary Table A3}

Clinopyroxene Major Element

Concentrations (wt. \%.)

\begin{tabular}{cccc}
\hline Sample & 594 & 680 & 774 \\
\hline \hline $\mathrm{SiO}_{2}$ & 50.79 & 50.66 & 50.69 \\
$\mathrm{TiO}_{2}$ & 0.70 & 1.00 & 1.08 \\
$\mathrm{Al}_{2} \mathrm{O}_{3}$ & 6.51 & 6.93 & 6.63 \\
$\mathrm{Cr}_{2} \mathrm{O}_{3}$ & 0.01 & 0.04 & 0.04 \\
$\mathrm{MgO}$ & 13.50 & 12.50 & 12.48 \\
$\mathrm{CaO}$ & 19.06 & 18.66 & 18.80 \\
$\mathrm{FeO}$ & 6.75 & 8.49 & 9.86 \\
$\mathrm{MnO}$ & 0.02 & 0.07 & 0.07 \\
$\mathrm{Na} 2$ & 1.58 & 2.51 & 2.13 \\
$\mathrm{Total}$ & 98.92 & 100.86 & 101.76 \\
$\mathrm{Mg} \#$ & 0.78 & 0.72 & 0.69 \\
\hline
\end{tabular}

All major element analysis was performed at FCAEM / FIU. All samples have the prefix 77 SL-.

$\mathrm{Mg} \#=(\mathrm{Mg}) /(\mathrm{Mg}+\mathrm{Fe})$ 


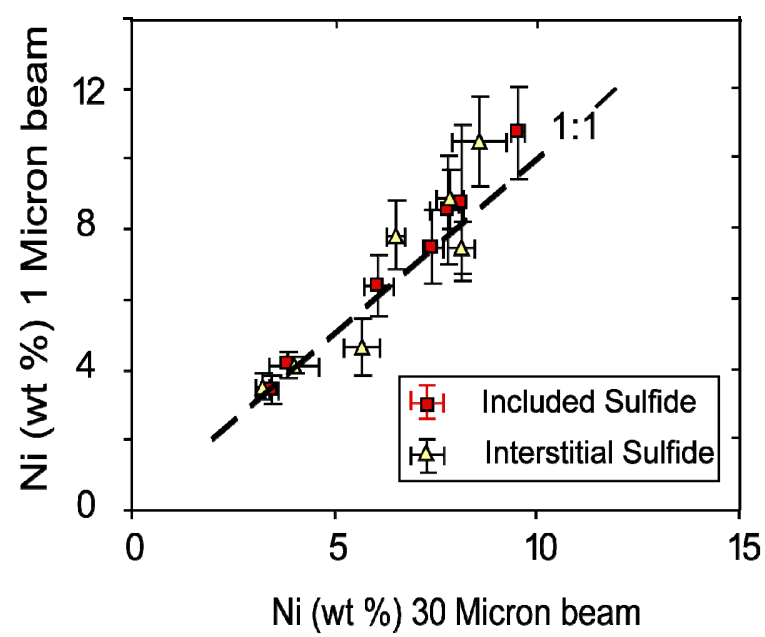

Fig A, Appendix Comparison between 1-2 $\mu \mathrm{m}$ and $30 \mu \mathrm{m}$ beam diameter EPMA analysis for the determination of $\mathrm{Ni}$. The error bar for $1 \mu \mathrm{m}$ and $30 \mu \mathrm{m}$ analyses are $20 \%$ and $5 \%$ respectively. 1:1 denotes a line of slope 1 . Within error the results are in moderate agreement. 


\section{HSE and Re-Os Extraction Protocol}

\section{Os Extraction}

1) Carius tubes were cleaned by boiling it in aqua regia

2) $2.5 \mathrm{gm}$ of powdered sample was put inside the cleaned carius tube and spiked with $0.05 \mathrm{ml}$ of PGE enriched solution (spike \#000601, provide by Munir Humayun at NHMFL), and the tubes were chilled immediately for 30 minutes

3) $10 \mathrm{~mL}$ of previously chilled inverse aqua regia $\left(\mathrm{HNO}_{3}\right.$ to $\left.\mathrm{HCL} 2: 1\right)$ were added and tubes were kept in ice water.

4) The tubes were sealed with oxyacetylene flame (note: first open the acetylene valve followed by oxygen, while turning off, turn off the oxygen gas at first)

5) The tubes were shaken well and were wrapped up in aluminum foil and placed inside a steel jacket.

6) The tubes were kept in the furnace $240^{\circ} \mathrm{C}$ for 72 hours.

7) The carius tubes were taken out from the furnace and cooled off in ice water (salt was used with the ice)

8) Oxy acetylene torch was used to reduce the pressure inside the tube by making a small hole towards the top (a gas escaping sound can be heard)

9) The tubes were cooled for 10 hours (the more it was cooled. the less bubbles were formed, when breaking open the tube)

10) The tubes were broken using a glass cutting tool. With a clean pipette it was transferred into a $10 \mathrm{~mL}$ centrifuge tube and centrifuged at $4000 \mathrm{rpm}$ for 5 minutes 
11) The clear aqua regia was transferred into a tube with $4 \mathrm{ml}$ of ice cold $\mathrm{CCL}_{4}$. It was shaken vigorously and centrifuged @ 4000 rpm for 5 minutes.

12) The floating aqua regia was removed and placed into another centrifuge tube with fresh $2 \mathrm{~mL}$ of $\mathrm{CCL}_{4}$ (Os goes from aqua regia into $\left.\mathrm{CCL}_{4}\right)$

13) $4 \mathrm{~mL}$ of $\mathrm{CCL}_{4}$ was transferred into a clean $20 \mathrm{~mL}$ savillex beaker with $5 \mathrm{~mL}$ of concentrated $\mathrm{HBr}$.

14) Step 12 using $2 \mathrm{~mL}$ of $\mathrm{CCL}_{4}$ was repeated for three more times (at the end we had

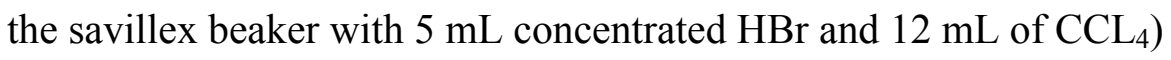

15) The savillex beakers were closed and placed on the hot plate at $80^{\circ} \mathrm{C}$ (note: Os goes from $\mathrm{CCl}_{4}$ into $\mathrm{HBr}$ )

16) The aqua regia was also dried down in the savillex beaker overnight (used for Ir$\mathrm{Ru}-\mathrm{Pd}-\mathrm{Pt}$ extraction)

17) Next day, CCL4-HBr beakers were cooled, and the $\mathrm{HBr}$ was removed in a clean centrifuge tube. CCL4 was discarded in a storage container (note: CCL4 is highly carcinogenic, so anything which has traces of CCL4 such as pipettes, beakers and centrifuge tubes should be kept separately for appropriate disposal)

18) The beakers were rinsed with deionized water, and $\mathrm{HBr}$ was put back in its own beaker and dried overnight at $80^{\circ} \mathrm{C}$.

19) Next day: the beakers were cooled off.

20) Conical $7 \mathrm{ml}$ beakers were prepared by putting Teflon tapes around the rim of the $7 \mathrm{~mL}$ beaker.

21) A drop of concentrated $\mathrm{HBr}$ was used to dissolve the cake from the bottom of the beaker and it was transferred on the cap of the conical $7 \mathrm{~mL}$ beaker. The caps 
were put on hot plate and dried down at $80^{\circ} \mathrm{C}$

22) After the cakes were dry, $5 \mu \mathrm{L}$ concentrated $\mathrm{HBr}$ was put on the cone of the $7 \mathrm{~mL}$ beaker.

23) $50 \mu \mathrm{L}$ of concentrated chromic acid was put on top of the dry cake and the beakers were quickly closed with the cap containing concentrated $\mathrm{HBr}$ (Note: $\mathrm{HBr}$ drop must stay on the beaker bottom (which is now on top) and chromic acid cannot splash the walls of the beaker)

24) The beakers were put upside down on the hot block at $60^{\circ} \mathrm{C}$ overnight.

25) Next day, the beakers were cooled down and opened carefully.

26) The small $\mathrm{HBr}$ drop was extracted and put into $1.5 \mathrm{~mL}$ centrifuge tubes. Deionized water was mixed with $\mathrm{HBr}$ to make a total solution of $100 \mu \mathrm{L}$ ready for Os and Os isotope analysis with MC-ICPMS.

\section{Ir-Ru-Pd-Pt Extraction}

27) The dry aqua regia (from step 16) were redissolved in $8 \mathrm{~mL} 0.15 \mathrm{~N} \mathrm{HCl}$ by ultrasonication (10 $\mathrm{ml}$ cation columns were used).

28) The solution was centrifuged @ 4000 rpm for 5 minutes

29) The $8 \mathrm{~mL}$ solution was split into two aliquots of $4 \mathrm{~mL}$ each, aliquot 1 was used for Ir-Ru-Pd-Pt and aliquot 2 was dried down at $80^{\circ} \mathrm{Cand}$ later used for $\mathrm{Re}$ analysis.

30) $4 \mathrm{~mL}$ of the sample and blank were passed through $10 \mathrm{~mL}$ of AG50W-X8 cation exchange resin (see the procedure for making the resin). The first $4 \mathrm{~mL}$ of acid coming out of the resin was discarded

31) The columns were flushed with $4 \mathrm{~mL}$ of $0.15 \mathrm{~N} \mathrm{HCl}$ and the samples were 
collected.

32) $70 \mathrm{~mL}$ of $6 \mathrm{~N} \mathrm{HCl}$ was flushed ( $10 \mathrm{~mL}$ at each time) through the resin and then it was backwashed with $0.15 \mathrm{~N} \mathrm{HCl}$ and pre-conditioned with $0.15 \mathrm{~N} \mathrm{HCl}$.

33) The $4 \mathrm{~mL}$ of sample was again flushed through the resin and the first $4 \mathrm{~mL}$ was discarded. It was followed with $0.15 \mathrm{HCl}$ flushing and the samples were collected (the samples were passed twice through the columns to ensure a clean PGE fraction and minimize polyatomic interferences). The samples were dried down and redissolved in 2\% HNO3 and analyzed with Element 1 HR-ICPMS.

\section{Re Extraction}

\section{Primary Column (2 mL)}

34) $2 \mathrm{~mL}$ volume columns were loaded with cleaned AG $1 \mathrm{x} 8$ anion resin and rinsed with $10 \mathrm{~mL}$ of $6 \mathrm{~N} \mathrm{HNO}_{3}$ followed by $2 \mathrm{~mL} 0.8 \mathrm{~N} \mathrm{HNO} 3$

35) The samples (from step 29) were dissolved in $5 \mathrm{~mL}$ of $0.8 \mathrm{~N} \mathrm{HNO}_{3}$ and flushed through the resin.

36) The column were rinsed with $2 \mathrm{~mL} 0.8 \mathrm{~N} \mathrm{HNO}_{3}-2 \mathrm{~mL} 0.8 \mathrm{~N} \mathrm{HNO}_{3}-5 \mathrm{~mL} 1 \mathrm{~N}$ $\mathrm{HCL}-2 \mathrm{~mL} 0.8 \mathrm{~N} \mathrm{HNO}_{3}-1 \mathrm{~mL} 6 \mathrm{~N} \mathrm{HNO}_{3}$

37) Re fraction was collected in $12 \mathrm{~mL} 6 \mathrm{~N} \mathrm{HNO}_{3}$ and dried down

\section{Cleanup Column $(250 \mu \mathrm{L})$}

38) $250 \mu \mathrm{L}$ volume columns were loaded with cleaned AG $1 \times 8$ anion resin and rinsed with $1 \mathrm{~mL}$ of $6 \mathrm{~N} \mathrm{HNO}_{3}-1 \mathrm{~mL} 6 \mathrm{~N} \mathrm{HNO}_{3}-0.5 \mathrm{~N} \mathrm{HNO}_{3}$

39) The samples (from step 37) were dissolved in $0.5 \mathrm{~mL}$ of $0.8 \mathrm{~N} \mathrm{HNO}_{3}$ and flushed through the resin. 
40) The column were rinsed with $0.5 \mathrm{~mL} 0.8 \mathrm{~N} \mathrm{HNO}_{3}-0.5 \mathrm{~mL} 0.8 \mathrm{~N} \mathrm{HNO}_{3}-0.2 \mathrm{~mL}$ $4 \mathrm{~N} \mathrm{HNO}_{3}$.

41)The clean Re cut was collected in $1.5 \mathrm{~mL}$ of $4 \mathrm{~N} \mathrm{HNO}_{3}$ and analyzed with Element 1 HR-ICPMS. 
VITA

INDRA SEKHAR SEN

$5^{\text {th }}$ July 1981

Born, Kolkata, India

December 2003

BSc. Jadavpur University, India

December 2005

MSc. Jadavpur University, India

2006- 2008

Teaching Assistant, FIU, Miami, USA

Spring 2009

Doctoral Evidence Acquisition Fellowship, FIU, USA

Summer 2009

BP America, Inc.'s Subsidiaries (BP), Houston, USA

Fall 2009

ExxonMobil Upstream Research Company, Houston, USA

2010

Doctoral Evidence Acquisition Fellowship, FIU, USA

HONORS AND AWARDS

- Woods Hole Oceanographic Institution (WHOI), USA, Post-Doctoral Fellowship (Accepted)

- Post-Doctoral Fellowship University of Alberta, Canada (Declined)

- 2009-2010: Doctoral Evidence Acquisition Fellowship (3 semester), FIU, USA

- 2009: Elected Associate member of Sigma Xi Scientific Research Society

- 2008: Outstanding Teaching Assistant Award, FIU, USA.

\section{$\underline{\text { RESEARCH FUNDING }}$}

2009: Sigma Xi Research Grant Award (ID Number is: G2009100334) Sulfides in Hawaiian Mantle: Can it Explain the Elevated ${ }^{186} \mathrm{Oss}^{187}$ Os Isotopes in Ocean Basalts?

\section{PEER REVIEWED PUBLICATION}

Sen I.S, Bizimis M, Sen G, Geochemistry of Sulfides in Hawaiian Garnet Pyroxenite Xenoliths: Implication for Highly Siderophile Elements in the Oceanic Mantle; Chemical Geology 273 (2010) pp. 180-192)

Sen I.S, Bizimis M, Huang S, Sen G; Re-Os Isotope Systematics and PGE Abundances in Garnet Pyroxenite Xenoliths from Oahu, Hawaii: Implications on Melt-Peridotite Reaction in the Oceanic Mantle (Submitted to EPSL) 


\section{POSTERS, ABSTRACTS \& REPORTS}

Sen I.S, Bizimis M, Huang S, Sen G (2010) Origin of sulfides and pyroxenites in the Hawaiian mantle: Insights from PGE and Os isotopes (Goldschmidt 2010)

Gionfriddo C, Bizimis M, Sen I.S, Salters V (2010) Chalcophile Elements in Peridotites as a Proxy for Sulfide Mineralization During Serpentinization (Goldschmidt 2010)

Sen I.S, Luo H, Hall J.S (2009), Linking Migration with Fluid Mixing - A Case Study from Plutonio Field, Block 18, Angola; Technology Fair, BP Westlake 4, Houston, Texas, Poster Number \# 41

Sen I.S, Bizimis M, Huang S, Sen G (2008), Re-Os Isotope Systematics and PGE Abundances in Garnet Pyroxenite Xenoliths from Oahu, Hawaii: Implications on MeltPeridotite Reaction in the Oceanic Mantle Eos Trans. AGU, 89(53), Fall Meet. Suppl., Abstract V43B-2160

Sen I.S, Bizimis M, Sen G (2008), Platinum Group Element Abundances in the Hawaiian Mantle: Constraints from in-Situ Sulfide and Bulk Rock Analyses of Garnet Pyroxenite Xenoliths from Oahu, 2008 Joint Meeting of the Geological Society of America, Abstract No: 150169

Sen I.S., Sen G. and Bizimis M (2007), "In-situ analysis of Highly Siderophile Elements in sulfides from Hawaiian garnet pyroxenite xenoliths" Research report for National High Magnetic Field Laboratory, Florida State University, Los Alamos National Laboratory, University of Florida

Sen I.S, Sen G, Bizimis M (2007), Sulfides in the Garnet Pyroxenite Xenoliths from Oahu, Hawaii, Eos Trans. AGU, 88(52), Fall Meet. Suppl, Abstract DI33A-1126

\section{MEMBERSHIPS IN PROFESSIONAL SOCIETY}

- American Association of Petroleum Geologist (AAPG)

- American Geophysical Union (AGU)

- Geological Society of America (GSA)

- Mineralogical Society of America (MSA) 